\author{
Universidade de São Paulo \\ Instituto de Astronomia, Geofísica e Ciências Atmosféricas \\ Departamento de Ciências Atmosféricas
}

\author{
Leonardo Moreno Domingues
}

\title{
Hydrological impact of climate change in the Jaguari river basin at Cantareira reservoirs system
}

\author{
(Impacto hidrológico das mudanças \\ climáticas na bacia do Rio Jaguari do \\ Sistema Cantareira)
}

São Paulo 

Leonardo Moreno Domingues

\title{
Hydrological impact of climate change in the Jaguari river basin at Cantareira reservoirs system
}

\author{
(Impacto hidrológico das mudanças \\ climáticas na bacia do Rio Jaguari do \\ Sistema Cantareira)
}

Tese apresentada ao Departamento de Ciências Atmosféricas do Instituto de Astronomia, Geofísica

e Ciências Atmosféricas da Universidade de São Paulo como requisito parcial para a obtenção do título de Doutor em Ciências.

Área de Concentração: Meteorologia Orientador: Prof. Dr. Humberto Ribeiro da Rocha

Versão Corrigida. O original encontra-se disponível na Unidade.

São Paulo 

To the possible readers of this work 



\section{Acknowledgements}

Writing is a solitary moment, and this text was substantially written during the social isolation due to SARS-CoV-2. However, I am glad it was one of the few moments of solitude of mine during the last 4 years. This work was only possible to be finished due to the multiple contribution of many people, which I'd like to acknowledge.

First of all, to my beloved wife, Titi, who were with me since the beginning of this project. She has listened to me so many times, and has helped me to get through many personal and academic difficulties. Thanks for trusting me even throughout the whole process. Also to my dear parents, sisters and nephew. They were there in any moment of my life, and always supported me.

To my supervisor, Humberto, who accepted me to be his undergraduate student in 2008. We have been working together since then, and it was an astonishing period in my life. Humberto has taught me about biosphere, climate, models, Fortran 77, Grapher 3, and many other academic issues, but he also taught me about cycles, philosophy, music, and life in general. I have appreciated our meetings, even those in which I left his room completely lost.

To Rafael de Abreu, who directly contributed to the findings of this thesis, always kind and generous in our discussions.

To ANA, INMET, CEMADEN, SABESP and IAC, which provided the rain gauge data used in this work.

To my current and ex LCB colleagues: Emília, Helber, Duda, Tatsch, Mota, Fagiolo, Gabriel, Raianny, Zezo, Thomas, Carla, Mari, Patrícia, Eduardo, Iza, Evandro and Rodolfo. They have taught me in different ways along the last 12 (!) years, sharing good moments of their lives with me. 
To my dear friends, the apostles (Pedro and Paulo), Pamela, Jacyra, Lari, my grand parents, my godddaughter Flora, Aline, Henrique, Carol, Marta, Marie, Sameh. Elis and Gal. Also, to my therapist.

To the IAG staff, especially Tião, Samuel, Djalma, Bete and Ana. Also to the developers of IAG-TESE class in ATEX.

To the University of São Paulo. It was a privilege to become who I am in such a rich environment. This research was only possible to be concluded due to public investment in education, and I'll use all the knowledge it has given me along the years to defend free and quality university to everyone.

This study was financed in part by the Coordenação de Aperfeiçoamento de Pessoal de Nível Superior - Brasil (CAPES) - Finance Code 001. 
a água que me chama

em mim deságua

a chama que me mágua

Paulo Leminski 



\section{Abstract}

Domingues, L.M., 2020. Hydrological impact of climate change in the Jaguari river basin at Cantareira reservoirs system. 100 pgs. Thesis (Doctorate) - Institute of Astronomy, Geophysics and Atmospheric Sciences, University of São Paulo, São Paulo. Corrected version.

A recent unprecedented drought at the Cantareira reservoirs system with spread water shortage affected much of São Paulo city during 2014 and 2015. Climate projections to this area indicate high concordance that it will be warmer in the late 21st century, but changes in rainfall are mixed among models. Due to its key importance in supplying water to a densely populated region, understanding the potential changes in the regional water budget of such a system under climate change is strategic. With a thoroughly calibrated physically-based SWAT model, we used forcing-response relationships of key climate variables (temperature, rainfall, humidity and $\mathrm{CO}_{2}$ concentration) based on CMIP5 projections under RCP 8.5 scenario, to estimate the impact of climate change in the surface water budget over the Jaguari river basin, the main supplier of Cantareira reservoirs system. This approach aimed to circumvent common issues of regional impact assessment with hydrological modeling as the use of few global models and the choice of the downscaling method. With temperature increase spanning from 1 to $5^{\circ} \mathrm{C}$, we found opposite responses in the future due to rainfall uncertainty in the projections: under increased rainfall, the mean evapotranspiration (discharge) is about to increase up to $25 \%$ (90\%); under less precipitation, evapotranspiration decreased up to about $10 \%$ and discharge to $50 \%$. Besides, we showed that the higher $\mathrm{CO}_{2}$ concentration had a strong effect on depleting the stomatal conductance in the future, resulting in a reduced evapotranspiration, which in turn, increased the discharge in near proportion. Temperature and relative humidity alone 
played minor roles when compared to the rainfall and $\mathrm{CO}_{2}$ concentration. With respect to the responses of extreme events, we showed that maximum discharge can reach more than twice the historical levels in the future with increasing rainfall and minimum flow can reduce up to about $30 \%$ in case of less precipitation. These two directions seem well likely so far, and caution to overcome the bad effects of either are needed for investigation and planning in more detail.

Keywords: Cantareira reservoirs system, climate change, water budget, SWAT 


\section{Resumo}

Domingues, L.M., 2020. Impactos hidrológicos das mudanças climáticas na bacia do rio Jaguari do Sistema Cantareira. 100 pgs. Tese (Doutorado) - Instituto de Astronomia, Geofísica e Ciências Atmosféricas, Universidade de São Paulo, São Paulo. Versão corrigida.

Uma recente seca histórica no Sistema Cantareira com ampla escassez regional afetou a cidade de São Paulo durante os anos de 2014 e 2015. As projeções climáticas para esta região apresentam alto grau de concordância que o final do século 21 será mais quente, mas as mudanças no padrão de precipitação são divergentes entre os modelos. Devido à grande importância no abastecimento hídrico de uma região densamente habitada, entender as potenciais alterações no balanço hídrico regional de tal sistema sob mudanças climáticas é bastante estratégico. Com o modelo físico SWAT cuidadosamente calibrado, foram usadas relações de "resposta ao forçamento" de variáveis climáticas chave (temperatura, precipitação, umidade e concentração de $\mathrm{CO}_{2}$ ) baseadas nas projeções do CMIP5 sob cenário RCP8.5, para estimar os impactos das mudanças climáticas no balanço hídrico sobre a bacia do Rio Jaguari, que contribui com maior vazão afluente ao Sistema Cantareira. Essa abordagem procurou contornar os problemas comuns em estudos de avaliação de impacto regional com modelagem hidrológica, como o uso de poucos modelos globais e a escolha do método de regionalização. Com aumentos de temperatura variando de 1 a $5^{\circ} \mathrm{C}$, foram encontradas respostas opostas para o clima futuro devido às incertezas da precipitação nas projeções: com aumento da chuva, a evapotranspiração (vazão específica) média pode aumentar em até $25 \%$ (90\%); com redução da chuva, evapotranspiração e vazão reduzem em até 10 e $50 \%$, respectivamente. Além disso, é mostrado que a concentração de $\mathrm{CO}_{2}$ tem um forte efeito em reduzir a condutância estomática, que resulta em menor evapotranspiração, 
que por sua vez, aumenta a vazão quase na mesma proporção. A temperatura e a umidade relativa isoladamente desempenharam papéis menores quando comparadas à chuva e à concentração de $\mathrm{CO}_{2}$. Com relação às respostas nos eventos extremos, mostramos que a vazão máxima pode superar o dobro do máximo histórico no clima futuro, e que as vazões mínimas podem reduzir em até $30 \%$ no caso de menos precipitação. Essas duas direções parecem igualmente prováveis, e é preciso cuidado para se adiantar aos maus efeitos de cada uma no processo detalhado de investigação e planejamento.

Palavras-chave: Sistema Cantareira, mudanças climáticas, balanço hídrico, SWAT 


\section{List of Figures}

1.1 Top: Percentage of total volume at the Cantareira Water reservoirs Equivalent System. Bottom: Annual (bars) and climatological rainfall (horizon-

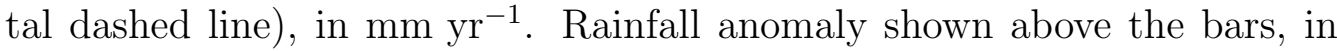
mm $\mathrm{yr}^{-1}$. Source: SABESP $(2021)$. . . . . . . . . . . . . . . . 24

3.1 Left: Altitude map of the study area, in meters. The rivers are displayed in blue segments, and main rivers are detached. The black dashed line delimits the river basin with F-25B gauge as outlet. Right: Geographic location of Jaguari river basin. Dark grey line delimits the Piracicaba river basin, and yellow shaded area the Cantareira water reservoirs system. . . . . . . . . . 32

3.2 Dormancy period in function of latitude. . . . . . . . . . . . . . . 39

3.3 Daily variation of leaf area index, in $\mathrm{m}^{2} \mathrm{~m}^{-2}$, in a year, for pasture (black line) and forest (red line) land covers. . . . . . . . . . . . . . . . . . . . . . 40

3.4 (a) Digital elevation map (m); (b) Reclassified land use map; (c) Reclassified soil map; (d) Position of each grid center for rainfall (black circles) and weather (red squares) data. . . . . . . . . . . . . . . 42

3.5 (a) Rain gauge positions of different sources: CEMADEN (grey dots), ANA (black triangles), INMET (red square), IAC (dark red star) and SABESP (blue cross), and (b) data availability in time (x-axis) for each rain gauge labelled in (a) (y-axis). Discontinuity represents missing data, and colors follow the same pattern than $(\mathrm{a}) \ldots \ldots \ldots \ldots$ 
3.6 Probabilities of occurrence (\%) of elasticity in relation to temperature of precipitation (P), specific humidity (q), evapotranspiration (ET) and precipitation minus evapotranspiration (P-ET), in $\%{ }^{\circ} \mathrm{C}^{-1}$, using the CMIP5 models. Source: de Abreu et al. (in prep). . . . . . . . . . . . . . . . . 46

3.7 Scatter plots of control RH (x-axis) and perturbed RH (y-axis), for three classes of $\epsilon_{q, T}: 5 \%{ }^{\circ} \mathrm{C}^{-1}$ (left), $7.5 \%{ }^{\circ} \mathrm{C}^{-1}$ (middle) and $10 \%{ }^{\circ} \mathrm{C}^{-1}$ (right). The point colors represent the mean air temperature increases from 1 to $5^{\circ} \mathrm{C}$, so that the darker the color, the higher the increase. The 1:1 reference line is displayed in each panel. . . . . . . . . . . . . . . . .

$3.8 \mathrm{CO}_{2}$ concentration along the years of simulation, in ppm, for historical (black line, $y=350+2 \cdot x$ ) and end century (red line, $y=750+8 \cdot x$ ) conditions.

4.1 Dotty plots between NSE index (y-axis) and the range of values assessed for each parameter (x-axis). In the top of each panel is shown the parameter name, whereas vertical red lines show the best values found in calibration process. Only NSE indexes $>-1$ are shown.

4.2 Flow duration curves of daily discharge, in $\mathrm{m}^{3} \mathrm{~s}^{-1}$, of not calibrated (blue line), calibrated (red line) and reference (black line) simulations. . . . . . . 56

4.3 Upper panel: Simulated (red line) and observed (black line) discharges, in $\mathrm{m}^{3} \mathrm{~s}^{-1}$. Vertical dashed line separates calibration from validation. Middle panel: Idem to upper, with y-axis in log scale. Lower panel: Basin-averaged daily precipitation, in $\mathrm{mm} \mathrm{d}^{-1} \ldots \ldots \ldots \ldots \ldots 7$

4.4 Left panel: Yearly average rainfall (light grey bars), evapotranspiration (dark grey bars) and specific discharge (black bars) along the years of simulation, in $\mathrm{mm} \mathrm{yr}^{-1}$, in Jaguari basin. Right panel: Mean annual values

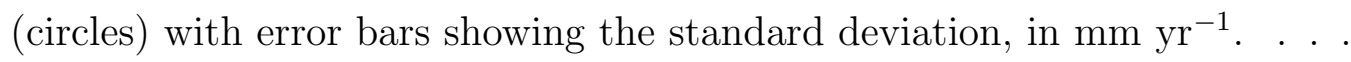

4.5 Left panel: Yearly average components of discharge calculated by SWAT along the years of simulation: surface flow (light grey bars), lateral flow (dark grey bars) and base flow (black bars), in $\mathrm{mm} \mathrm{yr}^{-1}$. Right panel: Mean annual values (circles) with error bars showing the standard deviation,

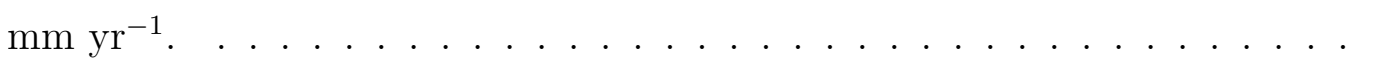


4.6 A) Monthly ET time series, in $\mathrm{mm} \mathrm{mo}^{-1}$ of SWAT (black line), GLEAM (red line), MOD16A2 (blue line) and TWB (green line) methods. B) Scatterplot between SWAT monthly ET in axis-x, and GLEAM (red dots), MOD16A2 (blue dots) and TWB (green dots) monthly ET in axis-y, in mm mo ${ }^{-1}$. The 1:1 reference line is displayed. C) Mean monthly ET, in $\mathrm{mm} \mathrm{d}^{-1}$, estimated by SWAT (black squares), GLEAM (red X), MOD16A2 (blue dots), and TWB (green open circles). D) ET average (circles) and 75th and 25th percentiles (bars), in $\mathrm{mm} \mathrm{d}^{-1}$, for each estimate in dry (May to Aug) and wet (Sep to Apr) seasons. Panels C and D used the common period of SWAT, GLEAM, MOD16A2 and TWB. . . . . . . . . . . .

4.7 Mean monthly a) transpiration (Et), b) soil evaporation (Es) and c) evapotranspiration (ET), in $\mathrm{mm} \mathrm{d}^{-1}$, for pasture (red lines and circles) and forest (black lines and circles). d) All period average of ET, Es and Et, in $\mathrm{mm} \mathrm{d}^{-1}$, for forest (black F) and pasture (red P). . . . . . . . . . . . . .

4.8 Daily time series, from 1995 to 2017, of a) integrated available soil water (vadose zone and shallow aquifer), in $\mathrm{mm}$; b) basin-averaged rainfall, in $\mathrm{mm} \mathrm{d}^{-1} ; \mathrm{c}$ ) available soil water profile (soil water storage minus content at wilting point), in mm, depicted for each soil layer (y-axis); and d) shallow aquifer storage, in $\mathrm{mm} . \ldots \ldots \ldots \ldots$

5.1 Hydrological responses of ET and Q shown as differences of experiment minus control simulation ( $\triangle \mathrm{ET}$, panels $\mathrm{A}$ and $\mathrm{C})$ and specific discharge

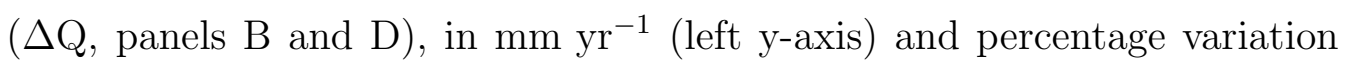
(right y-axis), forced by: temperature increase (x-axis, in ${ }^{\circ} \mathrm{C}$ ); elasticity of precipitation to temperature $\epsilon_{P, T}$, in $\%{ }^{\circ} \mathrm{C}^{-1}$ (colors), with actual changes of

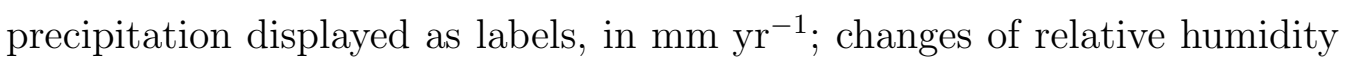
$(\mathrm{RH})$ with the cases lower (dotted line), alike (dashed line) and higher (solid line); and changes of $\mathrm{CO}_{2}$ concentration (historical in panels $\mathrm{A}-\mathrm{B}$ and end century in panels $\mathrm{C}-\mathrm{D}) \ldots \ldots \ldots \ldots \ldots$ 
5.2 Hydrological responses of ET and Q shown as differences of experiment minus control simulation for alike $\mathrm{RH}$ case $(\Delta \mathrm{ET}$, panel $\mathrm{A})$ and specific

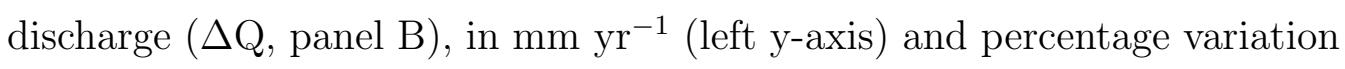

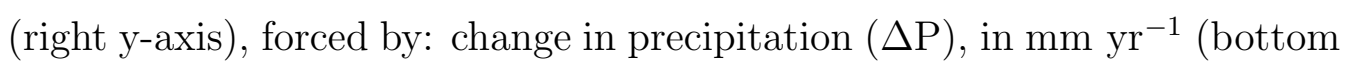
$\mathrm{x}$-axis) and percentage variation (top $\mathrm{x}$-axis); temperature increase, in ${ }^{\circ} \mathrm{C}$ (colors) and changes of $\mathrm{CO}_{2}$ concentration (historical in solid lines and end century in dashed lines). . . . . . . . . . . . . . . .

5.3 Responses in Et ( $\Delta$ Et, panels $\mathrm{A}$ and $\mathrm{C})$ and Es $(\Delta \mathrm{Es}$, panels $\mathrm{B}$ and $\mathrm{D})$ shown as differences of experiment minus control simulation, in $\mathrm{mm} \mathrm{d}^{-1}$ (left y-axis) and percentage variation (right y-axis), forced by: temperature increase (x-axis, in ${ }^{\circ} \mathrm{C}$ ); elasticity of precipitation to temperature $\epsilon_{P, T}$, in $\%{ }^{\circ} \mathrm{C}^{-1}$ (colors); changes of relative humidity $(\mathrm{RH})$ with the cases lower (dotted line), alike (dashed line) and higher (solid line); and changes of $\mathrm{CO}_{2}$ concentration (historical in panels A-B and end century in panels C-D). . . 72

5.4 Relative change of available water content of experiments with respect to control simulation $(\triangle \mathrm{AWC}$, in $\%$, x-axis) along $2 \mathrm{~m}$ depth (y-axis), forced by: elasticity of precipitation to temperature $\epsilon_{P, T}$, in $\%{ }^{\circ} \mathrm{C}^{-1}$ (colors); changes of relative humidity $(\mathrm{RH})$ with the cases lower (top panels), alike (mid panels) and higher (bottom panels); and changes of $\mathrm{CO}_{2}$ concentration (historical in the left panels and end century in the right panels). The arrows point to the direction of increasing temperature for each $\epsilon_{P, T}$ case. Vertical dashed

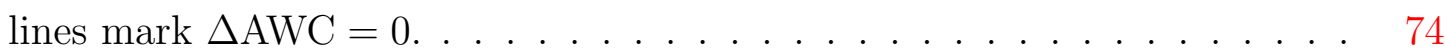

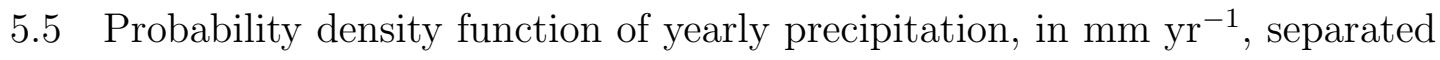
by A) elasticity (in $\%{ }^{\circ} \mathrm{C}^{-1}$ ) and $\mathrm{B}$ ) temperature increase $\left(\right.$ in ${ }^{\circ} \mathrm{C}$ ) cases. . . 76

5.6 Probability density function of yearly ET (left panels) and Q (right panels), in $\mathrm{mm} \mathrm{yr}^{-1}$, separated by A) elasticity (in $\%{ }^{\circ} \mathrm{C}^{-1}$ ) and $\mathrm{B}$ ) temperature increase $\left(\right.$ in $\left.{ }^{\circ} \mathrm{C}\right)$ cases. . . . . . . . . . . . . . . . . . 77 
5.7 Boxplot of experiment responses (y-axis, in $\mathrm{mm} \mathrm{yr}^{-1}$ ) in $\mathrm{P}$ (top panels), ET (middle panels) and Q (bottom panels), forced by: temperature increases (in ${ }^{\circ} \mathrm{C}$, columns), elasticity cases (in $\%{ }^{\circ} \mathrm{C}^{-1}$, colors), and $\mathrm{CO}_{2}$ concentration cases (historical and end century, x-axis). Observed boxplots are shown in historical cases (green plots) and CMIP5 model outputs ensemble (pink plots) are displayed. . . . . . . . . . . . . . . . . .

5.8 Histogram of daily precipitation, in $\mathrm{mm} \mathrm{d}^{-1}$, depicted by elasticity cases

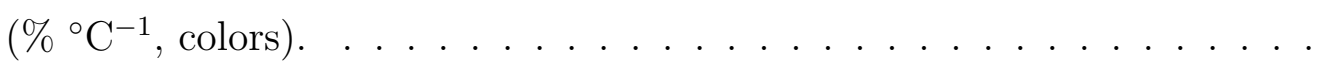

5.9 A. Flow duration curve of experiment discharges, in $\mathrm{m}^{3} \mathrm{~s}^{-1}$, forced by elasticity of precipitation to temperature $\epsilon_{P, T}$, in $\%{ }^{\circ} \mathrm{C}^{-1}$ (colors) and changes of $\mathrm{CO}_{2}$ concentration (historical in the left panels and end century in the right panels). The arrows point to the direction of increasing temperature (1, 3 and $5^{\circ} \mathrm{C}$ ) for each $\epsilon_{P, T}$ case. Thick green line depicts the control simulation. B. Idem to A, but with x-axis transformed to 100-exceedance probability, in \%. Log transformation is applied to values above 0.01 and linear extrapolation from 0.01 to 0 . Maximum and minimum values of distribution are marked as "X" above $0 \ldots \ldots \ldots \ldots \ldots$ 



\section{List of Tables}

3.1 Summary of cases with perturbations in key atmospheric variables. . . . . 49

4.1 Parameters used in evapotranspiration adjustment process. . . . . . . . . . 52

4.2 Set of parameters used in the calibration process, along with their range of variation, original value (default) and best value found. Along with the prefix $v$, the parameter default value is replaced by another one, with $r$ the parameter is relatively (\%) modified according to the default value, and with $a$, a value is added to the parameter default. Apostrophe is displayed where several values are found for the respective parameter. . . . . . . . . . . . 54

4.3 Performance indexes Nash-Sutcliffe efficiency (NSE), percent bias (Pbias, $\%$ ) and the coefficient of determination $\left(\mathrm{R}^{2}\right)$ for calibration and validation periods. Below each value is shown the classification according to Moriasi et al. (2015) . . . . . . . . . . . . . . . . . . 57 



\section{Contents}

1. Introduction . . . . . . . . . . . . . . . . . . . 23

1.1 Effects of the historical drought in the Jaguari river basin . . . . . . . . . . 23

1.2 Climate change and surface hydrology . . . . . . . . . . . . 25

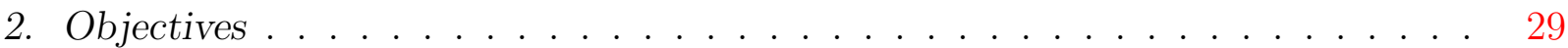

3. Material and Methods ......................... . . 31

3.1 Study area . . . . . . . . . . . . . . . . . . . 31

3.2 SWAT model description . . . . . . . . . . . . . . . . . . . . 31

3.2 .1 Discharge . . . . . . . . . . . . . . . . . 33

3.2.1.1 Overland flow . . . . . . . . . . . . . . . 33

3.2.1.2 Lateral flow . . . . . . . . . . . . . . . . . 33

3.2.1.3 Base flow . . . . . . . . . . . . . . . . 34

3.2.2 Evapotranspiration . . . . . . . . . . . . . . . . . . . . 34

3.2.2.1 Potential and actual transpiration . . . . . . . . . 35

3.2.2.2 Potential and actual soil evaporation . . . . . . . . . 36

3.2 .3 Plant growth . . . . . . . . . . . . . . . . 37

3.3 SWAT setup . . . . . . . . . . . . . . . . . . . 40

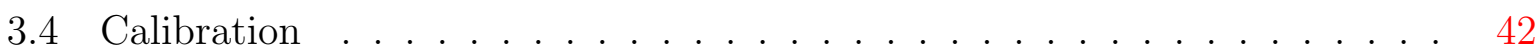

3.5 Experimental design of perturbations in climatic forcings . . . . . . . . . 44

3.5.1 The set of experiments . . . . . . . . . . . . . . 46

4. Model calibration and validation ....................... 51

4.1 Adjustments in evapotranspiration and discharge . . . . . . . . . . . . 51 
4.2 Calibration and validation performance . . . . . . . . . . . 53

4.3 Water balance . . . . . . . . . . . . . . . . . 57

4.3 .1 Simulated discharge . . . . . . . . . . . . . . . 58

4.3.2 Evapotranspiration .................... 60

4.3 .3 Soil moisture . . . . . . . . . . . . . . . . . 62

5. Assessment of climate change impacts . . . . . . . . . . . . . . 67

5.1 Evapotranspiration and discharge . . . . . . . . . . . . 67

5.2 Transpiration and soil evaporation . . . . . . . . . . . . . . 71

5.3 Soil water storage . . . . . . . . . . . . . . . . . . . . . 71

5.4 Uncertainties and distribution of events . . . . . . . . . . . . 73

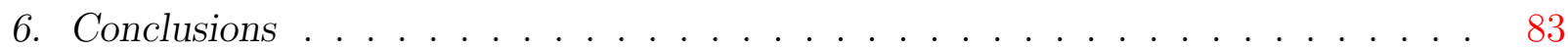

6.1 Suggestions for upcoming works . . . . . . . . . . . . 85

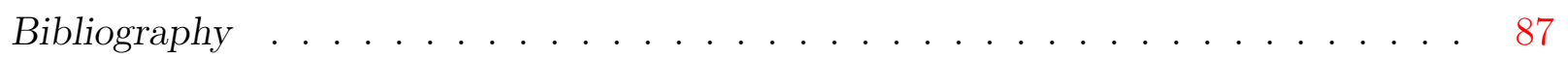


Chapter 1

\section{Introduction}

The climate projections for the 21st century show pronounced changes in global climate albeit with different responses regionally (Stocker et al., 2013). In Southeast Brazil region, there is a strong agreement among models that annual temperature may increase up to 5 ${ }^{\circ} \mathrm{C}$ under Representative Concentration Pathway (RCP) 8.5 scenario (van Vuuren et al., 2011) in the late 21st century, but the changes in rainfall for the same period are diverging (Magrin et al., 2014).

\subsection{Effects of the historical drought in the Jaguari river basin}

The Jaguari river is the main affluent to the Cantareira water reservoirs system in Southeast Brazil, that supplies around 65\% of São Paulo city (Deusdará-Leal et al., 2020), where after an above normal rainfall and water volume peaking period in 2009/2010 (Fig.1.1), it was affected by successive years with decreasing rainfall and volume, that reached criticality in 2014 mostly as the response of the historical drought during 2013/2014 (da Rocha and Domingues, 2017). The drought was caused by about $44 \%$ below average rainfall in 2014 over Southeast region (Coelho et al., 2016), when summer temperature was the highest since 1951, which must have also contributed to increase water losses as land evapotranspiration, open water reservoir evaporation and water withdrawals due to overall consumption (Milano et al., 2018; Nobre et al., 2016). It is estimated that the drought has affected around 80 million people (Tundisi and Tundisi, 2015). The rainfall and affluent discharge at the Cantareira system were only $32.5 \%$ and $25 \%$ of climatological averages between Dec/2013 and Feb/2014 (SABESP, 2020). The scarcity of the reservoirs pushed a substantial water shortage at regional scale, that was coped specially in São Paulo city 
with a suite of management measures of pressure reduction in water pipes, and reduction of industrial/domestic consumption stimulated via tariff discount (Deusdará-Leal et al., 2020; Millington, 2018). At least US\$ 5 billion were lost due to the hydro-socio-economic impacts of the drought in Southeast (Taffarello et al., 2016). In 2017, it came into force the Resolution No 925 (ANA and DAEE, 2017), that prescribes limits of withdrawals according to the reservoir volume condition, ranging from $33 \mathrm{~m}^{3} \mathrm{~s}^{-1}$ when volume is above $60 \%$ of capacity to $15.5 \mathrm{~m}^{3} \mathrm{~s}^{-1}$ when it is below 20\%. Deusdará-Leal et al. (2020) estimated that if Resolution $N^{\circ} 925$ had started in March 2014, the pumping volume used to maintain water demand would have been $32 \%$ inferior. Despite the allusion that the drought could have been attributed to climate change (Escobar, 2015), a comprehensive work of Otto et al. (2016) did not find significant evidence to confirm such hypothesis, rather a natural although very anomalous phenomena. Authors in general concern the drought as an exceptionality (Coelho et al., 2016; Nobre et al., 2016; Otto et al., 2016), with a return period of 98 years (Milano et al., 2018), possibly comparable to the drier episodes expected to occur in future climate projections if rainfall reduction is significant.
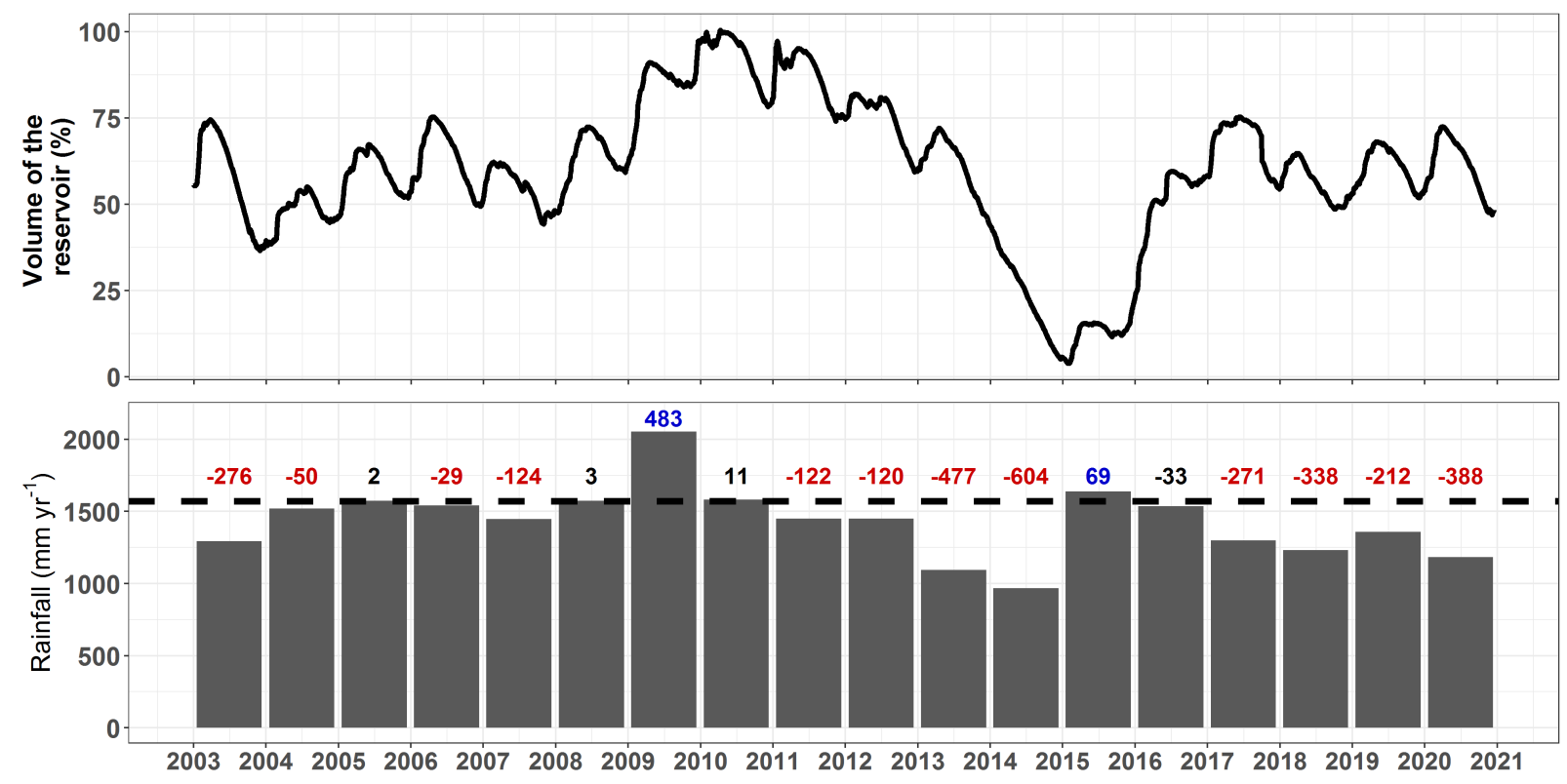

Figure 1.1: Top: Percentage of total volume at the Cantareira Water reservoirs Equivalent System. Bottom: Annual (bars) and climatological rainfall (horizontal dashed line), in

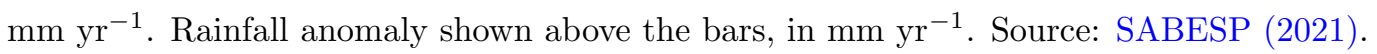




\subsection{Climate change and surface hydrology}

With respect to the impacts of climate change on the surface hydrological water budget at local and regional scales, it is believed that substantial refinement is needed to improve over the uncertainties shown by coarse scale climate models. The sensitivity of hydrological processes to climate change projections can be assessed in different ways, but most commonly using physically-based hydrological models (HMs) that take advantage of treating biophysical processes at high spatial resolution, such as evapotranspiration, soil moisture and water flows, which depend on various characteristics such as topography and land cover (Leavesley, 1994), or simple Budyko-type models, that combine temperature, radiation and water availability (Teng et al., 2012; Zhang et al., 2008). Besides rainfall and temperature, other climatic variables as vapor pressure deficit (vpd) and solar radiation are well known controls of evapotranspiration (ET) that consequently affect the mean discharge at catchment scale. The use of HMs to investigate climate change impacts poses various challenges, wherein we emphasize the biophysical response of land cover vegetation to vpd and $\mathrm{CO}_{2}$ concentration, and the strategy of how targets are met by using outputs of general circulation models (GCMs) and HM simulations.

Firstly, we expect increasing saturated vapor pressure in the lower troposphere due to the high confidence level of temperature increase in future climate projections (Held and Soden, 2006). However, the changes in relative humidity (RH) projections are less consensual. Whereas Randall et al. (2007) state that almost no change is expected in broad-scale RH, Collins et al. (2013) reported a decrease in near-surface RH. More recently, Byrne and O'Gorman (2016) suggested that the increase in saturation specific humidity surpassed other contributions that added moisture from oceanic source transports and land ET, that ended reducing the land $\mathrm{RH}$, thus increasing both vpd and potential evapotranspiration (PET). Guo et al. (2017) found that estimates using Penman-Monteith-FAO PET in moisten catchments were more sensitive to temperature changes, followed by $\mathrm{RH}$, and that solar radiation and wind speed played minor roles. However, the assessment of the authors did not include $\mathrm{CO}_{2}$ controls explicitly. Much of the increased $\mathrm{CO}_{2}$ effects on plants were approached in the Free-Air $\mathrm{CO}_{2}$ Enrichment (FACE) experiments that showed a general decrease in stomatal conductance $\left(\mathrm{g}_{\mathrm{s}}\right)$ to both $\mathrm{C} 3$ and $\mathrm{C} 4$ plants under risen $\mathrm{CO}_{2}$ concentration (Purcell et al., 2018; Ainsworth and Rogers, 2007). A reduced $\mathrm{g}_{\mathrm{s}}$ suppresses 
transpiration (Habermann et al., 2019; Purcell et al., 2018; Milly and Dunne, 2016) and can impact on soil water content and runoff as reported by Betts et al. (2007). Similar findings of the effects of higher $\mathrm{CO}_{2}$ concentration on soil hydrology are described in Habermann et al. (2019); Milly and Dunne (2016); Franks et al. (2013); Lockwood (1999). Prudhomme et al. (2014) showed that, despite uncertainties in magnitude, global impact models that addressed the stomata partial closure to increased $\mathrm{CO}_{2}$ reduce the drought response to climate change. A potential counter-effect of increasing transpiration due to higher leaf area index (LAI) in a rich $\mathrm{CO}_{2}$ environment is described by Lockwood (1999) to be "unlikely to happen".

With respect to the strategies to investigate impacts of climate change in regional surface hydrology, Di Baldassarre et al. (2011) mention about a common framework of selecting one or more scenarios of the International Panel on Climate Change (IPCC) and choosing one or more GCM projections. Then, bridging the gap between GCMs and HMs becomes crucial (Fowler et al., 2007; Xu, 1999), and coarse resolution GCM data must be treated to get unbiased and have finer resolution at regional watershed scales, what is often made up with dynamical or statistical downscaling, that ends providing inputs to HMs. At last, HMs need calibration evaluated under accurate and long term historical climate and discharge observations, and then they are supposed to work properly in future climates. Such procedure was used, for instance, in Döll et al. (2018) and Wilby and Harris (2006). Meanwhile, choosing between dynamical and statistical downscaling is a compromise involving several considerations, as argued by Fowler et al. (2007) and $\mathrm{Xu}$ et al. (2005): statistical downscaling is based on classical statistical procedures that incorporate observed data, with cheap application, but that depends on long records of accurate observations and does not include climate system feedbacks, so that unprecedented extremes, for instance, are not easy to be addressed; on the other hand, dynamical downscaling addresses climate feedbacks using physically consistent processes under regional atmospheric models, although with high computational costs and limited by the choice of usually a GCM and its intrinsic bias due to particular parametrizations of cloud cover, precipitation and surface fluxes, which strongly impact the downscaling. Di Baldassarre et al. (2011) also emphasize a great dependence of climate projections on the emission scenarios and anthropogenic activities, that in turn, are changing along the years. In IPCC AR4, the projections were based on Special Report on Emissions Scenarios (SRES) 
(Nakicenovic et al., 2000), followed by Representative Concentration Pathways (RCPs) in AR5, and the more recent on Shared Socioeconomic Pathways (SSPs), based on narratives of uncertainties around future sustainable development, regional inequality, fossil-fuelled development, etc (Riahi et al., 2017). These changes make comparison among scenarios of different generations difficult to assess.

Other uncertainties of HM simulations arise from the many possible different sets of parameters that can reproduce observations significantly, called equifinality (Beven and Freer, 2001). Uncertainties from GCMs and HM parameter's equifinality may affect water budget components differently. For example, Her et al. (2019) show that the uncertainty of multi-GCM ensembles are higher than that from multi-parameter HM ensembles for direct runoff in headwater watersheds. However, the opposite was true for soil moisture and ground water flows. In addition, the authors show that runoff uncertainties are much more correlated to GCM precipitation than temperature. On contrary, Wilby and Harris (2006) combined distinct uncertainties into a probabilistic low flow diagnostic using different emission scenarios, GCMs, downscaling procedures, HMs and set of parameters, and found that the isolated impact of GCMs choice was the main source of uncertainty.

Attempting to circumvent partly the many issues of common strategies that estimate regional hydrological impacts with climate change projections, and so create an uncertainty cascade, this work approached alternative ways with a sensitivity study that assess the whole range of likely impacts, based on the concept of the elasticity of key climate variables to air temperature that affect surface hydrology. The elasticity accounts the percentage or absolute change of a variable in response to a change in another. For instance, Held and Soden (2006) reported the absolute elasticity of precipitable water to temperature increase from climate change projections for the late 21 st century of about $7.5 \% \mathrm{~K}^{-1}$, and the elasticity of precipitation to temperature was less, of $2.2 \% \mathrm{~K}^{-1}$, due to energy-limited conditions (Vecchi and Soden, 2007). Other authors (e.g., Arnell, 2011; Xu et al., 2011) used pattern-scaling relationships, where each forcing climate variable to the HM is supposed to respond linearly to the changing mean annual temperature. Elasticity approach can be extended, for example, to relationships between precipitation and streamflow changes (e.g., Liu et al., 2017; Andréassian et al., 2016).

Previous studies were carried out in Jaguari river basin using both lumped (Gesualdo et al., 2019; Zhang et al., 2018) and distributed (Mohor and Mendiondo, 2017; Taffarello 
et al., 2018; Pontes et al., 2016) hydrological models. Considering the high spatial heterogeneity of physical and hydrological features of Jaguari basin as reported by Taffarello et al. (2016), and also the different land covers within the drainage area, a distributed model is possibly more adequate to represent the hydrology of such region.

Using the physically-based semi-distributed SWAT model, yet subject to the uncertainties of parameter calibration and the specific responses of its inner parametrizations, we designed a strategy using forcing-response relationships to estimate the impact of climate change in the surface water budget over the Jaguari river basin. With this approach we deliberately intend to identify the particular and summed contribution of key climatic variables (temperature, rainfall, air humidity and $\mathrm{CO}_{2}$ concentration) on the variability of the water budget in historical time and in the future. 
Chapter 2

\section{Objectives}

This work aimed to assess the impact of future climate change on the hydrological processes and water budget in the Jaguari river at Cantareira reservoirs system, via forcings based on the elasticity of key climate variables (rainfall and air humidity) to the air temperature and future scenarios of $\mathrm{CO}_{2}$ concentration, and the responses calculated with simulations for the historical and future time using a thoroughly calibrated physicallybased model.

With this purpose, the following specific goals were established:

- Set up the boundary conditions for the SWAT model upstream the inlet of Jaguari water reservoir, using long term data of hydrometeorological variables during the years 1995-2017, here defined as the historical forcings, in order to calibrate the model and perform the experimental simulations;

- Calibrate/validate the SWAT model for discharge, and also provide calculations of evapotranspiration and soil moisture that represent the hydrological regimes adequately;

- Perform the experiments using the calibrated SWAT model and a set of perturbations in the historical forcings of key climatic variables, accordingly to individual elasticities of rainfall and air humidity to air temperature, and future scenarios of $\mathrm{CO}_{2}$ concentration, ranged over most projections of the CMIP5 data set;

- Discuss the particular and summed contribution of each key climatic variable on the variability of the mean and extreme values of the water budget, both at the historical time and in the future, as a response to the main question on the impact of climate change. 
Chapter 3

\section{Material and Methods}

\subsection{Study area}

The Cantareira water reservoirs system is a group of reservoirs, tunnels and channels that collect and transpose water from part of Piracicaba river basin to Upper Tietê basin (Kelman, 2015), supplying around 8.8 million people (Whately and Cunha, 2007) in the Metropolitan Area of São Paulo, in Southeast Brazil (Fig. 3.1). The region is in the boundary of São Paulo and Minas Gerais states, comprising areas of the Mantiqueira Mountains.

It is composed by the reservoirs in Jaguari, Jacareí, Cachoeira and Atibainha Rivers, within the Piracicaba river watershed, and one in Juqueri River in Upper Tietê watershed. Jaguari and Jacareí reservoirs are connected to each other and are the main suppliers of the System, with an average contribution of $25.2 \mathrm{~m}^{3} \mathrm{~s}^{-1}$ (ANA and DAEE, 2015). The Jaguari river basin totals $1027 \mathrm{~km}^{2}$ of contribution area that corresponds to $84 \%$ of the upstream area related to Jaguari-Jacareí reservoir (ANA and DAEE, 2015).

We used the streamflow gauge 25B (SABESP, 2020) at $22.875^{\circ} \mathrm{S}$ and $46.369^{\circ} \mathrm{W}$ as the Jaguari basin outlet, that sums $94 \%\left(965.7 \mathrm{~km}^{2}\right)$ of the total upstream area of the Jaguari reservoir, and presents a mean discharge of $18.6 \mathrm{~m}^{3} \mathrm{~s}^{-1}$. The gauge is downstream of the confluence of Camanducaia and Jaguari rivers, and is around $1000 \mathrm{~m}$ below the river head altitude.

\subsection{SWAT model description}

Soil and Water Assessment Tool (SWAT) is a semi-distributed, continuous-time model, which represents processes from small to large basin scales, on daily time step, to 

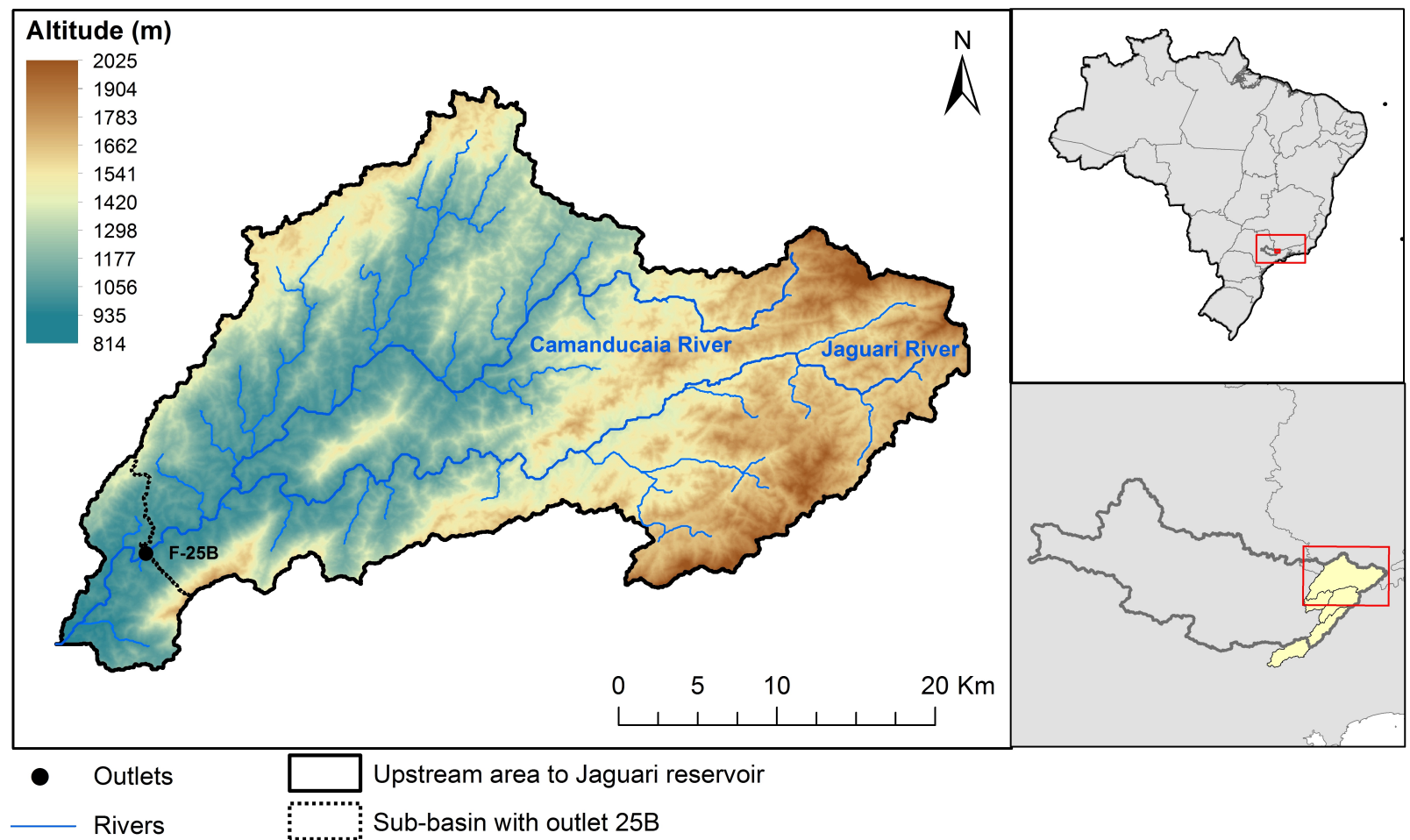

Figure 3.1: Left: Altitude map of the study area, in meters. The rivers are displayed in blue segments, and main rivers are detached. The black dashed line delimits the river basin with F-25B gauge as outlet. Right: Geographic location of Jaguari river basin. Dark grey line delimits the Piracicaba river basin, and yellow shaded area the Cantareira water reservoirs system.

assess the impacts of management on yields of water, sediments, and agricultural chemical components (Gassman et al., 2007). The model is called semi-distributed because a given watershed is initially divided in sub-basins, according to the topography, and then, divided in hydrological response units (HRUs), which are areas of common declivity class, soil and land use. The water balance is addressed in the HRUs level, and the main processes are summarized in Equation 3.1 (Neitsch et al., 2011).

$$
S W_{t}=S W_{0}+\sum_{i=1}^{t}\left(R_{d a y}-Q_{\text {surf }}-Q_{\text {lat }}-E_{a}-w_{\text {seep }}\right)
$$

where $S W_{t}$ is the soil water content at a given time $t, S W_{0}$ is the initial soil water content on day $i, R_{\text {day }}, Q_{\text {surf }}, Q_{\text {lat }}, E_{a}$ and $w_{\text {seep }}$ are the precipitation, the surface flow, the lateral flow, the evapotranspiration and the water exiting the vadose zone from the soil profile, respectively, on day $i$. All terms are expressed in $\mathrm{mmH}_{2} \mathrm{O}$.

Water can be stored in the canopy, in the soil layers, and in the shallow and deep aquifers, the latter being a water removal from the system. The HRU-scale water flow is 
then aggregated and routed in the drainage network.

The main processes are described in the sub-sections below.

\subsubsection{Discharge}

The discharge in each HRU is a contribution of three different terms: the overland flow, the lateral flow and the base flow. These components are separately computed, and then evaluated to maintain the mass balance.

\subsubsection{Overland flow}

The overland flow, or surface runoff, is calculated using the SCS curve number method (SCS, 1972). According to Neitsch et al. (2011), the curve number $(C N)$ "... is a function of the soil's permeability, land use and antecedent soil water conditions". Once $C N$ is given, surface runoff can be estimated using Equations 3.2 and 3.3 (Neitsch et al., 2011):

$$
\begin{aligned}
& S=25.4\left(\frac{1000}{C N}-10\right) \\
& Q_{\text {surf }}=\frac{\left(R_{d a y}-0.2 S\right)^{2}}{\left(R_{d a y}+0.8 S\right)}
\end{aligned}
$$

where $Q_{\text {surf }}$ is the surface runoff, $S$ is the retention parameter and $R_{\text {day }}$ is the rainfall, all terms in $\mathrm{mmH}_{2} \mathrm{O}$. Once $Q_{\text {surf }}$ is calculated, the amount of water infiltrating will be the difference between $R_{d a y}$ and $Q_{\text {surf }}$.

\subsubsection{Lateral flow}

The lateral flow occurs in the subsurface layer when the water which is percolating down the soil encounters an impermeable layer, ponding above it (Neitsch et al., 2011; Loan and Moore, 1984). It is likely to be an important term when hydraulic conductivity is high, which is usual in watersheds presenting humid forests, whose litter helps to maintain high surface permeability (Loan and Moore, 1984). The lateral flow is calculated in SWAT according to equation 3.4 (Neitsch et al., 2011):

$$
Q_{\text {lat }}=0.024 \cdot\left(\frac{2 \cdot S W_{\text {ly,excess }} \cdot K_{\text {sat }} \cdot \operatorname{slp}}{\phi_{d} \cdot L_{\text {hill }}}\right)
$$


where $Q_{l a t}$ is the lateral flow $\left(\mathrm{mm} \mathrm{d}^{-1}\right), S W_{l y, \text { excess }}$ is the water content that exceeds the field capacity content from each layer $l y\left(\mathrm{mmH}_{2} \mathrm{O}\right), K_{\text {sat }}$ is the saturated hydraulic conductivity $\left(\mathrm{mm} \mathrm{h}^{-1}\right)$, slp is average slope of the subbasin $\left(\mathrm{m} \mathrm{m}^{-1}\right), \phi_{d}$ is the drainable porosity of the soil layer $\left(\mathrm{mm} \mathrm{mm}^{-1}\right)$ and $L_{\text {hill }}$ is the hillslope length $(\mathrm{m})$. The factor 0.024 converts $\mathrm{mm} \mathrm{h}^{-1}$ from $K_{\text {sat }}$ to $\mathrm{mm} \mathrm{d}^{-1}$ and $\mathrm{m}$ from $L_{\text {hill }}$ to $\mathrm{mm}$.

\subsubsection{Base flow}

The groundwater flow, or base flow, is the contribution of shallow aquifer water storage to the discharge. The excess of water leaving the bottom soil layer along with the direct contribution from crack soils, apart from a percentage that flows straight to deep aquifer, will recharge the shallow aquifer. On the other hand, water can be removed from shallow aquifer by pumping and revap process, along with the base flow. The base flow would only exist when a threshold water level is reached in the shallow aquifer, according to equations 3.5 and 3.6 (Neitsch et al., 2011):

$$
\begin{gathered}
Q_{g w, i}=Q_{g w, i-1} \cdot e^{-\alpha_{g w} \cdot \Delta t}+w_{r c h r g, s h} \cdot\left(1-e^{-\alpha_{g w} \cdot \Delta t}\right), \text { if } a q_{s h}>a q_{s h t h r, q} \\
Q_{g w, i}=0, \text { if } a q_{s h} \leq a q_{s h t h r, q}
\end{gathered}
$$

where $Q_{g w, i}$ is the base flow reaching the channel on day $i\left(\mathrm{mmH}_{2} \mathrm{O}\right), Q_{g w, i-1}$ is the base flow contribution from day $i-1\left(\mathrm{mmH}_{2} \mathrm{O}\right), \alpha_{g w}$ is the recession constant, $\Delta t$ is the time step ( 1 day), $w_{\text {rchrg,sh }}$ is the amount of water recharging the shallow aquifer on day $i\left(\mathrm{mmH}_{2} \mathrm{O}\right)$, $a q_{s h}$ is the storage of shallow aquifer water on day $i$ and $a q_{s h t h r, q}$ is the threshold water level in the shallow aquifer in which base flow occurs $\left(\mathrm{mmH}_{2} \mathrm{O}\right)$.

\subsubsection{Evapotranspiration}

Evapotranspiration (ET) is a combined term of three different processes in the watershed that loses water vapour to the atmosphere: evaporation from vegetative surfaces, plant transpiration and soil evaporation.

Potential evapotranspiration (PET) is estimated in this work using a modified version of Penman-Monteith method proposed by Jensen et al. (1990). It represents the maximum rate of ET in a day, modulating the potential evaporation from vegetative surfaces $\left(E s_{\max }\right)$ 
and plant transpiration $\left(E t_{\max }\right)$ rates, which are treated separately in the model. PenmanMonteith PET is calculated based on a reference crop (alfalfa) at a height of $40 \mathrm{~cm}$ (Neitsch et al., 2011):

$$
P E T=\frac{\Delta \cdot(R n-G)+\gamma \cdot K_{1} \cdot\left(0.622 \cdot \lambda \cdot \frac{\rho_{a i r}}{P}\right) \cdot \frac{v p d}{r_{a}}}{\lambda\left(\Delta+\gamma \cdot\left(1+\frac{r_{c}}{r_{a}}\right)\right)}
$$

where $\Delta$ is the slope of the saturation vapor pressure-temperature curve, $R n$ is the net radiation $\left(\mathrm{MJ} \mathrm{m}^{-2} \mathrm{~d}^{-1}\right), G$ is the ground heat flux $\left(\mathrm{MJ} \mathrm{m}^{-2} \mathrm{~d}^{-1}\right), \gamma$ is the psychrometric constant $\left(\mathrm{kPa}{ }^{\circ} \mathrm{C}^{-1}\right), K_{1}$ is a dimension coefficient, $\lambda$ is the latent heat of vaporization (MJ kg-1), $\rho_{\text {air }}$ is the air density $\left(\mathrm{kg} \mathrm{m}^{-3}\right), P$ is the atmospheric pressure $(\mathrm{kPa})$, vpd is the vapour pressure deficit $(\mathrm{kPa}), r_{c}$ is the plant canopy resistance $\left(\mathrm{s} \mathrm{m}^{-1}\right)$, and $r_{a}$ is the aerodynamic resistance $\left(\mathrm{s} \mathrm{m}^{-1}\right)$. The term $K_{1} \cdot\left(0.622 \cdot \lambda \cdot \frac{\rho_{\text {air }}}{P}\right)$ is estimated as $1710-6.85 \cdot \overline{T_{a v}}$, where $\overline{T_{a v}}$ is the mean air temperature $\left({ }^{\circ} \mathrm{C}\right)$.

\subsubsection{Potential and actual transpiration}

$E t_{\text {max }}$ is estimated similarly to PET (Equation 3.7). The differences between them are in $r_{a}$ and $r_{c}$ calculations. The $r_{c}$ resistance in SWAT depends on two limiting: the concentration of $\mathrm{CO}_{2}\left(\left[\mathrm{CO}_{2}\right]\right)$ and $v p d$. First, it is adjusted the conductance for a single leaf $\left(g_{l}\right.$, expressed in $\left.\mathrm{m} \mathrm{s}^{-1}\right)$ due to $v p d$ (Easterling et al., 1992; Stockle et al., 1992), described in Equations 3.8 and 3.9:

$$
\begin{gathered}
g_{l}=g_{l, m x} \cdot\left[1-\Delta g_{l, d c l} \cdot\left(v p d-v p d_{t h r}\right)\right], \text { if } v p d>v p d_{t h r} \\
g_{l}=g_{l, m x}, \text { if } v p d \leq v p d_{t h r}
\end{gathered}
$$

where $g_{l, m x}$ is the maximum conductance for a single leaf $\left(\mathrm{m} \mathrm{s}^{-1}\right), \Delta g_{l, d c l}=\frac{1-f r_{g, m x}}{v p d_{f r}-v p d_{t h r}}$ is the rate of decline in $g_{l}$ per unit increase in $v p d\left(\mathrm{~m} \mathrm{~s}^{-1} \mathrm{kPa}^{-1}\right), f r_{g, m x}$ is the fraction of $g_{l, m x}$ achieved at vapor pressure deficit $v p d_{f r}$, and $v p d_{t h r}$ is the threshold $v p d$ above which a plant will start reducing leaf conductance $(\mathrm{kPa})$, assumed to be $1.0 \mathrm{kPa}$ for all plant species (Neitsch et al., 2011). The parameters $g_{l, m x}, v p d_{f r}$ and $f r_{g, m x}$ are user-defined for each land use.

Then, $\left[\mathrm{CO}_{2}\right]$ effects are addressed (Easterling et al., 1992; Stockle et al., 1992):

$$
g_{l, C O_{2}}=g_{l} \cdot\left(1.4-0.4 \cdot \frac{\left[C O_{2}\right]}{330}\right)
$$


where $g_{l, C O_{2}}$ is the conductance for a single leaf adjusted for $\left[\mathrm{CO}_{2}\right]$, in $\mathrm{m} \mathrm{s}^{-1}$. The $\left[\mathrm{CO}_{2}\right]$ is originally a time invariant variable in SWAT, and the user needs to change the source code to take into account the $\left[\mathrm{CO}_{2}\right]$ variation in time.

Both vpd and $\left[\mathrm{CO}_{2}\right]$ can act as stress factors to evapotranspiration, when surpassing 1 $\mathrm{kPa}$ and $330 \mathrm{ppm}$, respectively, thus reducing the conductance. Then, $r_{c}$ is calculated for canopy as the inverse of $g_{l, C O_{2}}$, adjusted to the factor $0.5 \cdot L A I$, where $L A I$ is the leaf area index $\left(\mathrm{m}^{2} \mathrm{~m}^{-2}\right)$ :

$$
r_{c}=\left[g_{l, C O_{2}} \cdot(0.5 \cdot L A I)\right]^{-1}
$$

$E t_{\max }$ controls the potential water uptake from each soil layer. As root density uses to be more extensive close to the soil surface, the potential water uptake is set in the model to be much greater in the upper layer, so that $50 \%$ and $95 \%$ of the total uptake occurs in the upper $6 \%$ and $30 \%$ of the root zone, respectively. Considering this restrictive profile of potential water uptake, the upper layers might not meet the demand in some cases. To address this limitation, users are able to increase the potential water uptake of lower layers in order to supply the demand not met by the overlying layers (modifying parameter EPCO) (Neitsch et al., 2011). Additionally, when the water stored in the soil layers is low, the water uptake decays exponentially according to Equation 3.12:

$$
\begin{gathered}
w_{u p, l y}^{\prime}=w_{u p, l y} \cdot \exp \left[5 \cdot\left(\frac{S W_{l y}}{0.25 \cdot A W C_{l y}}-1\right)\right], \text { if } S W_{l y}<0.25 \cdot A W C_{l y} \\
w_{u p, l y}^{\prime}=w_{u p, l y}, \text { if } S W_{l y} \geq 0.25 \cdot A W C_{l y}
\end{gathered}
$$

where $w_{u p, l y}^{\prime}$ is the adjusted potential water uptake for layer $l y, w_{u p, l y}$ is the potential water uptake previous to the adjustment for layer $l y, S W_{l y}$ is the soil water content of layer $l y$ and $A W C_{l y}$ is the available water capacity for layer $l y$, all terms expressed in $\mathrm{mmH}_{2} \mathrm{O}$. The potential water uptake from each soil layer will be extracted as long as it does not exceed the difference $S W_{l y}-W P_{l y}$, where $W P_{l y}$ is the water content at the wilting point. Then, the actual transpiration will be the sum of water uptake from each soil layer.

\subsubsection{Potential and actual soil evaporation}

$E s_{\max }$ depends on the product of PET and the soil cover index. The latter varies from 0 to 1, and computes the aboveground biomass and residue effect in reducing $E s_{\max }$, 
so that the more biomass and residue the closer to zero it is. When the sum of $E t_{\max }$ and $E s_{\max }$ exceeds PET, soil evaporation is weighted by the factor $r$ (Equation 3.14)

$$
r=\frac{P E T}{E t_{\max }+E s_{\max }}
$$

If the sum continues exceeding PET, both $E s_{\max }$ and $E t_{\max }$ are weighted by an updated $r$ (if $r$ was used in the previous step, $E s_{\max }$ was modified, and so does $r$ ).

When the snow storage is not null, $E s_{\max }$ is initially used to sublimate the snow. Then, the remaining evaporative demand is oriented to the soil water. In the study basin, $E s_{\max }$ is directly oriented to evaporate the soil water. SWAT model partitions the evaporative demand by depth, so that $50 \%$ of the demand must be taken from the top $10 \mathrm{~mm}$ and 95\% from top $100 \mathrm{~mm}$ of soil. However, similarly to the water uptake, users are also able to modify the evaporative demand with depth in order to favour evaporation from lower levels, using a compensation coefficient (ESCO). The field capacity for each soil layer will be a constraint to the potential evaporation, according to Equations 3.15 and 3.16:

$$
\begin{gathered}
E s_{\text {max }, l y}^{\prime}=E s_{\text {max }, l y} \cdot \exp \left(\frac{2.5 \cdot\left(S W_{l y}-F C_{l y}\right)}{F C_{l y}-W P_{l y}}\right), \text { if } S W_{l y}<F C_{l y} \\
E s_{\text {max }, l y}^{\prime}=E s_{\text {max }, l y}, \text { if } S W_{l y} \geq F C_{l y}
\end{gathered}
$$

where $E s_{\text {max,ly }}^{\prime}$ is the adjusted potential evaporation, $E s_{\max , l y}$ is the potential evaporation, $S W_{l y}$ is the soil water content, $F C_{l y}$ is the water content at field capacity and $W P_{l y}$ is the water content at wilting point, all terms expressed in $\mathrm{mmH}_{2} \mathrm{O}$ for a given layer $l y$. Lastly, water will be removed from each layer as long as the evaporative demand does not represent more than $80 \%$ of $A W C_{l y}$. Otherwise, only $0.8 \cdot A W C_{l y}$ will be removed. The actual soil evaporation for a given day will be the sum of the water removed from each layer.

\subsubsection{Plant growth}

Plant growth in SWAT is linked to the approach of heat units (HU). It is assumed that plants reach maturity when accumulate a given amount of HU, that is calculated according to Equations 3.17 and 3.18.

$$
H U_{i}=\left(\frac{T_{\max , i}+T_{\min , i}}{2}\right)-T_{b a s e, j}, \text { if }\left(\frac{T_{\max , i}+T_{\min , i}}{2}\right)>T_{b a s e, j}
$$




$$
H U_{i}=0, \text { if }\left(\frac{T_{\max , i}+T_{\min , i}}{2}\right) \leq T_{b a s e, j}
$$

where $H U, T_{\max }$ and $T_{\min }$ are, respectively, the heat units, maximum and minimum temperatures, in ${ }^{\circ} \mathrm{C}$, for day $i$, and $T_{\text {base }}$ is the base temperature $\left({ }^{\circ} \mathrm{C}\right)$ for plant $j$. If the $\mathrm{HU}$ is accumulated along the time, it is possible to define a quantity that represents the maturity for each plant $j$, that is called potential heat units $\left(P H U_{j}\right)$. When $j$ is a crop, the PHU represents the interval between planting and harvesting, whilst for trees and perennials it is the period between budding and leaf senescence (Strauch and Volk, 2013). A fraction $\left(F R_{P H U, i, j}\right)$ ranging from 0 to 1 can be defined to express the stage of growth:

$$
F R_{P H U, i, j}=\frac{\sum_{k=1}^{i} H U_{k}}{P H U_{j}}
$$

The leaf area index (LAI) is controlled by the $F R_{P H U, i, j}$. The rise until the maximum LAI $\left(L A I_{m x}\right)$ is a sigmoid-like curve that depends on two shape parameters, which along with $L A I_{m x}$, can be adjusted by the user. Once $L A I_{m x}$ is reached, it is maintained constant until senescence surpasses leaf growth, and LAI decreases linearly to 0. Another feature of the LAI curve is the dormancy period, which is defined for regions south of $20^{\circ} \mathrm{S}$ or north of $20^{\circ}$ N. Figure 3.2 shows the dormancy period for a range of latitudes in Southern hemisphere. When the day-length reaches a minimum threshold, plants undergo dormancy and do not grow, so that part of the biomass is converted to residue and LAI reaches its minimum $\left(L A I_{m n}\right)$. Dormancy also marks the beginning of a new growth cycle for trees and perennials, while for crops the new cycle can be schedule with planting and harvesting operations.

Along with $g_{l, m x}$, LAI also modulates the transpiration (Eq. 3.11), and influence its seasonality as well. Although using a dynamic approach for LAI seems appropriate to represent different climate conditions throughout the years, this mechanism brings some difficulties in the adjustment. First, dormancy in SWAT depends exclusively on the day of the year, and not on biophysical parameters related to the soil moisture, nutrients, abscisic acid, among other factors. Second, the shape parameters are not able to provide realistic seasonal patterns of LAI for Southern Hemisphere, which can only be reached using management operations of harvesting and planting (Strauch and Volk, 2013), but it does not make sense for natural land covers such as forests. Lastly, the plant growth will change under some climate perturbation scenarios, once the heat units approach will be modified, 


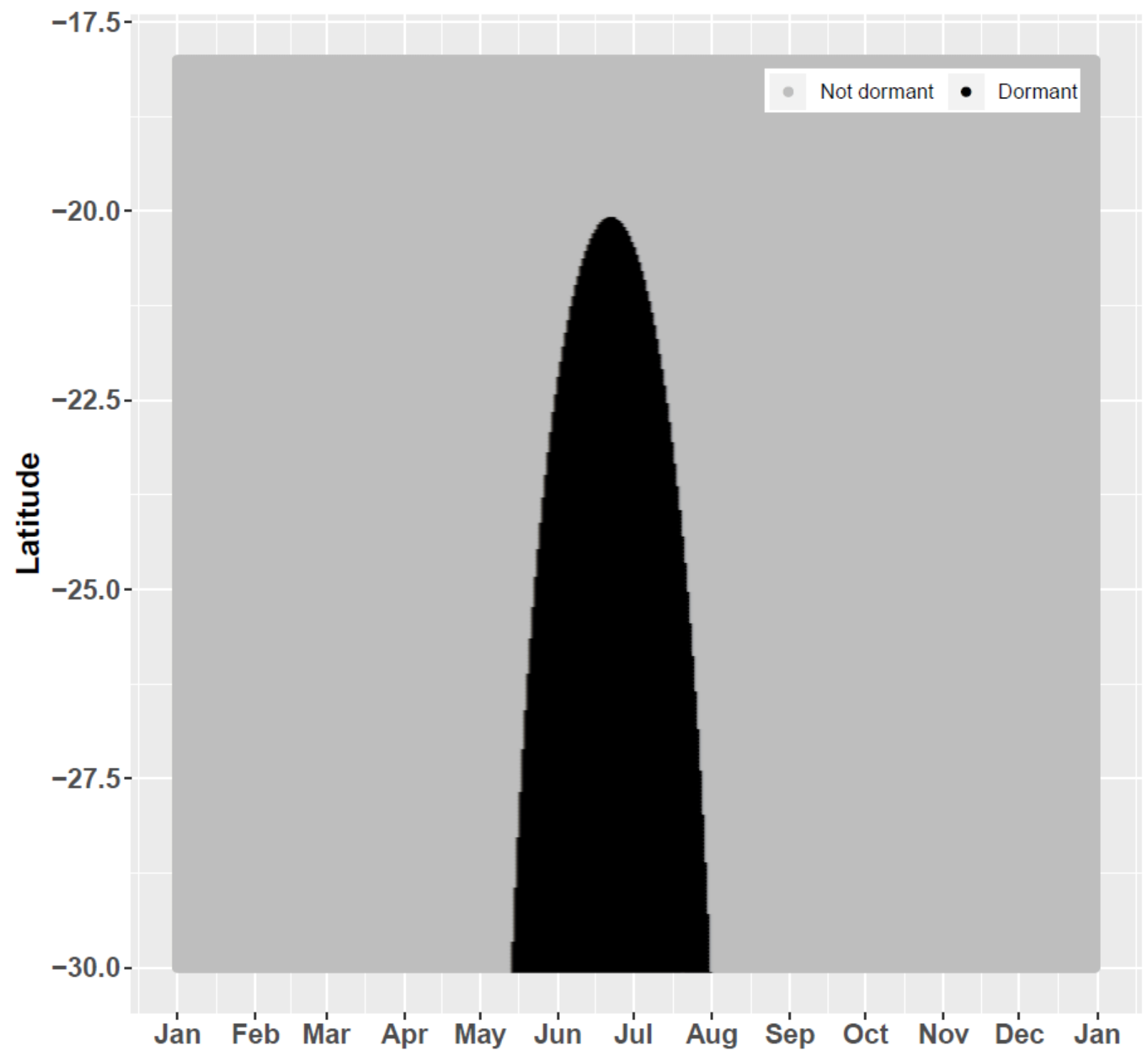

Figure 3.2: Dormancy period in function of latitude.

making it difficult to address the specific contribution from climate and phenology in the results. For this reason, we propose a modification in plant growth using an analytic equation (Equation 3.20), as previously used by Mota da Silva (2013). It supposes a sinusoidal behavior, whose amplitude depends on the prescribed $L A I_{m x}$ and $L A I_{m n}$.

$$
L A I_{i, j}=L A I_{m x, j}-\left(L A I_{m x, j}-L A I_{m n, j}\right) \cdot\left[0.5 \cdot\left(\sin \left(5.5 \pi+\frac{\pi i}{182}\right)+1\right)\right]^{1.1}
$$

where indexes $i$ and $j$ represent the day of the year and the land cover, respectively, and 182 is the day of the year when $L A I_{m n, j}$ is expected. The fitted LAI curves for both pasture and forest land covers are shown in Figure 3.3. 


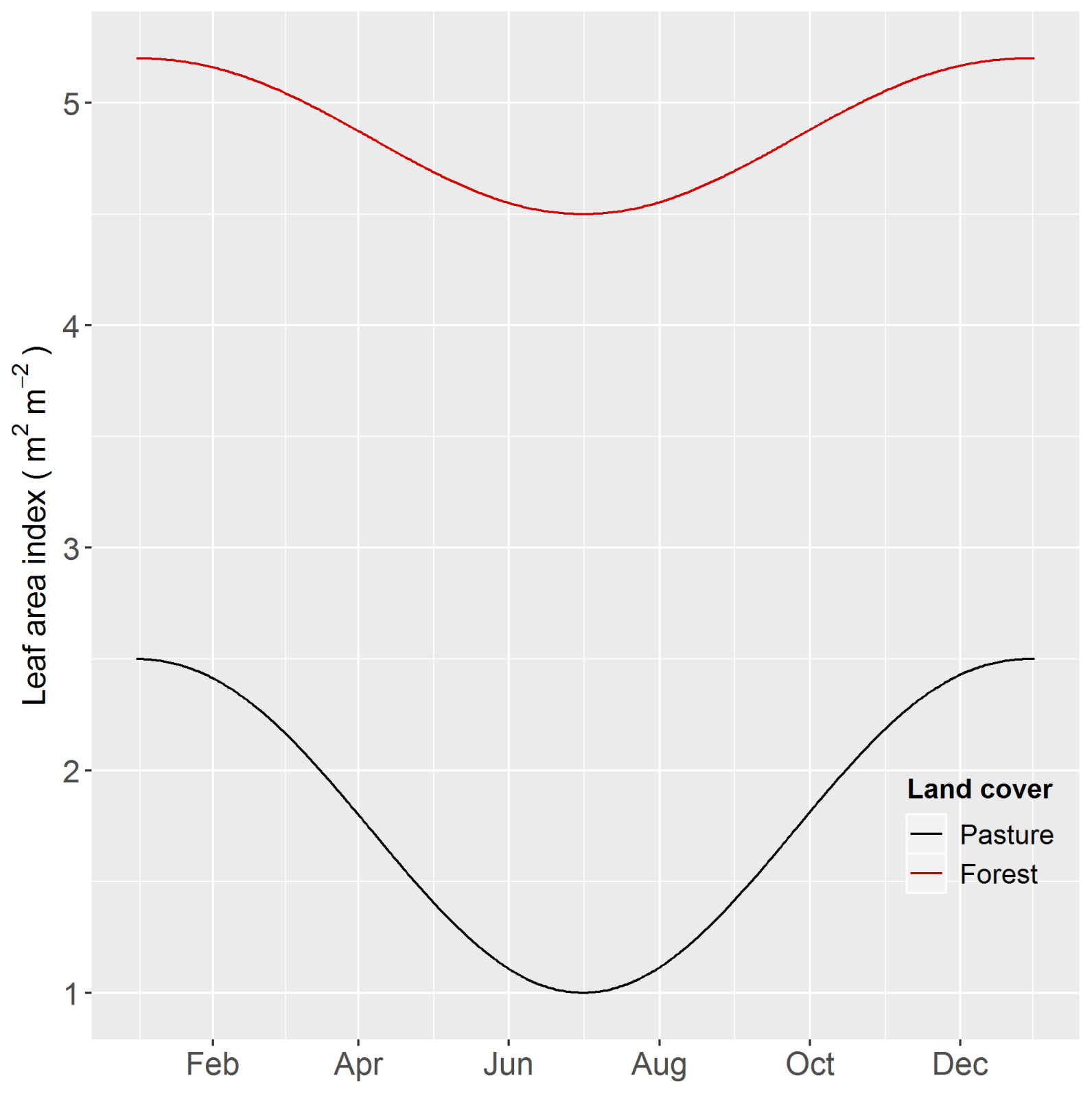

Figure 3.3: Daily variation of leaf area index, in $\mathrm{m}^{2} \mathrm{~m}^{-2}$, in a year, for pasture (black line) and forest (red line) land covers.

\subsection{SWAT setup}

SWAT 2012 rev. 591 was used in this work. The boundary conditions were built under a Geographic Information System (GIS) platform, ArcGIS ${ }^{\circledR}$ 10.2.2, via ArcSWAT 2012.10.2.18 extension. Details are described below:

- Digital Elevation Map (DEM) was taken from the ASF DAAC (2015) dataset, with a resolution of 12.5 meters (Fig. 3.4a). This data is used to delineate the watershed, main rivers and tributaries, sub-basins and the declivity classes that are used in HRU 
definition;

- Land use map (Fig. 3.4b) was adapted from IBGE (2015). For simplicity, agriculture was reclassified into pasture, forested areas were generalized in a single class, and mosaic classes were reclassified into the dominant cover (pasture or forest). Pasture and forest were initially set according to Mota da Silva (2013), and the remaining class (urban) is set as default;

- Soil map (Fig. 3.4c) from Minas Gerais State (UFV-CETEC-UFLA-FEAM, 2010) was adapted to represent two classes: Red-Yellow Latosol (LVA) and Red-Yellow Argisol (PVA). The physical properties of the soil were initially set according to Pontes et al. (2016);

- Rainfall data was built merging available gauges held by different sources: Agência Nacional de Águas (ANA, 2018), Companhia de Saneamento Básico do Estado de São Paulo (SABESP, 2018), Centro Nacional de Monitoramento e Alertas de Desastres Naturais (CEMADEN, 2018), Monte Verde station from Instituto Nacional de Meteorologia (INMET) and Extrema, Piracaia, Vargem and Bragança Paulista stations from Instituto Agronômico de Campinas (IAC). These data were daily interpolated using the inverse distance weighting (IDW) method (Pebesma, 2004), in a $0.1^{\circ} \times 0.1^{\circ}$ grid. The quality control removed daily spikes, consecutive zero and non zero days of rainfall, and monthly zeros during DJF trimester. In order to check whether the data were accordingly removed, a visual analysis was carried out merging both original and consisted data, with the closest gauges ( $<10 \mathrm{~km}$ radius). Besides that, the visual analysis has removed periods when a gauge continuously underestimated the rainfall, possibly due to clogging, time lags from conventional gauges, among other random errors. The gauges position as well as their availability in time are shown in Fig. 3.5;

- Maximum and minimum temperature, wind speed, relative humidity and solar radiation (hereafter referred as weather data) were taken from ERA-Interim reanalysis (Dee et al., 2011), and present $\approx 80 \mathrm{~km}$ resolution. Both rainfall and weather coordinates are from the center of each grid, that are treated as stations (Fig. 3.4d);

- We set $\mathrm{CO}_{2}$ concentration based on observed mean global temporal rates during 
the range of time (Thoning et al., 2020), starting from $350 \mathrm{ppm}$ and increasing approximately at 2 ppm per yr.

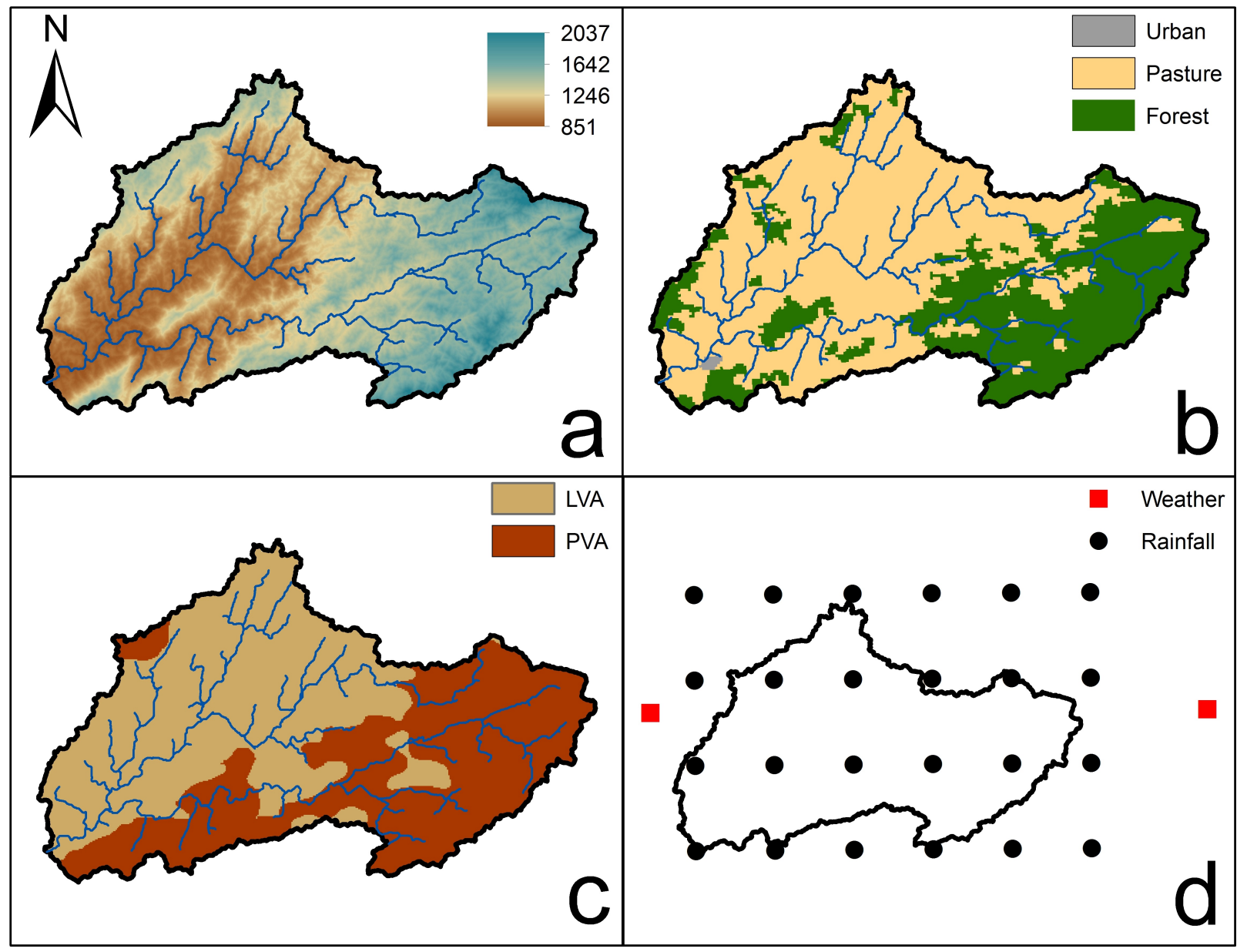

Figure 3.4: (a) Digital elevation map (m); (b) Reclassified land use map; (c) Reclassified soil map; (d) Position of each grid center for rainfall (black circles) and weather (red squares) data.

\subsection{Calibration}

In this work, we used the streamflow gauge $25 \mathrm{~B}$ as a reference to calibrate the Jaguari basin, which was deliberately chosen to be the basin outlet (see Fig. 3.1). This gauge was selected because it is the closest to the inlet of Jaguari dam, it is daily updated and comprises a relatively long period (1990 - present). The data passed through quality control process in order to remove random errors, and was compared to gauges F-23, close to Camanducaia river outlet (northern portion of the basin area), and F-28, from Middle Jaguari, to assess other potential mistakes in the record. The period $2003-2017\left(\approx \frac{2}{3}\right.$ 


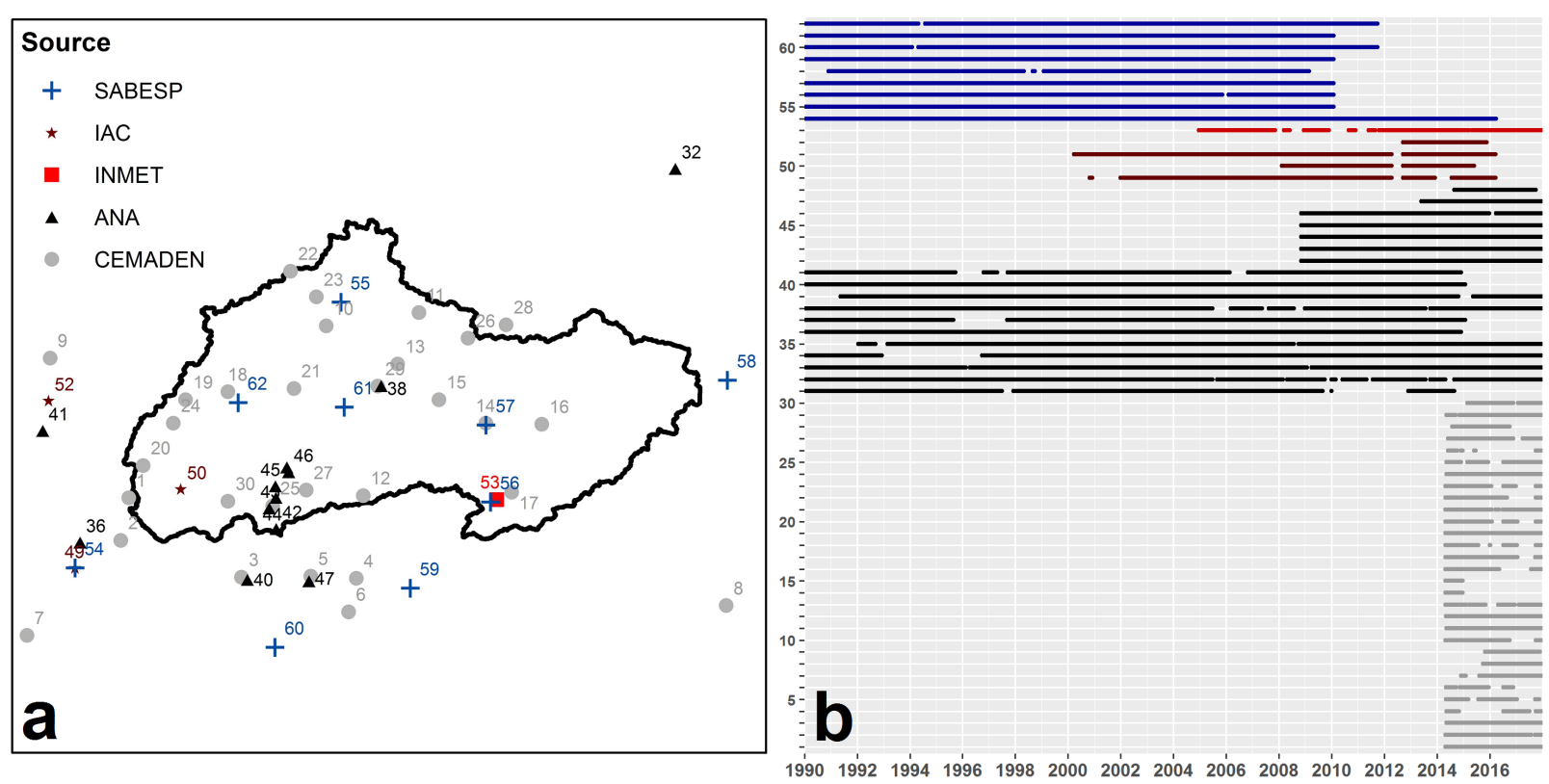

Figure 3.5: (a) Rain gauge positions of different sources: CEMADEN (grey dots), ANA (black triangles), INMET (red square), IAC (dark red star) and SABESP (blue cross), and (b) data availability in time (x-axis) for each rain gauge labelled in (a) (y-axis). Discontinuity represents missing data, and colors follow the same pattern than (a).

of the time series) was selected for calibration because it comprises a higher inter-annual variability than $1995-2002\left(\approx \frac{1}{3}\right.$ of the time series), that was used for validation. A warm up period of 5 yr was carried out for both calibration (1998-2002) and validation (1990-1994) steps.

The calibration was divided in two steps: (1) an exploratory and (2) a fine tuning. The exploratory step used prescribed parameters based on literature (Rafee et al., 2019; Pontes et al., 2016; Mota da Silva, 2013; Strauch and Volk, 2013) to run the Particle Swarm Optimization algorithm from SWAT-CUP (Abbaspour, 2015) and provide a list of the most sensitive parameters, that were used in the step 2. Along with that, some adjustments in evapotranspiration and discharge partitions were performed in this step and are described in Chapter 4.

The fine tuning process of calibration was carried out with swatplusR 0.2.7 package (Schürz, 2019) running in R (R Core Team, 2013). Latin Hypercube Sampling (LHS) was used to produce a 2000-length distribution of 15 parameters to be calibrated (selected from the previous step). Then, for each combination out of the 2000 possibilities, it was generated a SWAT output, and the discharge was evaluated using the Nash-Sutcliffe efficiency (NSE) index (Nash and Sutcliffe, 1970), expressed as: 


$$
N S E=1-\frac{\sum_{t=1}^{T}\left(Q_{m}^{t}-Q_{o}^{t}\right)^{2}}{\sum_{t=1}^{T}\left(Q_{o}^{t}-\overline{Q_{o}}\right)^{2}}
$$

where the $Q_{m}^{t}$ and $Q_{o}^{t}$ are the modelled and observed discharges at time t, and $\overline{Q_{0}}$ is the mean of the observed discharge. NSE index ranges from $-\infty$ to 1 , where 1 represents the perfect match between modelled and observed flows.

The simulation presenting the best NSE index is then used in the validation period.

It is important to highlight that the transition from SWAT-CUP to swatplusR was due to efficiency issues, once the latter was performed using parallel processing. As the source code was modified to address the changes listed in Sections 3.3 and 3.2.3, for $\mathrm{CO}_{2}$ concentration and LAI, it needed to be recompiled, so that the time to perform a single simulation with the current executable increased more than twice.

\subsection{Experimental design of perturbations in climatic forcings}

The elasticity $\left(\epsilon_{z, x}\right)$ addresses how much a percentage change $\frac{d z}{\bar{z}}$ of a given variable $\mathrm{z}$ responds to another percentage change $\frac{d x}{\bar{x}}$ of a variable $\mathrm{x}$, where $\bar{z}$ and $\bar{x}$ represent mean values of $\mathrm{z}$ and $\mathrm{x}$, respectively. The elasticity is a simple form to address the impact of changing a variable in another one.

In this work, we defined the experimental design by using the elasticity of key atmospheric variables (precipitation and air humidity) to near surface air temperature. The temporal change of mean air temperature $(\mathrm{T})$ was assessed with correspondent changes in rainfall (P) and specific humidity (q), defined as the elasticities $\epsilon_{P, T}$ and $\epsilon_{q, T}$, respectively, that accounted for the percentage of change in $\mathrm{P}$ (or q) by $1^{\circ} \mathrm{C}$ change of temperature, as follows:

$$
\begin{aligned}
\epsilon_{P, T} & =\frac{1}{\bar{P}} \frac{\Delta P}{\Delta T} \\
\epsilon_{q, T} & =\frac{1}{\bar{q}} \frac{\Delta q}{\Delta T}
\end{aligned}
$$

where $\Delta P, \Delta T$ and $\Delta q$ are temporal changes of $\mathrm{P}, \mathrm{T}$ and $\mathrm{q}$, respectively, and $\bar{P}$ and $\bar{q}$ are mean values of $\mathrm{P}$ and $\mathrm{q}$, all calculated over a prescribed range of time.

We used the estimates of precipitation and specific humidity elasticities to temperature calculated over the historical and future global climate simulations of 37 models of the 
Coupled Model Intercomparison Project - Phase 5 (CMIP5, Taylor et al., 2012) ${ }^{1}$ assessed by de Abreu et al. (in prep). The authors first interpolated the GCM outputs to a common $0.5^{\circ} \times 0.5^{\circ}$ horizontal resolution grid, and the ensemble mean of each model was calculated over a grid box centered in Southeast Brazil. They calculated the difference of an average variable in future climate (years 2075-2099) minus the average in the historical period (years 1980-2004) as estimates for $\Delta X$, where $X$ is a variable used in Eqs. 3.22 and 3.23, and $\bar{X}$ calculated during the entire period from 1980 to 2099. Only statistically significant changes were taken into account. For the future climate, the authors used the RCP8.5 (van Vuuren et al., 2011) ensembles, that usually constrained higher $\mathrm{CO}_{2}$ concentration (and also higher temperatures) out of other scenarios at the end of the 21st century, that was selected deliberately in order to obtain the highest signal-to-noise ratio responses to increasing $\mathrm{CO}_{2}$. The heat map of $\epsilon_{P, T}$ and $\epsilon_{q, T}$ (Fig. 3.6) shows there is a large spread over the models for elasticity of rainfall and less for humidity. The estimates of $\epsilon_{q, T}$ showed systematic increase in specific humidity with temperature, that ranged up to $10 \%{ }^{\circ} \mathrm{C}^{-1}$. For precipitation, the elasticity varied from patterns of decreasing to increasing precipitation, roughly from -10 to $+20 \%{ }^{\circ} \mathrm{C}^{-1}$, that agreed with reports of divergent contributions in the late century (Magrin et al., 2014). Also in Fig. 3.6 is shown the spread of CMIP5 models for elasticities of ET and P-ET. For ET, the elasticity ranged approximately from -5 to $5 \%{ }^{\circ} \mathrm{C}^{-1}$, with a positive average though, while P-ET presented a much wider range, roughly from -20 to $20 \%{ }^{\circ} \mathrm{C}^{-1}$. We stress that since elasticity relationships account for temporal rates of temperature, the absolute changes (of either humidity or rainfall) can be highly pronounced in future climate. For example, the elasticity value of $\epsilon_{P, T}=10 \%{ }^{\circ} \mathrm{C}^{-1}$ seems modest for a $1{ }^{\circ} \mathrm{C}$ warmer temperature, although it leads to a $30 \%$ of absolute increase in rainfall for a $3{ }^{\circ} \mathrm{C}$ warmer temperature climate. Likewise, the $\epsilon_{P, T}=20 \%{ }^{\circ} \mathrm{C}^{-1}$ leads to a $60 \%$ absolute increase in rainfall for the same $3^{\circ} \mathrm{C}$ increase of temperature. However, the probabilities of the rainfall elasticity among the set of models are different, wherein highest and lowest elasticities are less likely, though significant.

\footnotetext{
${ }^{1}$ ACCESS1.0, ACCESS1.3, BNU-ESM, CCSM4, CESM1-BGC, CESM1-CAM5, CESM1-WACCM, CMCC-CESM, CMCC-CM, CMCC-CMS, CNRM-CM5, CSIRO-Mk3.6.0, CanESM2, FGOALS-g2, GFDL-CM3, GFDL-ESM2G, GFDL-ESM2M, GISS-E2-H, GISS-E2-H-CC, GISS-E2-R, GISS-E2-RCC, HadGEM2-CC, HadGEM2-ES, IPSL-CM5A-LR, IPSL-CM5A-MR, IPSL-CM5B-LR, MIROC-ESM, MIROC-ESM-CHEM, MIROC5, MPI-ESM-LR, MPI-ESM-MR, MRI-CGCM3, NorESM1-M, NorESM1ME, BCC-CSM1.1, BCC-CSM1.1(m) and INM-CM4
} 


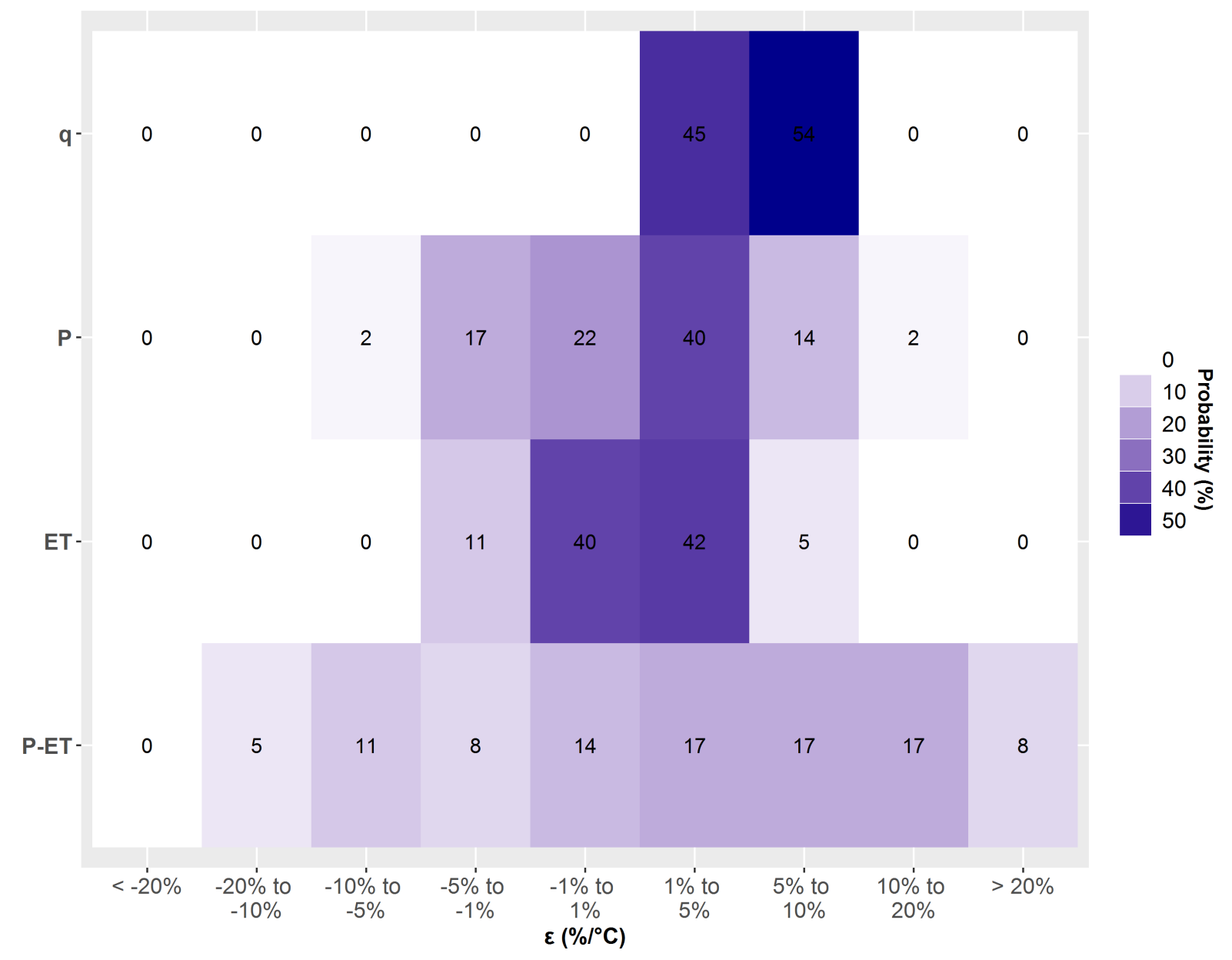

Figure 3.6: Probabilities of occurrence (\%) of elasticity in relation to temperature of precipitation (P), specific humidity (q), evapotranspiration (ET) and precipitation minus evapotranspiration (P-ET), in $\%{ }^{\circ} \mathrm{C}^{-1}$, using the CMIP5 models. Source: de Abreu et al. (in prep).

\subsubsection{The set of experiments}

We chose the 23 yr weather data (1995-2017) used for model calibration as the reference forcing data to simulate the hydrological outputs, here referred to as the Control experiment. Upon that, we defined case-specific perturbations on the key forcing variables (air temperature, humidity, precipitation and $\mathrm{CO}_{2}$ concentration) to define the set of experiments.

Firstly, for the temperature, we defined 5 cases of varying temperature, with perturbations prescribed as changes in mean daily air temperature (Tav) from +1 to $+5^{\circ} \mathrm{C}$ above the control, each case respectively. Maximum increase of $5^{\circ} \mathrm{C}$ comprises the upper limit of interquartile range (IQR) of CMIP5 projections for temperature increase, $4.6^{\circ} \mathrm{C}$, estimated 
by de Abreu et al. (in prep). Additionally, Raftery et al. (2017) points to a likely increase in temperature between 2 and $4.9^{\circ} \mathrm{C}$, already considering the effects of emission mitigation policies. The SWAT model was forced with maximum and minimum temperatures, so both variables were simply offset according to each perturbation case.

Second, for air relative humidity $(\mathrm{RH})$, we defined 3 cases with perturbations based on the $\epsilon_{q, T}$ variability derived from the CMIP variability (Fig. 3.6): $\epsilon_{q, T}=5,7.5$ and 10 $\%{ }^{\circ} \mathrm{C}^{-1}$, respectively. With the control case $\mathrm{RH}$ and Tav, we calculated the water vapour pressure $e=e_{s} \cdot R H$, where $e_{s}$ is the saturated water vapor pressure, dependent on Tav. Then, $\mathrm{e}_{\mathrm{s}}$ is updated to case specific temperature $\left(+1\right.$ to $\left.+5^{\circ} \mathrm{C}\right)$, e is incremented at the 3 percentages of $\epsilon_{q, T}$, and RH cases are calculated. The prescribed perturbations in control RH (Fig. 3.7) shows that they conveniently represented variations with reduced, alike and increased $\mathrm{RH}$ when compared to the control case, for elasticities of 5, 7.5 and 10 $\%{ }^{\circ} \mathrm{C}^{-1}$, respectively. We also noted interesting features: the changes compared to the control case were most pronounced with increasing RH, except for the alike case (Fig. 3.7 middle); as the alike case incidentally compared well with the control case, it is suggested that to keep RH approximately constant with increasing temperature required a $7.5 \%$ increase of specific humidity per ${ }^{\circ} \mathrm{C}$ of temperature change. Furthermore, we made some simplifications: for the $10 \%{ }^{\circ} \mathrm{C}^{-1}$ case, a few cases exceeded $\mathrm{RH}$ a little beyond $100 \%$ particularly for higher temperature increases, that we limited to $100 \%$ to keep consistency. Based on the comparison to the RH control case, in summary, we referred to the 3 cases as lower $\mathrm{RH}\left(5 \%{ }^{\circ} \mathrm{C}^{-1}\right)$, alike $\mathrm{RH}\left(7.5 \%{ }^{\circ} \mathrm{C}^{-1}\right)$ and higher $\mathrm{RH}\left(10 \%{ }^{\circ} \mathrm{C}^{-1}\right)$, respectively.

Third, for precipitation, we defined 4 cases with perturbations based on $\epsilon_{P, T}$ variability (Fig. 3.6): $-5,0,5$ and $10 \%{ }^{\circ} \mathrm{C}^{-1}$, that totalled $94.3 \%$ of all probabilities. The rainfall was changed by simple scaling of every daily rainfall episode of control case to percentages according to the 4 aforementioned cases and to case specific temperature $\left(+1\right.$ to $\left.+5^{\circ} \mathrm{C}\right)$.

Finally, to alter the $\mathrm{CO}_{2}$ concentration, we defined perturbations in 2 cases (Fig. 3.8): the first with prescribed daily time series as used in the calibration, here referred to as Historical case; the second based on the projected temporal rates for the RCP 8.5 during 2075-2099 (van Vuuren et al., 2011), that started at $750 \mathrm{ppm}$ and increased at 8 ppm $\mathrm{yr}^{-1}$, referred to as the end century case.

Despite being a key model forcing that controls ET, the incoming solar radiation was chosen not to be altered in our experiments, based on its low mean elasticity as noted by 


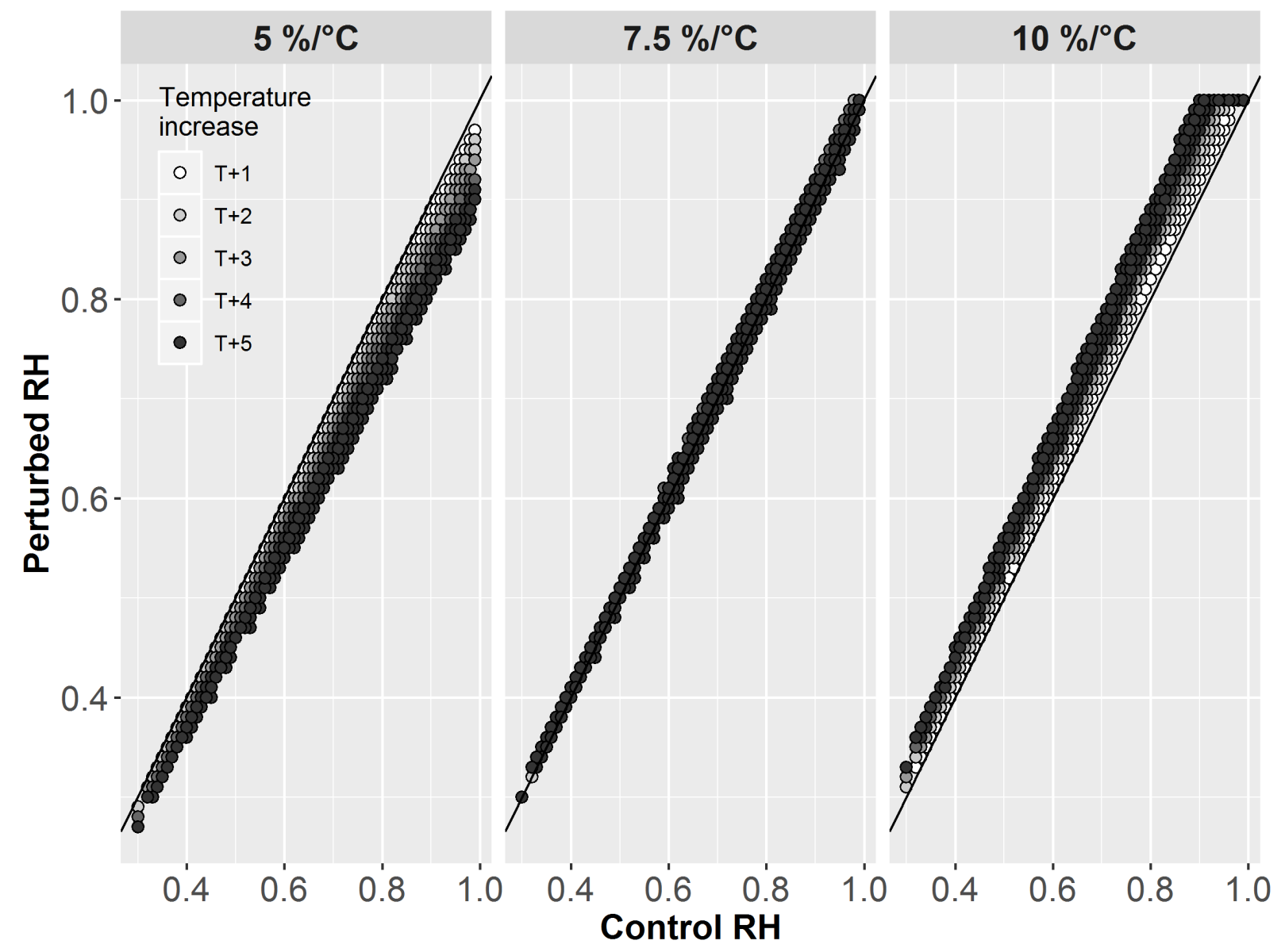

Figure 3.7: Scatter plots of control RH (x-axis) and perturbed $\mathrm{RH}$ (y-axis), for three classes of $\epsilon_{q, T}: 5 \%{ }^{\circ} \mathrm{C}^{-1}$ (left), $7.5 \%{ }^{\circ} \mathrm{C}^{-1}$ (middle) and $10 \%{ }^{\circ} \mathrm{C}^{-1}$ (right). The point colors represent the mean air temperature increases from 1 to $5^{\circ} \mathrm{C}$, so that the darker the color, the higher the increase. The 1:1 reference line is displayed in each panel.

de Abreu et al. (in prep). Furthermore, we assumed ground wind speed as being of minor impact, and was also not altered, helping to keep the design simpler.

In summary, we defined a set of 120 simulations plus a control case, with conditions shown in Table 3.1, that were run with the calibrated SWAT model each one spanning a 28 years-long range of time, that combined specific cases of air temperature (5 cases), precipitation (4 cases), air relative humidity (3 cases) and air $\mathrm{CO}_{2}$ concentration (2 cases). The impacts are discussed with outputs for key hydrological variables as the difference between the experiment minus the control simulation, based on averages of each simulation during the 28 yr range that were assessed partly during the last 23 yr (once first 5 yr were taken as warm up for soil moisture). 


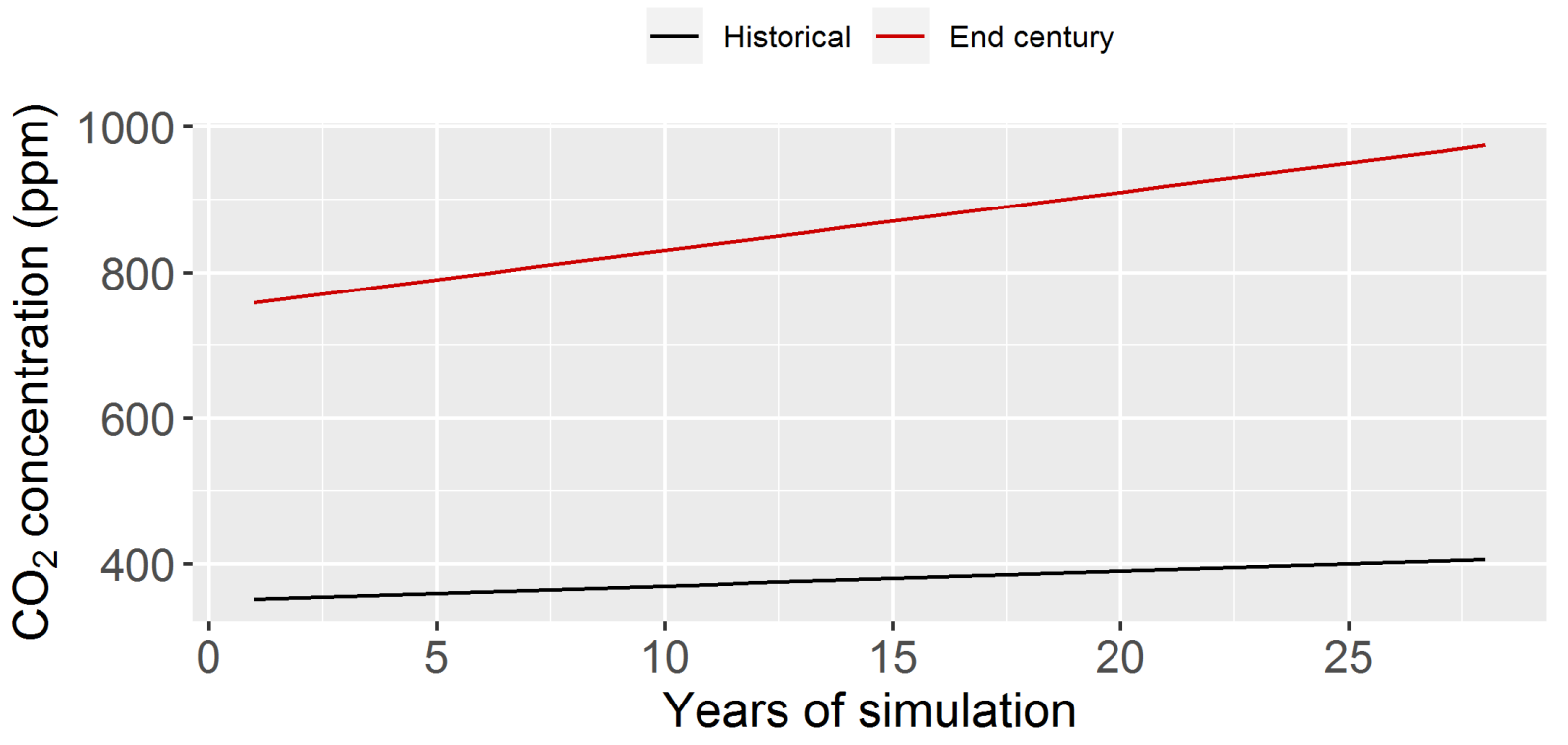

Figure 3.8: $\mathrm{CO}_{2}$ concentration along the years of simulation, in ppm, for historical (black line, $y=350+2 \cdot x$ ) and end century (red line, $y=750+8 \cdot x$ ) conditions.

Table 3.1 - Summary of cases with perturbations in key atmospheric variables.

\begin{tabular}{ll}
\hline Perturbated variable & \multicolumn{1}{c}{ Cases } \\
\hline Temperature $\left({ }^{\circ} \mathrm{C}\right)$ & $+1,+2,+3,+4,+5$ \\
\hline Rainfall $\left(\%{ }^{\circ} \mathrm{C}^{-1}\right)$ & $-5,0,5,10$ \\
\hline Relative humidity & Lower, Alike, Higher \\
\hline $\mathrm{CO}_{2}$ concentration & Historical, End century \\
\hline
\end{tabular}


Chapter 4

\section{Model calibration and validation}

In this Chapter, the SWAT adjustments and the calibration performance are described. We evaluated the added value of calibration to the discharge simulation analysing the flow duration curve before and after calibration, and also put emphasis on the water budget terms of soil moisture and evapotranspiration.

\subsection{Adjustments in evapotranspiration and discharge}

We adjusted specific conditions that control the partition of ET into transpiration and soil evaporation, and the baseflow compared to the total discharge (Q), previously to the fine tuning calibration.

Regarding ET, it was assessed that soil evaporation was recurrently larger than transpiration on both forest and pasture covers using SWAT default and Mota da Silva (2013) parameters. Domingues (2014) estimated that transpiration accounts for 2.1 (1.6) $\mathrm{mm} \mathrm{d}^{-1}$ in Atlantic subtropical forest (pasture), in ET annual average, which represents 68\% (53\%) of ET, while soil evaporation represents $8 \%$ (23\%). Small magnitude of soil evaporation in closed forested areas may be expected due to the reduced incoming radiation reaching the soil (shadowing) (Marthews et al., 2008), and to the litter above the ground (Magliano et al., 2017). We worked on the adjustments with the following actions:

- Maximize ESCO parameter (see Section 3.2.2.2) to restrict evaporation to the top layer;

- Reduce the available water capacity (AWC), which is the difference between the water content at field capacity and the water content at permanent wilting point, in the 
Table 4.1 - Parameters used in evapotranspiration adjustment process.

\begin{tabular}{|l|c|c|c|}
\cline { 2 - 4 } \multicolumn{1}{l|}{} & Unit & Forest & Pasture \\
\hline $\begin{array}{l}\text { BLAI } \\
\text { Maximum potential leaf area index }\end{array}$ & $\mathrm{m}^{2} \mathrm{~m}^{-2}$ & 5.2 & 2.5 \\
\hline $\begin{array}{l}\text { ALAI_MIN } \\
\text { Minimum leaf area index for plant during dormant period }\end{array}$ & $\mathrm{m}^{2} \mathrm{~m}^{-2}$ & 4.5 & 1.0 \\
\hline $\begin{array}{l}\text { GSI } \\
\text { Maximum stomatal conductance }\end{array}$ & $\mathrm{mm} \mathrm{s}^{-1}$ & 8.5 & 1.0 \\
\hline $\begin{array}{l}\text { ESCO } \\
\text { Soil evaporation compensation factor }\end{array}$ & - & 1.0 & 1.0 \\
\hline $\begin{array}{l}\text { RDMX } \\
\text { Maximum root depth }\end{array}$ & $\mathrm{m}$ & 2.0 & 2.0 \\
\hline $\begin{array}{l}\text { VPDFR } \\
\text { Vpd corresponding to the second point on the gl curve }\end{array}$ & $\mathrm{kPa}$ & 2.0 & 2.0 \\
\hline
\end{tabular}

top layer. It lowers the soil water storage in this layer, and increases the percolation to the deeper layers;

- Increase $g_{l, m x}$ and maximum rooting depth to boost transpiration. As $E t_{\max }$ and $E s_{\max }$ are calculated separately, increasing $E t_{\max }$ may reduce $E s_{\max }$ in cases when their sum exceeds PET (see Section 3.2.2.2);

- Adjust $L A I_{m x}$ (BLAI) and $L A I_{m n}$ (ALAI_MIN) from Equation 3.20.

The results are summarized in Table 4.1.

In the simulated discharge, the drought flows were repeatedly underestimated. It happened because the percolation from the bottom soil layer to the shallow aquifer was limited, producing almost no base flow. Seepage to next layer and lateral flow are calculated individually in the model, and both depends on the drainable water (amount exceeding field capacity) leaving each soil layer. As slope is significant in this basin, the lateral flow tends to be larger than the seepage. In order to maintain the mass balance, the sum of lateral flow and seepage cannot surpass the drainable water. If it happens, a ratio $r=\frac{\text { seepage }}{\text { seepage+lateral flow }}$ is calculated, then seepage is multiplied by $r$ and lateral flow by (1-r). In other words, it is needed to maximize the seepage, without boosting the lateral flow to address the issues with drought flows. For this reason, it was tested a combination of values for some soil parameters that influence seepage and lateral flow: bulk density 
$\left(\rho_{b}\right)$, saturated hydraulic conductivity $\left(K_{\text {sat }}\right)$ and the available water content $(A W C)$. For simplicity, these parameters were set identically for each layer of soils LVA and PVA as $\rho_{b}=0.9 \mathrm{Mg} \mathrm{m}^{-3}, K_{\text {sat }}=65 \mathrm{~mm} \mathrm{~h}^{-1}$ and $A W C=0.13^{1}$.

\subsection{Calibration and validation performance}

The set of parameters, their range of variation, units and default/best values are listed in Table 4.2. Along with the table it is presented the dotty plots between NSE index and the parameters range (Fig. 4.1). In order to improve the visualization, only NSE $>-1$ is shown in y-axes, which represents $96.2 \%$ of the total data. The best values from Table 4.2 are shown in the vertical red lines of Fig. 4.1. It was performed a two sample t-test for each combination of NSE index and parameter range, testing the null hypothesis that the values of a given parameter do not modify the NSE index. Considering a confidence level of 95\%, we can reject the null hypothesis for all parameters except GW_DELAY, HRU_SLP, SLSUBBSN, CN2 and GWQMN. In other words, we assume that the remaining parameters were sensitive in the calibration process. Although such variables were not considered sensitive, not including them in the calibration modifies the performance.

The added value of calibration to the simulation can be seen in the comparison between flow duration curves before and after the procedure (Fig. 4.2). The SWAT-default simulated discharge generates high peaks, overestimating exceedance probabilities below $\approx 15 \%$, and underestimating the remaining probabilities, reaching zero in many periods of the time series (not shown in Fig. 4.2 because y-axis is in log scale). It resembles a flow duration curve in a highly impermeable soil. On the other hand, the calibrated simulation is closer to the reference flow duration curve in practically all exceedance probabilities. It can be seen that for discharges below $\approx 20 \mathrm{~m}^{3} \mathrm{~s}^{-1}$, the calibrated flow is recurrently underestimating the reference, except in the extreme low values, where it is overestimated.

The best values from calibration (Table 4.2) were used in the 1995-2002 period for validation. The performances of both calibration and validation are shown in Table 4.3. Considering the indexes and Moriasi et al. (2015) classification for daily discharge, it is possible to affirm that performance was good for both periods. Analysing the simulated time series (Fig. 4.3), we noted that the underestimation of discharges below $\approx 20 \mathrm{~m}^{3} \mathrm{~s}^{-1}$

\footnotetext{
${ }^{1}$ Except in the top layer, where $\mathrm{AWC}=0.10$ to restrict soil evaporation.
} 
Table 4.2 - Set of parameters used in the calibration process, along with their range of variation, original value (default) and best value found. Along with the prefix $v$, the parameter default value is replaced by another one, with $r$ the parameter is relatively (\%) modified according to the default value, and with $a$, a value is added to the parameter default. Apostrophe is displayed where several values are found for the respective parameter.

\begin{tabular}{|c|c|c|c|c|}
\hline Parameter & Definition & Range & Defaut & Best \\
\hline \multicolumn{5}{|c|}{ Surface runoff } \\
\hline $\begin{array}{c}\mathrm{r} \\
\mathrm{CN} 2\end{array}$ & Curve number at condition II & $\begin{array}{c}-40 \% \\
40 \%\end{array}$ & $0 \%$ & $-39.7 \%$ \\
\hline \multicolumn{5}{|c|}{ Lateral flow } \\
\hline $\begin{array}{c}\mathrm{v} \\
\mathrm{LAT}_{-} \mathrm{TTIME}\end{array}$ & Lateral flow travel time (days) & $\begin{array}{l}1.0 \\
6.0\end{array}$ & 0.0 & 4.0 \\
\hline \multicolumn{5}{|c|}{ Peak rate } \\
\hline $\mathrm{OV} \_\mathrm{N}$ & Manning's "n"value for overland flow & $\begin{array}{c}0.17 \\
0.4\end{array}$ & 0.1 & 0.36 \\
\hline $\begin{array}{c}\mathrm{r} \\
\text { HRU_SLP }\end{array}$ & Average slope of the subbasin $\left(\mathrm{m} \mathrm{m}^{-1}\right)$ & $\begin{array}{l}-25 \% \\
25 \%\end{array}$ & $0 \%$ & $-15 \%$ \\
\hline V & Average slope of tributary channels $\left(\mathrm{m} \mathrm{m}^{-1}\right)$ & $\begin{array}{l}0.001 \\
0.055\end{array}$ & * & 0.010 \\
\hline $\begin{array}{c}\mathrm{r} \\
\text { SLSUBBSN }\end{array}$ & Average slope length $(\mathrm{m})$ & $\begin{array}{l}-25 \% \\
25 \%\end{array}$ & $0 \%$ & $-2.6 \%$ \\
\hline \multicolumn{5}{|c|}{ Channel flow } \\
\hline $\begin{array}{c}\mathrm{v} \\
\mathrm{CH} \_\mathrm{S} 2\end{array}$ & $\begin{array}{l}\text { Average slope of main channel along } \\
\text { the channel length }\left(\mathrm{m} \mathrm{m}^{-1}\right)\end{array}$ & $\begin{array}{c}0.001 \\
0.02\end{array}$ & * & 0.013 \\
\hline $\begin{array}{c}\mathrm{v} \\
\mathrm{CH} \_\mathrm{N} 2\end{array}$ & Manning's "n"value for the main channel & $\begin{array}{c}0.025 \\
0.3\end{array}$ & 0.014 & 0.14 \\
\hline $\begin{array}{c}\mathrm{v} \\
\mathrm{CH} \_\mathrm{K} 2\end{array}$ & $\begin{array}{l}\text { Effective hydraulic conductivity in the main } \\
\text { channel alluvium }\left(\mathrm{mm} \mathrm{h}^{-1}\right)\end{array}$ & $\begin{array}{c}5 \\
120 \\
\end{array}$ & 0 & 36 \\
\hline \multicolumn{5}{|c|}{ Shallow aquifer } \\
\hline $\begin{array}{c}\mathrm{v} \\
\mathrm{RCHRG} \mathrm{DP}\end{array}$ & Deep aquifer percolation factor & $\begin{array}{l}0.0 \\
0.2\end{array}$ & 0.05 & 0.19 \\
\hline $\begin{array}{c}\mathrm{v} \\
\text { ALPHA_BF }\end{array}$ & Baseflow recession constant (days) & $\begin{array}{l}0.0 \\
0.1\end{array}$ & 0.048 & 0.027 \\
\hline $\begin{array}{c}\mathrm{a} \\
\text { REVAPMN }\end{array}$ & $\begin{array}{l}\text { Threshold depth of water in the shallow aquifer } \\
\text { to revap or percolation do deep aquifer occur }(\mathrm{mm})\end{array}$ & $\begin{array}{c}-500 \\
0\end{array}$ & 750 & -177 \\
\hline $\begin{array}{c}\mathrm{r} \\
\text { GW_DELAY }\end{array}$ & Groundwater delay (days) & $\begin{array}{l}-20 \% \\
20 \%\end{array}$ & 31 & $1.8 \%$ \\
\hline $\begin{array}{c}\mathrm{v} \\
\mathrm{GW} \text { REVAP }\end{array}$ & Groundwater "revap" coefficient & $\begin{array}{l}0.1 \\
0.5\end{array}$ & 0.02 & 0.2 \\
\hline $\begin{array}{c}\mathrm{a} \\
\text { GWQMN }\end{array}$ & $\begin{array}{l}\text { Threshold depth of water in the shallow aquifer } \\
\text { required for base flow to occur }(\mathrm{mm})\end{array}$ & $\begin{array}{c}-100 \\
100\end{array}$ & 400 & 98 \\
\hline
\end{tabular}




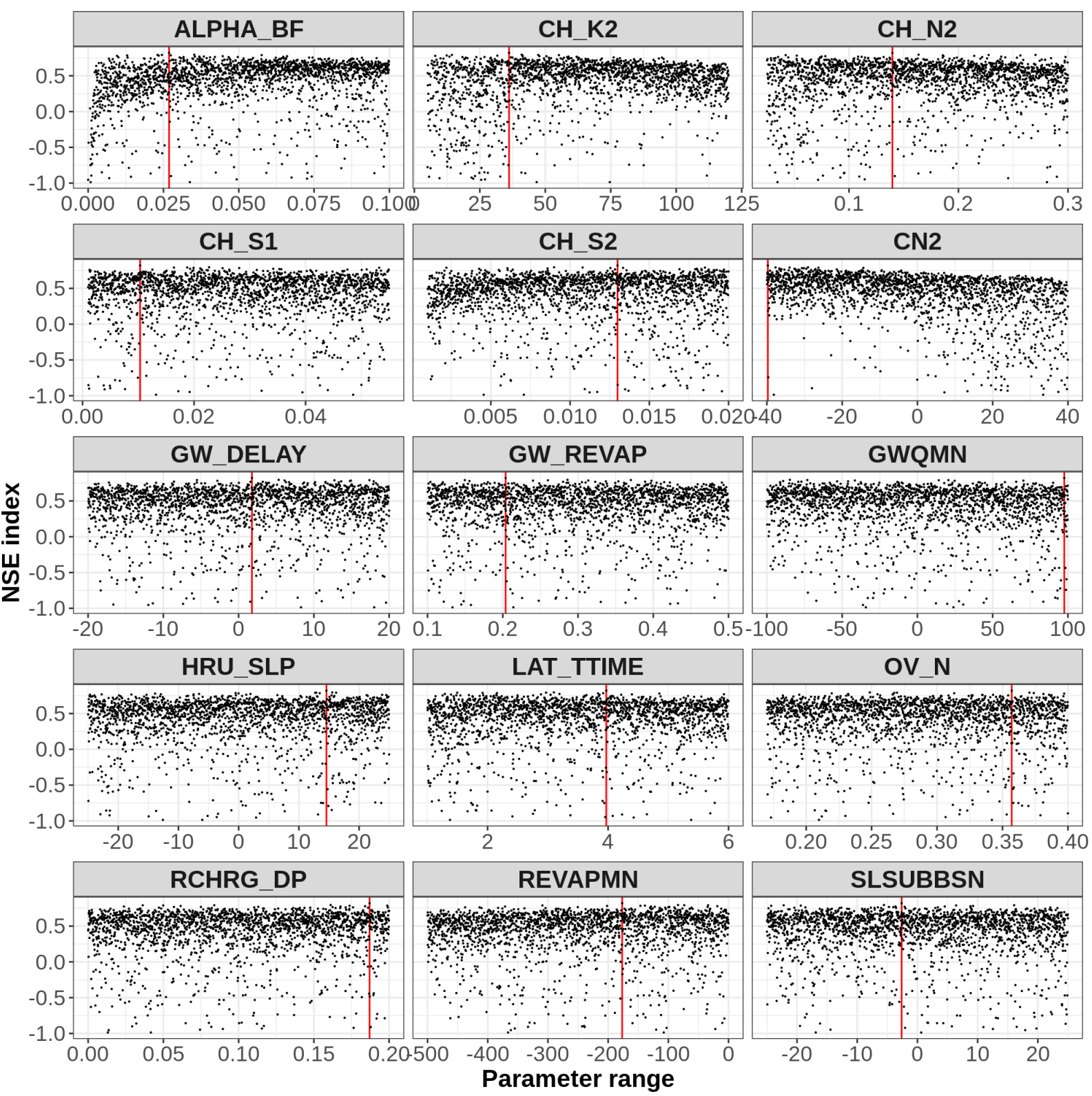

Figure 4.1: Dotty plots between NSE index (y-axis) and the range of values assessed for each parameter (x-axis). In the top of each panel is shown the parameter name, whereas vertical red lines show the best values found in calibration process. Only NSE indexes $>-1$ are shown.

shown in Fig. 4.2 comprises the recession limbs and the minima of the hydrograph. On contrary, the years of 2014, 2015 and 2017 presented the lowest discharge minima of the time series, and were overestimated by the model, which is also shown in the flow duration curve for probabilities close to $100 \%$. According to Krause et al. (2005), the main disadvantage of NSE is that it often overestimates (underestimates) the performance in peak (low) flow conditions, due to the difference between observed and simulated flows 


\section{Flow duration curve}

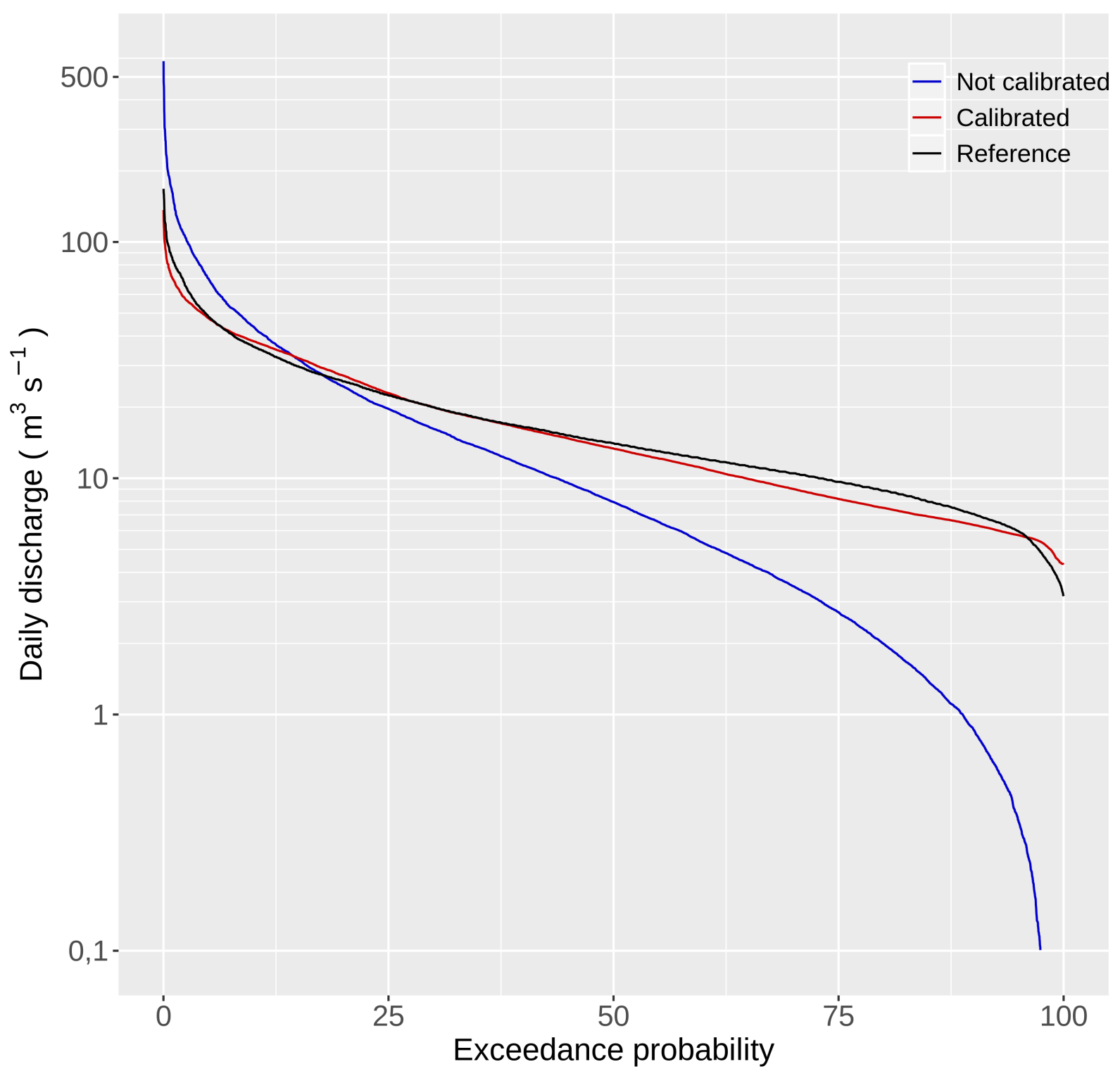

Figure 4.2: Flow duration curves of daily discharge, in $\mathrm{m}^{3} \mathrm{~s}^{-1}$, of not calibrated (blue line), calibrated (red line) and reference (black line) simulations.

being computed as square values. Another important issue is that the later period comprises an extreme drought event that hampers the model performance on calibration, and overestimates the validation (Zheng et al., 2018) (note that in Table 4.2 the validation performance is superior, except by pbias index). In addition, the rain gauges density has changed throughout the period (Fig. 3.5), especially after 2014 with CEMADEN gauges, which may impact the mean rainfall representation in the basin. Overall, we believe that the calibration was successful to proceed with the analysis present in Section 5. 
Table 4.3 - Performance indexes Nash-Sutcliffe efficiency (NSE), percent bias (Pbias, \%) and the coefficient of determination $\left(\mathrm{R}^{2}\right)$ for calibration and validation periods. Below each value is shown the classification according to Moriasi et al. (2015).

\begin{tabular}{|c|c|c|c|}
\cline { 2 - 4 } \multicolumn{1}{c|}{} & NSE & Pbias (\%) & $\mathrm{R}^{2}$ \\
\hline Calibration & $\begin{array}{c}0.82 \\
\text { (very good) }\end{array}$ & $\begin{array}{c}-2.9 \\
\text { (very good) }\end{array}$ & $\begin{array}{c}0.82 \\
\text { (good) }\end{array}$ \\
\hline Validation & $\begin{array}{c}0.85 \\
\text { (very good) }\end{array}$ & $\begin{array}{c}-6.2 \\
\text { (good) }\end{array}$ & $\begin{array}{c}0.85 \\
\text { (good) }\end{array}$ \\
\hline
\end{tabular}
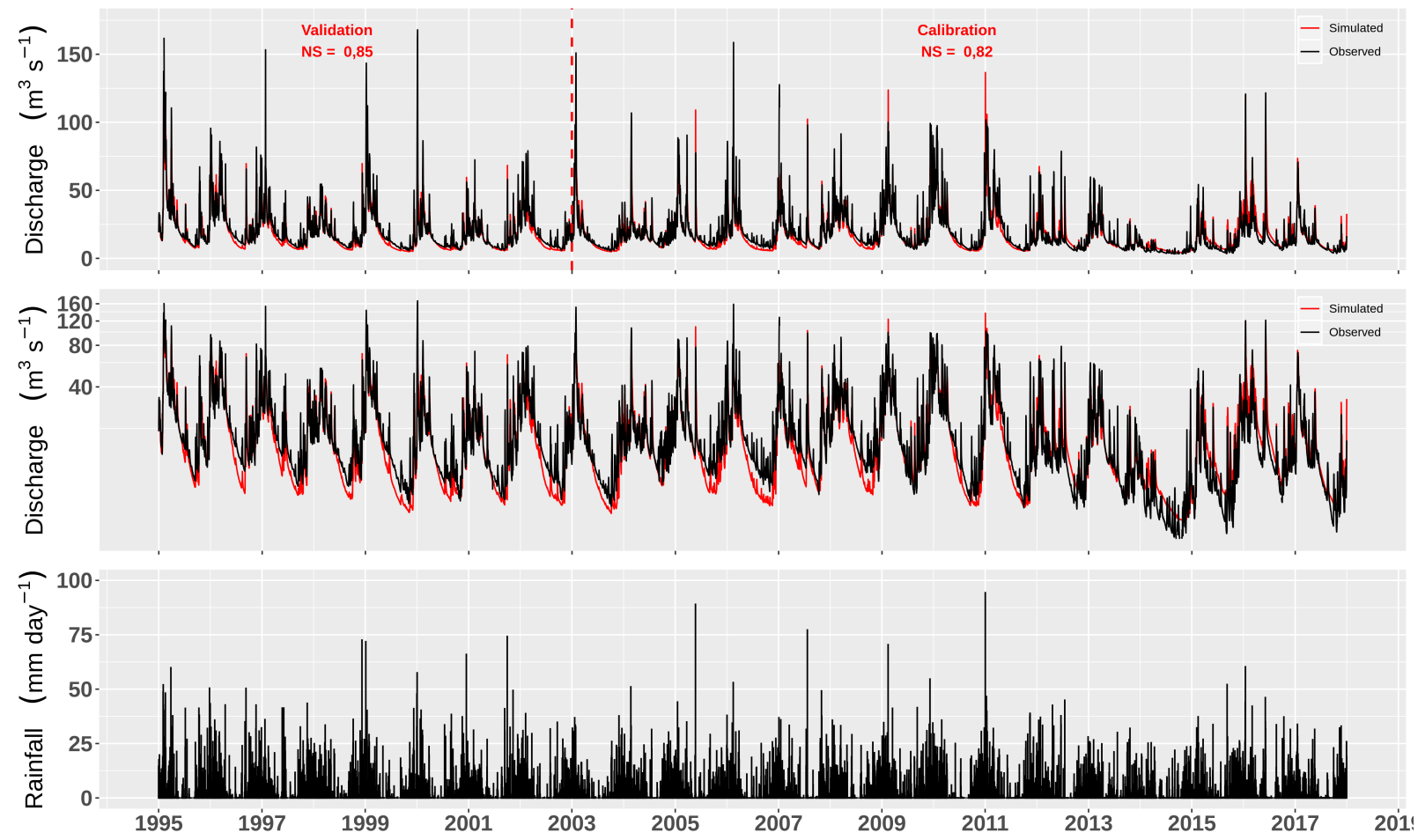

Figure 4.3: Upper panel: Simulated (red line) and observed (black line) discharges, in $\mathrm{m}^{3} \mathrm{~s}^{-1}$. Vertical dashed line separates calibration from validation. Middle panel: Idem to upper, with $\mathrm{y}$-axis in log scale. Lower panel: Basin-averaged daily precipitation, in $\mathrm{mm} \mathrm{d}^{-1}$.

\subsection{Water balance}

In this section, it is assessed the water balance in Jaguari basin. Rainfall (P), evapotranspiration (ET) and specific discharge (Q) time series are exported for each HRU, and a weighted average considering the HRU area is carried out to represent the basin average (Fig. 4.4). The mean rainfall in the basin is $1541 \pm 206 \mathrm{~mm} \mathrm{yr}^{-1}$. In long term, this amount is essentially partitioned in ET $\left(935 \pm 56 \mathrm{~mm} \mathrm{yr}^{-1}\right)$ and Q $\left(603 \pm 144 \mathrm{~mm} \mathrm{yr}^{-1}\right)$. The evaporative index (ratio ET/P) and runoff coefficient (ratio $\mathrm{Q} / \mathrm{P}$ ) were estimated as $61 \%$ and $39 \%$, respectively. We noted that $\mathrm{Q}$ variance was directly linked to the $\mathrm{P}$ one, 
whereas ET presented less variance than P and Q. Besides, ET was recurrently superior in magnitude to $\mathrm{Q}$ throughout the years. Although this pattern is also soil moisture dependant, in rainier years (1995, 1996 and 2009) Q magnitude is quite close to ET, while in drier years ET is far dominant. In 2014, for instance, ET was $80 \%$ of the rainfall.

ANA and DAEE, 2015 estimated mean P and Q for Jaguari and Jacareí contribution areas $\left(1230 \mathrm{~km}^{2}\right)$ to Cantareira System: 1592 and $646 \mathrm{~mm} \mathrm{yr}^{-1}$, respectively, which results in a runoff coefficient of $41 \%$. These values are quite close to the results simulated by SWAT. Henriques (2019) assessed long term values of water balance components for subbasins of PCJ watershed (Jaguari basin is within PCJ). In his work, P annual average is lower than our estimates, $\approx 1315 \mathrm{~mm} \mathrm{yr}^{-1}$, while $\mathrm{Q}$ ranges from 381 to $553 \mathrm{~mm} \mathrm{yr}^{-1}$ and ET from 751 to $947 \mathrm{~mm} \mathrm{yr}^{-1}$, resulting in runoff coefficients ranging from 29 to $42 \%$. It is important to focus that, although the references of ANA and DAEE, 2015 and Henriques (2019) provide valuable information for comparison, the long term period in which the averages were calculated are different from this work. In addition, the sub-basins used by Henriques (2019) are not from Jaguari basin.

\subsubsection{Simulated discharge}

In the Section 3.2.1 we described how SWAT calculates the three components of discharge: overland, lateral and base flows. In this section, the magnitudes of each component after calibration are discussed.

The flow duration curve (Fig. 4.2) showed that the SWAT-default simulation presented high peaks and underestimated values above $15 \%$ exceedance probability. The mechanism that calibration addressed to reduce the peaks was reducing the overland flow and maximizing the infiltration (e.g., see the expressive reduction in CN2 parameter in Table 4.2). As already discussed in this section, it was needed to maximize the percolation from the bottom soil layer to the shallow aquifer to improve the drought flow representation. The increase in infiltration has also helped to accomplish the minima.

Fig. 4.5 shows the SWAT-calculated specific discharge (Q) components after calibration. Lateral flow (Qlat) is the main component, supplying $497 \pm 113 \mathrm{~mm} \mathrm{yr}^{-1}$ in average, which represents $85 \%$ of total flow. Then, base flow $\left(\mathrm{Q}_{\mathrm{gw}}\right)$ and surface flow $\left(\mathrm{Q}_{\mathrm{surf}}\right)$ supply $81 \pm 26 \mathrm{~mm} \mathrm{yr}^{-1}$ (14\% of Q) and $5.6 \pm 3.4 \mathrm{~mm} \mathrm{yr}^{-1}$ (1\% of Q), respectively. One could have already guessed the magnitude of $Q_{\text {lat }}$ with respect to the others because the outlet 


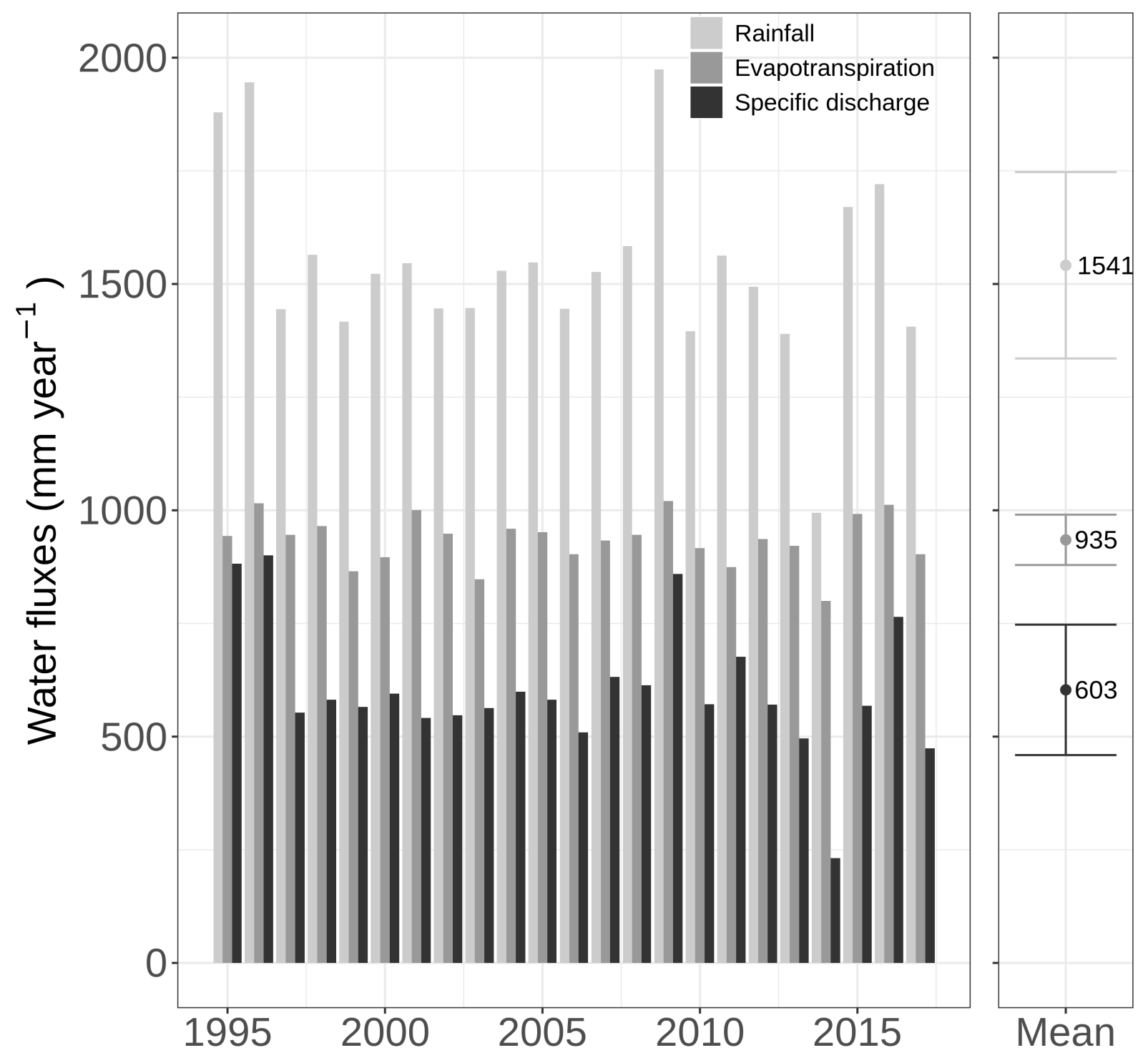

Figure 4.4: Left panel: Yearly average rainfall (light grey bars), evapotranspiration (dark

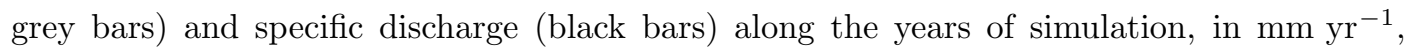
in Jaguari basin. Right panel: Mean annual values (circles) with error bars showing the

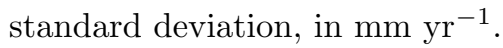

is in the upstream portion of the entire watershed, where high slope is observed. In addition, $K_{\text {sat }}=65 \mathrm{~mm} \mathrm{~h}^{-1}$ is also considerably high, and according to Equation 3.4, both slp and $K_{\text {sat }}$ directly modulates $\mathrm{Q}_{\text {lat }}$. In this context of high $K_{\text {sat }}$, the macroporosity stands out, so that the response time of the flow in this scenario approaches the one from $\mathrm{Q}_{\text {surf }}$. This is possibly the reason why peaks are well simulated even producing almost no $\mathrm{Q}_{\text {surf }}$. Henriques (2019) estimated much higher contribution of $\mathrm{Qgw}_{\mathrm{gw}}$ to Q in PCJ watershed, from $60 \%$ to $66 \%$. However, it is important to stress that a model is a simplification of the real, 
complex system, and it may be difficult the comparison between simulated and observed discharge components.

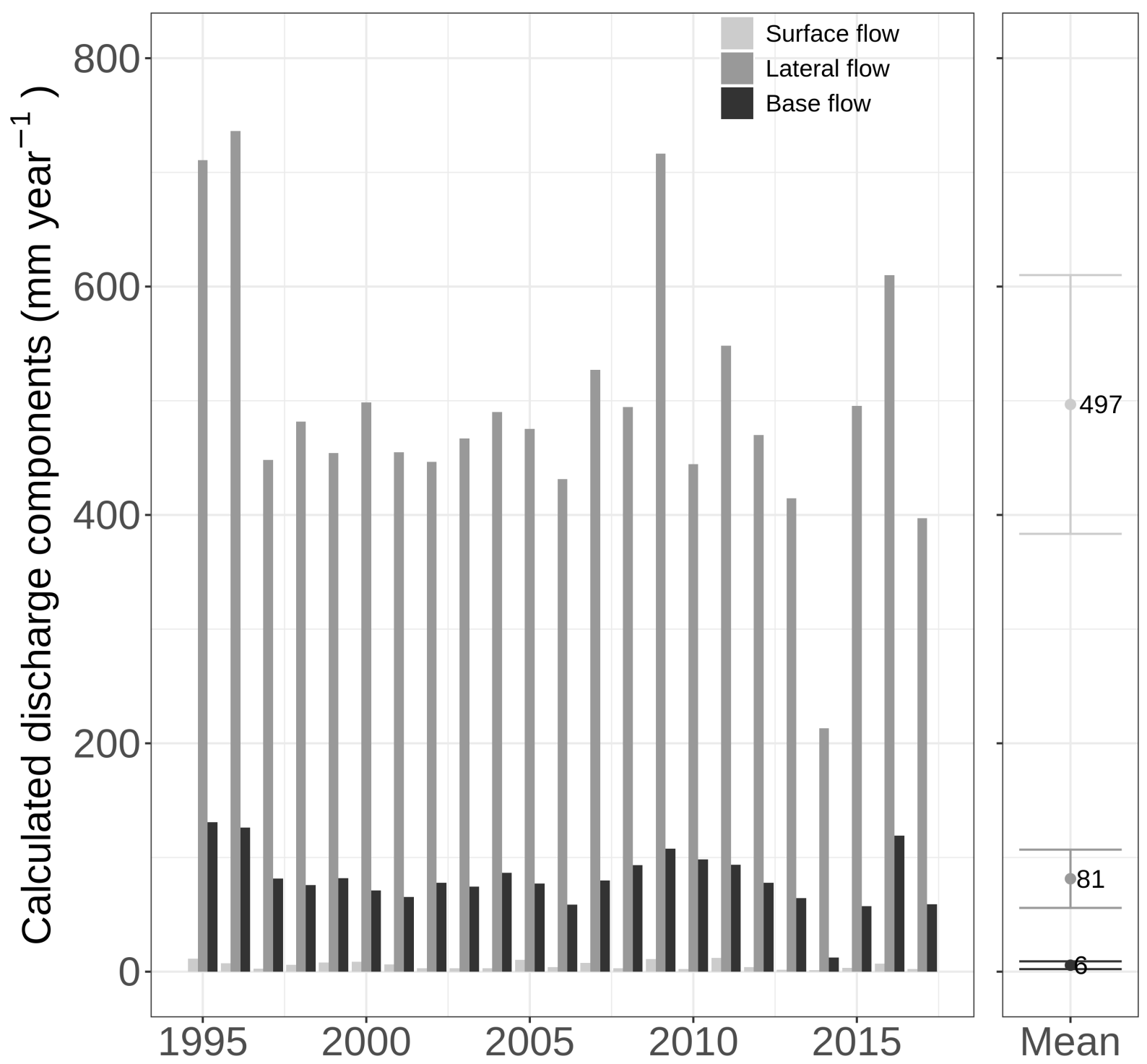

Figure 4.5: Left panel: Yearly average components of discharge calculated by SWAT along the years of simulation: surface flow (light grey bars), lateral flow (dark grey bars) and base flow (black bars), in $\mathrm{mm} \mathrm{yr}^{-1}$. Right panel: Mean annual values (circles) with error bars showing the standard deviation, $\mathrm{mm} \mathrm{yr}^{-1}$.

\subsubsection{Evapotranspiration}

Many estimates of ET on global basis are available, e.g., using satellite and models (Miralles et al., 2011; Mu et al., 2011), reanalysis data (Dee et al., 2011), land surface model (Dirmeyer et al., 2006; Domingues, 2014), also at small watershed scale using field 
measures (da Rocha et al., 2009), and at regional scale with field water budget (Henriques, 2019). The use of these estimates depend on individual temporal and spatial scales, and the accuracy is intrinsically posed by the specific method. Some studies used the field water budget method at watershed scale to validate calculated ET (Zhang et al., 2010; Liu et al., 2016). In this section, we evaluate the ET calculated by SWAT by comparing it to remote sensing derived products, namely the Global Land Evaporation Amsterdam Model (GLEAM, Miralles et al. (2011)) with $\approx 25 \mathrm{~km}$ resolution, and the MODIS Global Evapotranspiration (MOD16A2, Mu et al. (2011)), with $500 \mathrm{~m}$ resolution, and also a terrestrial water balance method.

We interpolated six grid cells of GLEAM data (with IDW method) surrounding the basin to the Jaguari centroid, and MOD16A2 time series was estimated using the grid cells within Jaguari. Lastly, the terrestrial water balance (TWB) was estimated using monthly field P and Q time series, and terrestrial water storage (TWS) from GRACE satellite (CSR RL05 Mascon, Save et al., 2016) as proxy to soil water storage variation $\Delta \mathrm{S}$ (Henriques, 2019).

Fig. 4.6 shows the comparison of the calculated ET (ET-SWAT) to GLEAM, MOD16A2 and TWB. Both GLEAM and MOD16A2 overestimated ET-SWAT and TWB at lower ranges, generally in dry season $\left(\approx<60 \mathrm{~mm} \mathrm{mo}^{-1}\right.$ or $\left.2 \mathrm{~mm} \mathrm{~d}^{-1}\right)$. As emphasized in Fig. 4.6-C, for the wet season, GLEAM showed good agreement with SWAT and TWB between December and March but greatly overestimated them from September to November. Regarding MOD16A2, it underestimated the others in almost all months of the wet season (Sep to Aug).

We chose TWB as the main reference source to compare our calculations. Especially in annual or long term averages, TWB is about to be a more genuine data as it relies mostly on direct observational data. On a monthly basis, TWB seemed vulnerable to show outlier peaks, probably due to coarse spatial resolution of GRACE satellite, a matter which can explain its higher variance (see Figs. 4.6-A and D). It was relevant how ETSWAT compared well with the TWB and better than the other estimates, even on a mean monthly basis, with exceptions in Apr-Jun (Fig. 4.6-C) likely due to atypical oscillations of TWB that we cannot explain rather than from the resolution issue. The comparisons of mean seasonal ET showed that ET-SWAT was quite close to TWB (1.3 against 1.3 $\mathrm{mm} \mathrm{d}^{-1}$ in dry season, and 3.2 against $3.1 \mathrm{~mm} \mathrm{~d}^{-1}$ in wet season, Fig. 4.6-D). We believe 
that the model adjustments made for ET calculations were directly responsible for this successful comparison.

A further question would be: how much did transpiration (Et) and soil evaporation (Es) compose the ET-SWAT calculations? With the mean monthly terms aggregated separately for both forest and pasture land covers over the basin, the components showed similar seasonal patterns (Fig. 4.7-A, B and C), with Et responding for most of ET (Fig. 4.7-D) and ranging from $\approx 0.75$ to $3.25 \mathrm{~mm} \mathrm{~d}^{-1}$ (Fig. 4.7-A), while Es varied from $\approx 0.3$ to $1.3 \mathrm{~mm} \mathrm{~d}^{-1}$ (Fig. 4.7-B). Comparing forest and pasture, Et was higher in the forest and Es in the pasture, with differences more evident in the rainy season. Such alternation of magnitude between Et and Es over forest and pasture turned ET over forest only slightly higher than over pasture (Fig. 4.7-C and D). Other estimates with the SiB2 model over approximately the same domain (Domingues, 2014) showed good agreement to currently calculated ET and also closer comparability to forest and pasture Et, but authors showed generally higher mean ET of $3.1 \mathrm{~mm} \mathrm{~d}^{-1}$ over forest and $2.9 \mathrm{~mm} \mathrm{~d}^{-1}$ over pasture.

\subsubsection{Soil moisture}

The soil water storage is an important variable modulating ET and Q fluxes. The basin-averaged rainfall (Fig. 4.8-B) is the only source of water updating the soil water profile. Infiltration process can be addressed in Fig. 4.8-C: water starts penetrating the top layer, and when it reaches the field capacity content, the surplus continues infiltrating to the adjacent layer, and so on. Note that Fig. 4.8-C does not compute the unavailable water (content at wilting point), and for this reason the layers can reach zero in certain periods. With an enough amount of water, the percolation may reach the bottom layer, and a potential excess will recharge the shallow aquifer (Fig. 4.8-D). However, as part of the excess is used in the lateral flow, the percolation can be limited to moisten the bottom layers of the soil profile. For this reason, the maximum values of stored water is smaller in the bottom layers in comparison to depths from 25 to $100 \mathrm{~cm}$. In general, as infiltration happens from the top to the bottom layer, the profile seems tilted to the left. The same pattern is observed when the soil is getting drier, more evident in the dry season. Note that the first layer is, in average, drier than the remaining layers. It is due to the soil evaporation which is restricted to the top layer, and to the lower AWC prescribed to this layer, besides transpiration. In the remaining profile, water removal is exclusively due 
A

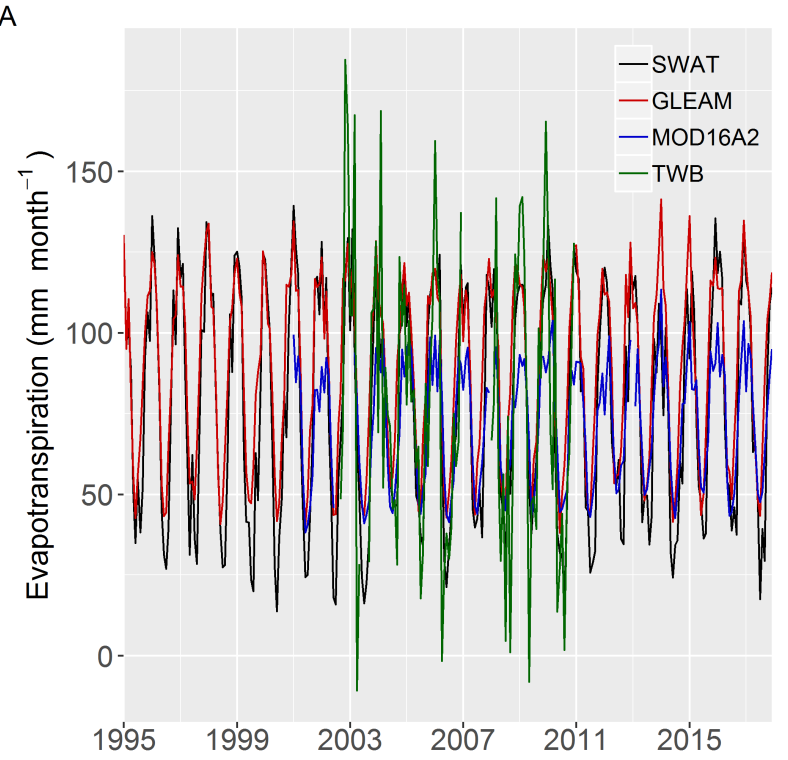

B

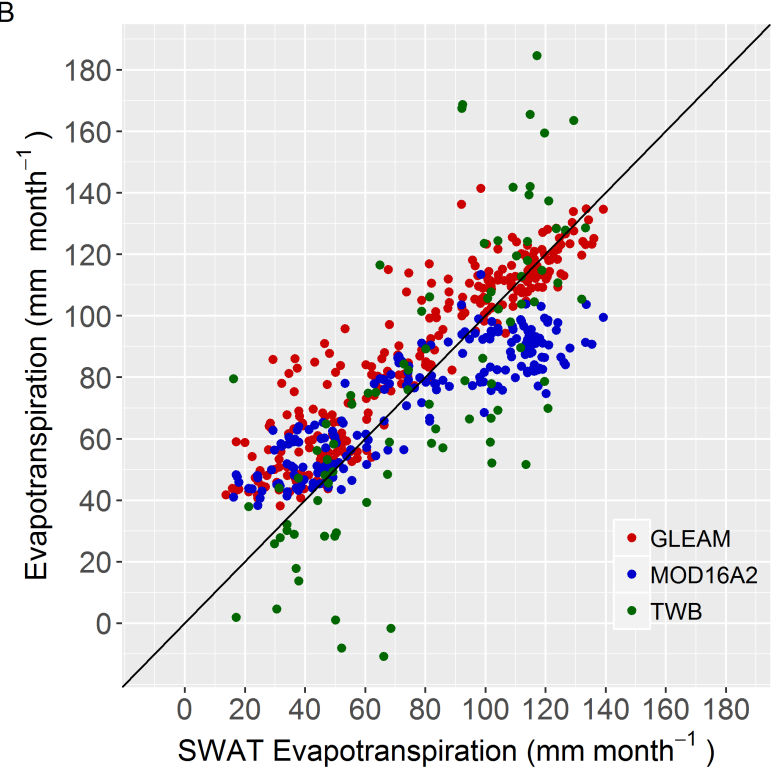

D

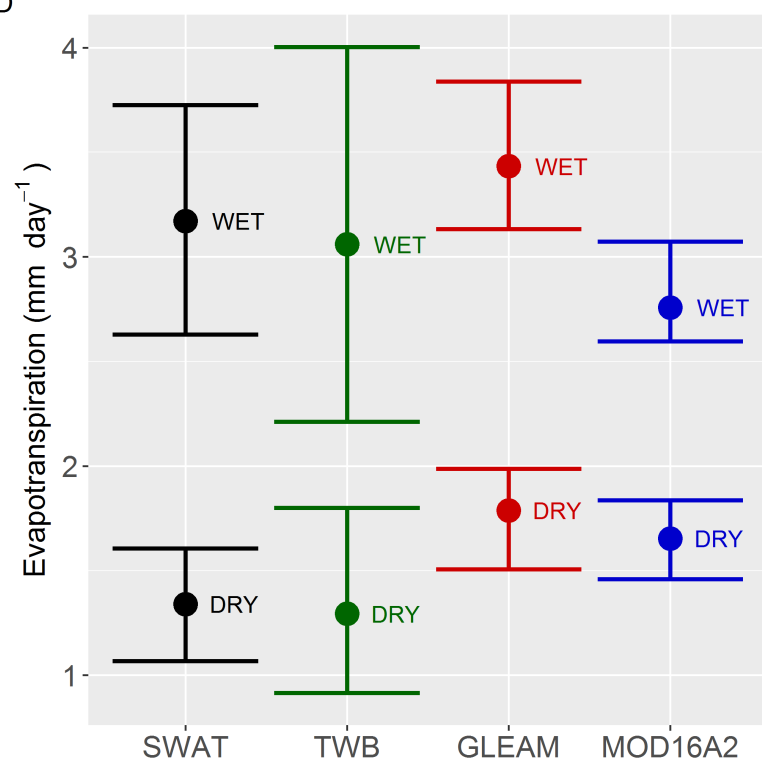

C

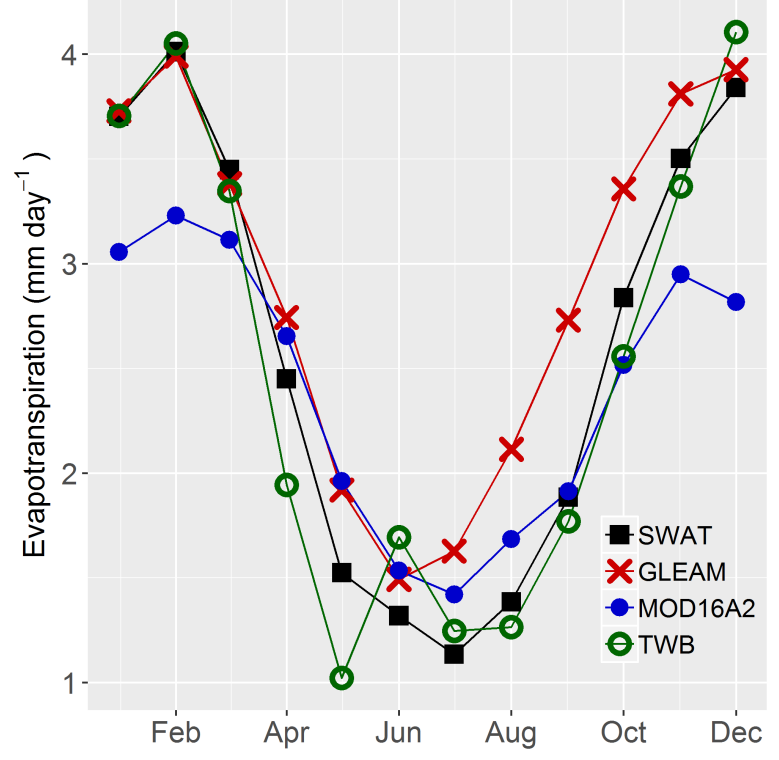

Figure 4.6: A) Monthly ET time series, in $\mathrm{mm} \mathrm{mo}^{-1}$ of SWAT (black line), GLEAM (red line), MOD16A2 (blue line) and TWB (green line) methods. B) Scatterplot between SWAT monthly ET in axis-x, and GLEAM (red dots), MOD16A2 (blue dots) and TWB (green dots) monthly ET in axis-y, in $\mathrm{mm} \mathrm{mo}^{-1}$. The 1:1 reference line is displayed. C) Mean monthly $\mathrm{ET}$, in $\mathrm{mm} \mathrm{d}^{-1}$, estimated by SWAT (black squares), GLEAM (red X), MOD16A2 (blue dots), and TWB (green open circles). D) ET average (circles) and 75th and 25th percentiles (bars), in $\mathrm{mm} \mathrm{d}^{-1}$, for each estimate in dry (May to Aug) and wet (Sep to Apr) seasons. Panels C and D used the common period of SWAT, GLEAM, MOD16A2 and TWB.

to transpiration. An important realistic feature is that variance in storage reduces from the top to the bottom (excluding the top layer). There is a clear distinction in the annual pattern during the 2014 drought, showing a depletion in the storage from the whole profile, 
A

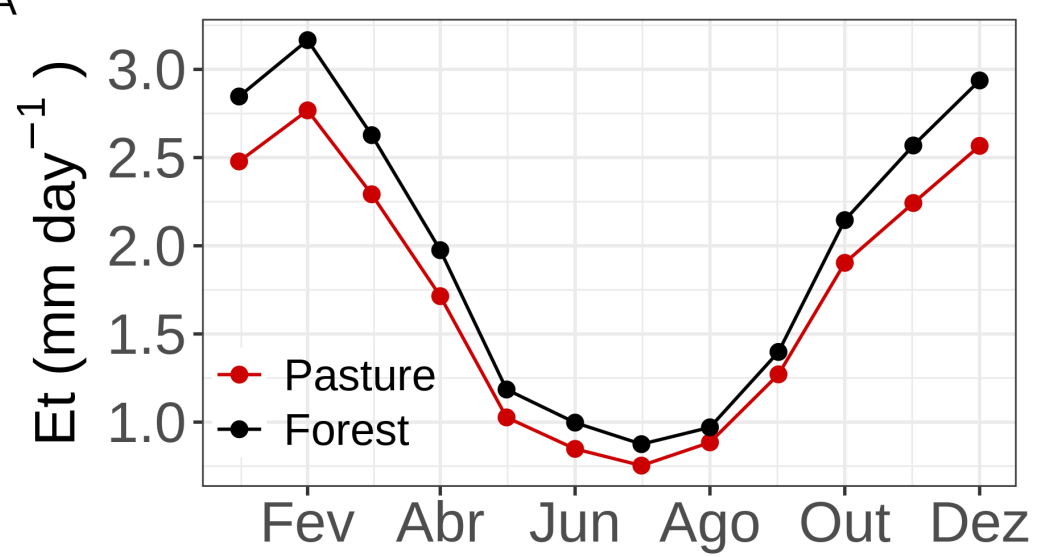

B

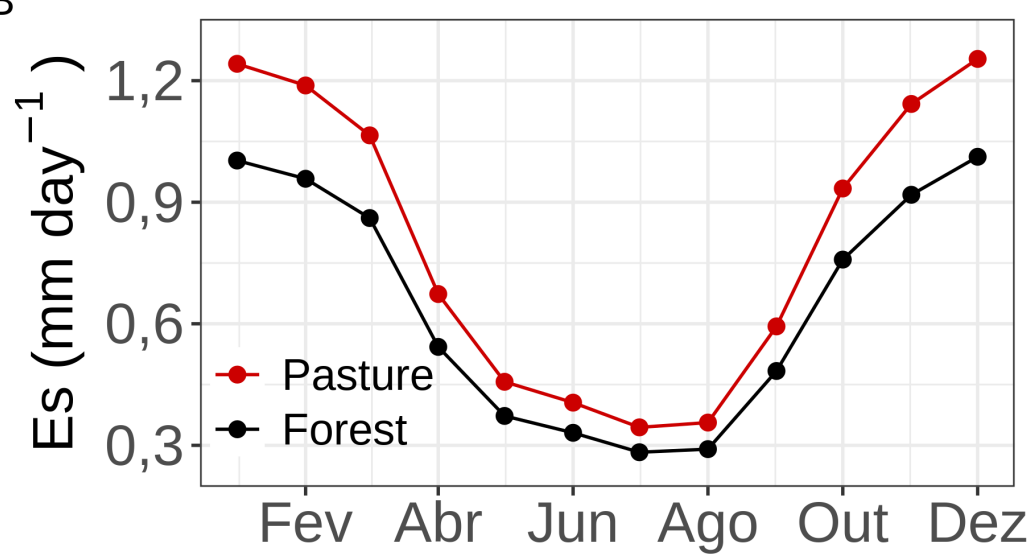

C

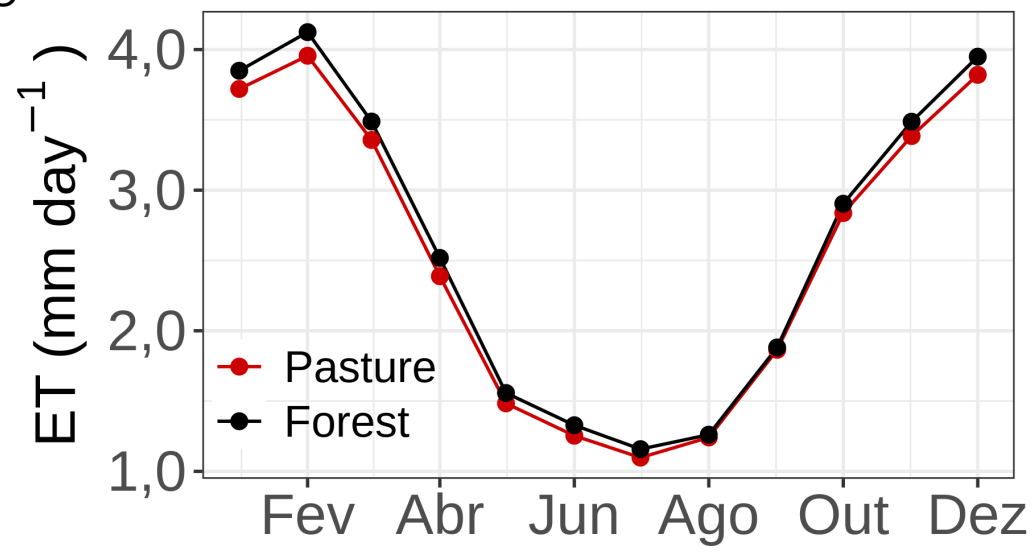

D

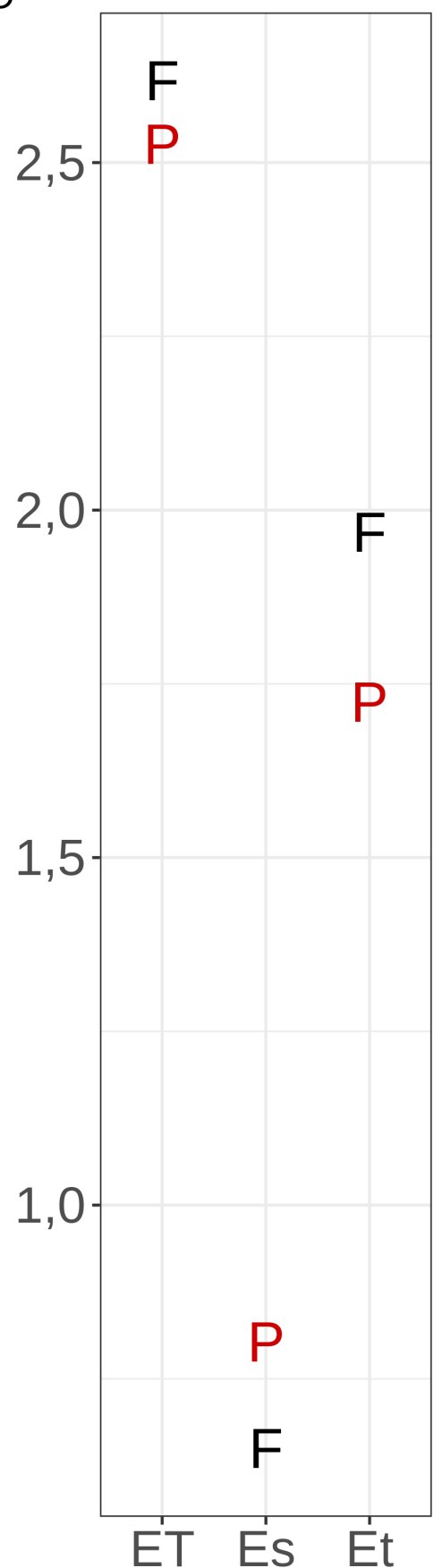

Figure 4.7: Mean monthly a) transpiration (Et), b) soil evaporation (Es) and c) evapotranspiration (ET), in $\mathrm{mm} \mathrm{d}^{-1}$, for pasture (red lines and circles) and forest (black lines and circles). d) All period average of ET, Es and Et, in $\mathrm{mm} \mathrm{d}^{-1}$, for forest (black F) and pasture $($ red $\mathrm{P})$.

and in the shallow aquifer as well (Fig. 4.8-A, D). This structure suggests that ET in 2014 was the lowest in the entire time series because it was water-limited. Finally, it is worthy noting that until the end of the time series, the deeper layers have not reached the same 
magnitude in the rainy season than before 2014 .
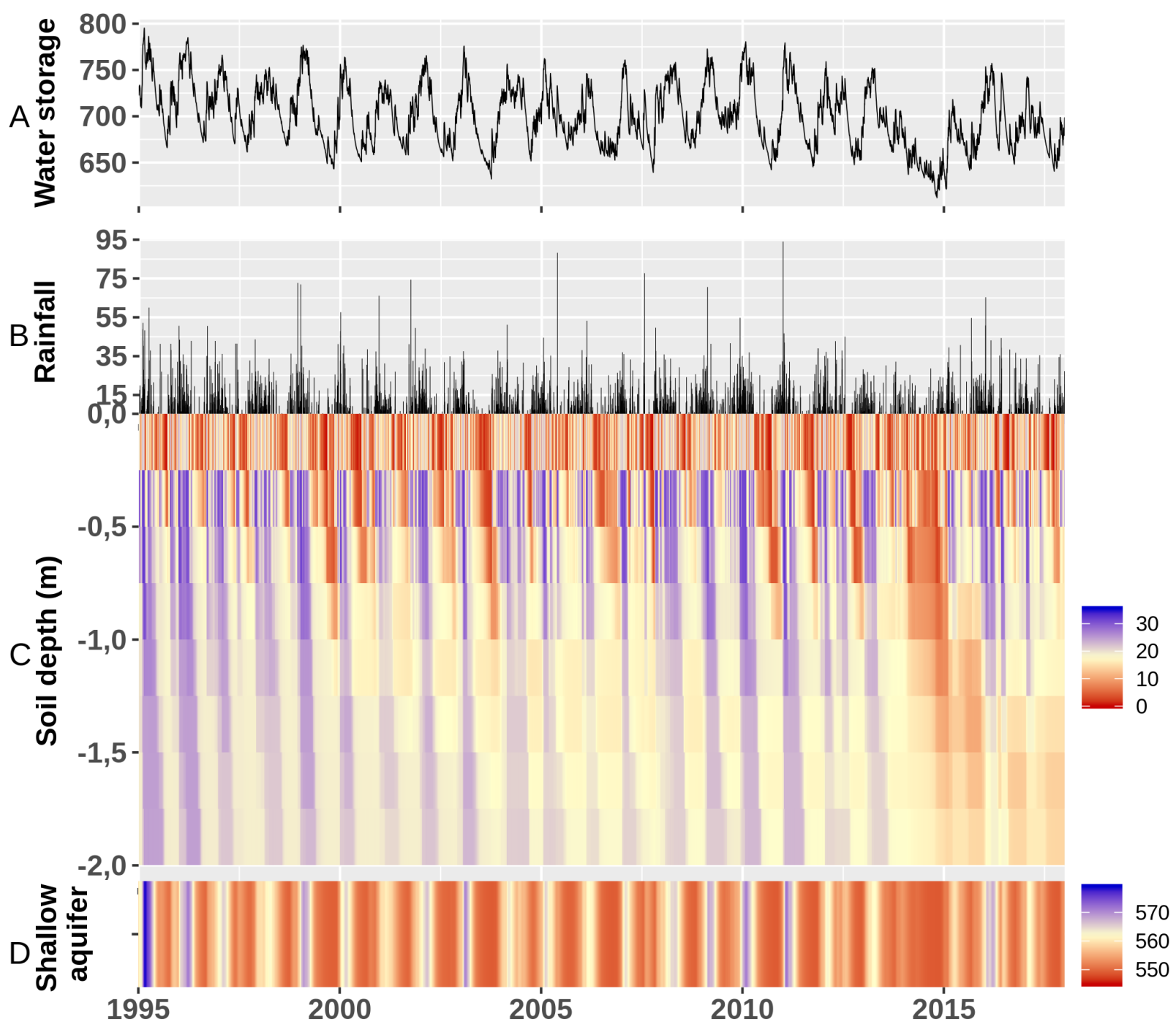

Figure 4.8: Daily time series, from 1995 to 2017, of a) integrated available soil water (vadose zone and shallow aquifer), in $\mathrm{mm}$; b) basin-averaged rainfall, in $\mathrm{mm} \mathrm{d}^{-1}$; c) available soil water profile (soil water storage minus content at wilting point), in $\mathrm{mm}$, depicted for each soil layer (y-axis); and d) shallow aquifer storage, in $\mathrm{mm}$. 
Chapter 5

\section{Assessment of climate change impacts}

In this Chapter, we discuss the outputs of the simulation runs with the calibrated model, in order to assess the climate change impacts on the hydrological components of the water budget at the Jaguari river.

\subsection{Evapotranspiration and discharge}

Figure 5.1 shows the differences $\Delta \mathrm{ET}$ and $\Delta \mathrm{Q}$ between the experiments minus the control simulation for ET and Q, respectively, and depicts the effect of increasing temperature with growing abscissa, the effect of RH with distinct line types, the effect of rainfall with distinct colors and the labels displaying actual changes of precipitation.

With the historical $\mathrm{CO}_{2}$ case (Fig. 5.1-A, B) and no change in precipitation $\left(\epsilon_{P, T}=0\right.$ $\%{ }^{\circ} \mathrm{C}^{-1}$, grey lines), we noted the effects of only temperature and humidity: for all $\mathrm{RH}$ cases, ET generally increased near linearly with temperature, from about 13 to $64 \mathrm{~mm} \mathrm{yr}^{-1}$ (1 to 7\%) (Fig. 5.1-A), and Q reduced approximately at the same ET rates (Fig. 5.1-B). The perturbation of lowering $\mathrm{RH}$ tended to enhance the increasing ET with temperature by less than $5 \%$, and likewise helped to decrease $\mathrm{Q}$ at similar deviations.

Also for the historical $\mathrm{CO}_{2}$, but with forcings of less precipitation in future, wherein $\mathrm{P}$ was prescribed to reduce from 77 to $385 \mathrm{~mm} \mathrm{yr}^{-1}$ with increasing temperature $\left(\epsilon_{P, T}=-5\right.$ $\%{ }^{\circ} \mathrm{C}^{-1}$, red lines in Fig. 5.1-A, B), we noted that ET and Q were simultaneously reduced for all RH cases. Whereas reduction in ET was much less than that in rainfall, from 7 to 88 mm $\mathrm{yr}^{-1}$ (1 to $9 \%$ ), changes in $\mathrm{Q}$ were much higher and compared better to $\mathrm{P}$, namely from 68 to $294 \mathrm{~mm} \mathrm{yr}^{-1}$ (11 to 49\%), all for the alike RH case. Additionally, the perturbation of lowering $\mathrm{RH}$ tended to reverse the effect of decreasing ET with temperature, though 
only by less than $2 \%$.

Finally, for the historical $\mathrm{CO}_{2}$ cases, with higher precipitation forcing, $\mathrm{P}$ was prescribed to increase from 76 to $384 \mathrm{~mm} \mathrm{yr}^{-1}$ for $\epsilon_{P, T}=5 \%{ }^{\circ} \mathrm{C}^{-1}$, and from 154 to $771 \mathrm{~mm} \mathrm{yr}^{-1}$ for $\epsilon_{P, T}=10 \%{ }^{\circ} \mathrm{C}^{-1}$ (labels in Fig. 5.1-A, B, blue and black lines). The responses to temperature and humidity changes showed that, for all RH cases, both ET and Q generally increased near linearly with temperature. Regarding the responses of distinct precipitation changes, for $\epsilon_{P, T}=5$ and $10 \%{ }^{\circ} \mathrm{C}^{-1}$, respectively, ET increased up to maxima of 161 and $229 \mathrm{~mm} \mathrm{yr}^{-1}$ (17 and 24\%) (Fig. 5.1-A), and Q up to 218 and $530 \mathrm{~mm} \mathrm{yr}^{-1}$ (36 and 88\%) (Fig. 5.1-B). Similar to the $\epsilon_{P, T}=0 \%{ }^{\circ} \mathrm{C}^{-1}$ case, the comparison of higher to lower $\mathrm{RH}$ with $\epsilon_{P, T}=10 \%{ }^{\circ} \mathrm{C}^{-1}$ tended to enhance the increasing ET with temperature, up to about

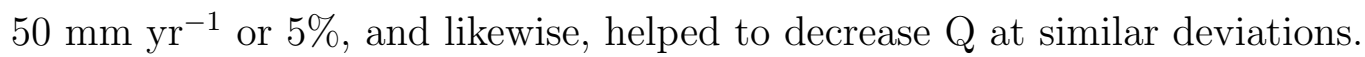

Comparing all cases of precipitation changes, it is suggested that the less precipitation forcing $\left(\epsilon_{P, T}=-5 \%{ }^{\circ} \mathrm{C}^{-1}\right.$, red lines in Fig. 5.1-A, B) may have led to an apparently pronounced soil moisture deficit, that in turn limited ET and its increasing response to lowering RH and increasing temperature. Differently, other cases with constant/increasing precipitation $\left(\epsilon_{P, T}=0,5\right.$ and $\left.10 \%{ }^{\circ} \mathrm{C}^{-1}\right)$ did not constrain such response of increasing ET.

Concerning $\triangle \mathrm{ET}$ in the end century $\mathrm{CO}_{2}$ cases (Fig. 5.1-C) compared to the historical $\mathrm{CO}_{2}$, a dominant feature appears in reducing ET relatively to the control, that is, $\Delta \mathrm{ET}$ was prevailing negative, mostly due to the expected decrease of transpiration under high $\mathrm{CO}_{2}$ concentration. Notwithstanding, the response pattern of ET to increasing temperature and $\mathrm{RH}$ showed similar directions compared to historical $\mathrm{CO}_{2}$ cases. The only exception was at $5{ }^{\circ} \mathrm{C}$ warmer case with $\epsilon_{P, T}=10 \%{ }^{\circ} \mathrm{C}^{-1}$, where ET responded positively. Considering the varying $\mathrm{RH}$, the changes were below $5 \%$ with respect to control with increasing temperature. In summary, changes in ET with temperature and $\mathrm{RH}$ at the end century $\mathrm{CO}_{2}$ ranged approximately between -15 to $-20 \%$ (less precipitation forcing case) and -15 to $+5 \%$ (constant/increasing precipitation forcing cases). Such dominant reduction in ET led to an overall increase in Q relatively to the control case. Indeed, all cases of end century $\mathrm{CO}_{2}$ (Fig. 5.1-D) showed higher $\Delta \mathrm{Q}$ compared to the historical $\mathrm{CO}_{2}$ (Fig. 5.1-B). Changes in $\mathrm{Q}$ with temperature and $\mathrm{RH}$, at the end century $\mathrm{CO}_{2}$, ranged approximately between -30 to $+10 \%$ (less precipitation forcing case) and +10 to $125 \%$ (constant/increasing precipitation forcing cases). Interestingly, for the less precipitation forcing $\left(\epsilon_{P, T}=-5 \%{ }^{\circ} \mathrm{C}^{-1}\right.$, red line in Fig. 5.1-D), Q increased (by about $10 \%$ ) at the $1^{\circ} \mathrm{C}$ warmer case, did not alter at $2^{\circ} \mathrm{C}$ case, 
and kept descending at warmer cases. That is, for temperature increase above $2^{\circ} \mathrm{C}$, the crescent water gains in the system, resulted from descending ET, were offset by crescent losses of precipitation.

A

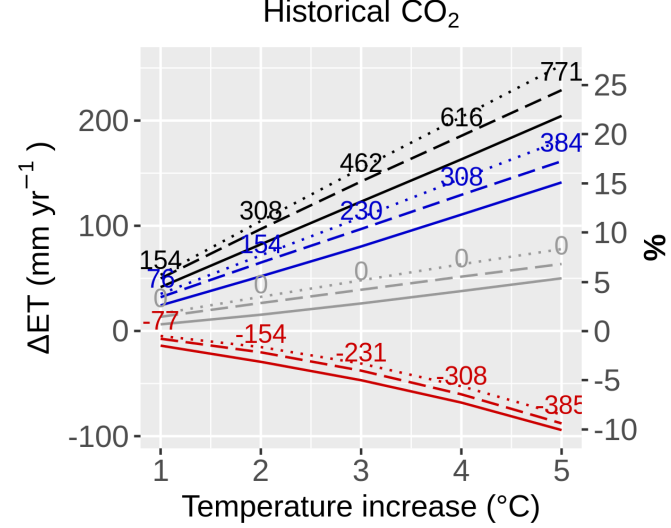

B

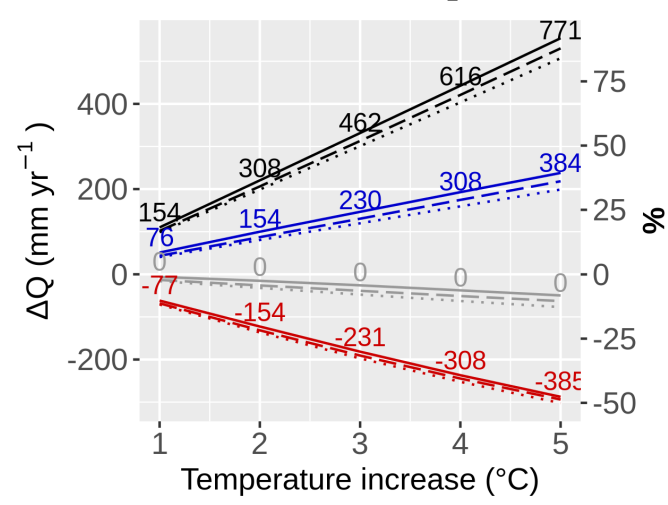

C

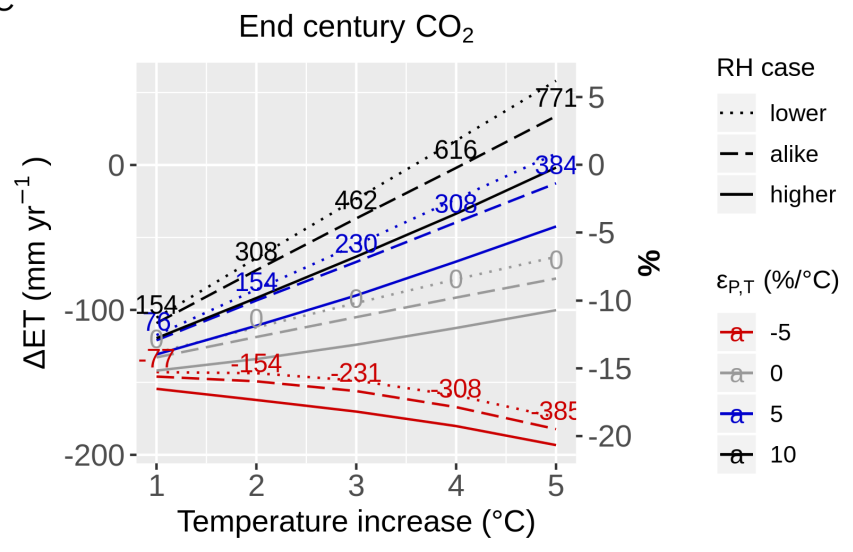

$\mathrm{D}$

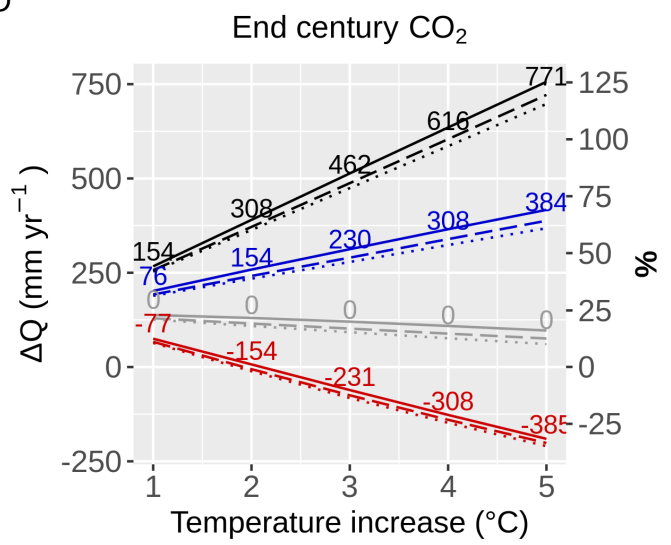

Figure 5.1: Hydrological responses of ET and Q shown as differences of experiment minus control simulation ( $\Delta \mathrm{ET}$, panels $\mathrm{A}$ and $\mathrm{C})$ and specific discharge $(\Delta \mathrm{Q}$, panels $\mathrm{B}$ and $\mathrm{D})$, in $\mathrm{mm} \mathrm{yr}^{-1}$ (left y-axis) and percentage variation (right y-axis), forced by: temperature increase (x-axis, in ${ }^{\circ} \mathrm{C}$ ); elasticity of precipitation to temperature $\epsilon_{P, T}$, in $\%{ }^{\circ} \mathrm{C}^{-1}$ (colors), with actual changes of precipitation displayed as labels, in $\mathrm{mm} \mathrm{yr}^{-1}$; changes of relative humidity $(\mathrm{RH})$ with the cases lower (dotted line), alike (dashed line) and higher (solid line); and changes of $\mathrm{CO}_{2}$ concentration (historical in panels A-B and end century in panels C-D).

So far, the forcings of precipitation changes were determining in the responses of ET and $\mathrm{Q}$ under future climatic conditions. In the realm of this point, the precipitation changes $(\Delta \mathrm{P}$ in Fig. 5.2-A, B) showed higher spread with increasing temperature, which evolved both from the option to use elasticity to define the forcings and the simulated variability of global models for the region of investigation. The responses of $\mathrm{Q}$ to precipitation changes ranged from about -50 to $100 \%$ and were broader than those for ET (-20 to 20\%) (Fig. $5.2)$. 
Interestingly, the responses of both $\mathrm{ET}$ and $\mathrm{Q}$ to $\Delta \mathrm{P}$ were not seemingly linear, most obviously shown for $\mathrm{ET}$ at $5^{\circ} \mathrm{C}$ (red lines in Fig. 5.2-A). The sensitivity of ET to $\Delta \mathrm{P}$ can be estimated simply as the approximated slope $\Delta \mathrm{ET} / \Delta \mathrm{P}$, and considering, for example, the increase in $5^{\circ} \mathrm{C}$, we noted that it decreased with increasing precipitation. Indeed, under conditions of below average rainfall, and consequently, less soil moisture, an increment in the rainfall may attenuate the soil water stress limiting ET. However, in above average rainfall cases, and unchanged incoming radiation, it is the energy that limits ET rates. Fig. 5.2-A also shows the ET sensitivity to be higher for historical case compared to end century case, partly explained by the $\mathrm{CO}_{2}$ effect on stomatal conductance helping to dampen the responses. Conversely, the sensitivity $\Delta \mathrm{Q} / \Delta \mathrm{P}$ increased with precipitation.

A

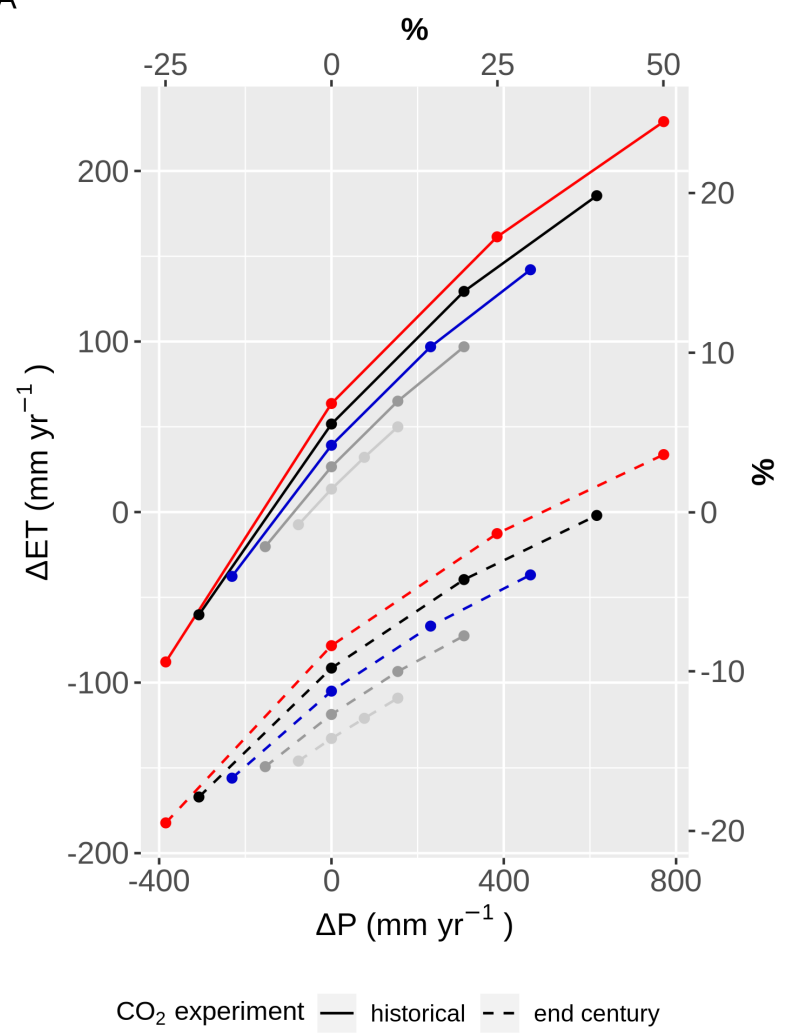

B

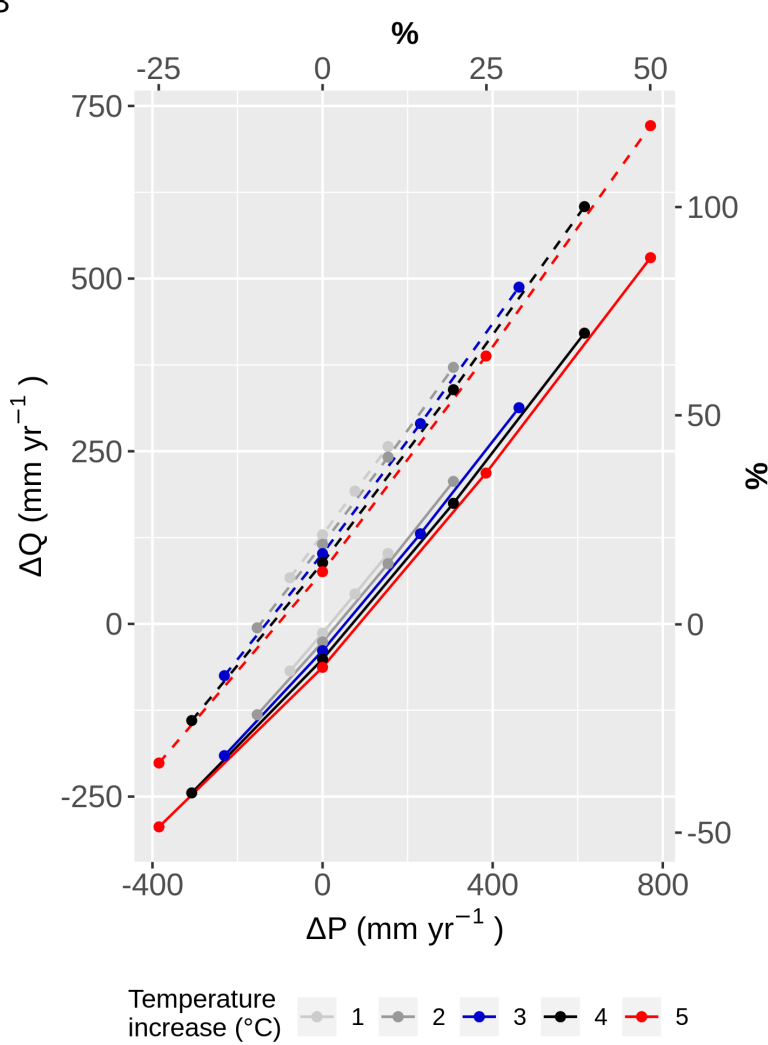

Figure 5.2: Hydrological responses of ET and Q shown as differences of experiment minus control simulation for alike $\mathrm{RH}$ case $(\Delta \mathrm{ET}$, panel $\mathrm{A})$ and specific discharge $(\Delta \mathrm{Q}$, panel $\mathrm{B})$, in $\mathrm{mm} \mathrm{yr}^{-1}$ (left y-axis) and percentage variation (right y-axis), forced by: change in precipita-

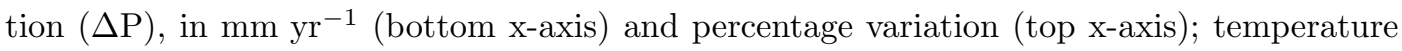
increase, in ${ }^{\circ} \mathrm{C}$ (colors) and changes of $\mathrm{CO}_{2}$ concentration (historical in solid lines and end century in dashed lines). 


\subsection{Transpiration and soil evaporation}

We show in this sub-section how the ET components of transpiration (Et) and soil evaporation (Es) responded differently to the climatic perturbations.

The patterns of $\Delta \mathrm{Et}$ (Fig. 5.3-A, C) prevailed on $\Delta \mathrm{ET}$, directly contributing to the change signal response in $\triangle \mathrm{ET}$ from historical to end century $\mathrm{CO}_{2}$ cases (in constant/increasing precipitation forcing cases), and in the effect of increasing ET with the lowering RH. In general, under historical $\mathrm{CO}_{2}$ cases (Fig. 5.3-A), $\Delta$ Et decreased up to about $15 \%$ in $\epsilon_{P, T}=-5 \%{ }^{\circ} \mathrm{C}^{-1}$ cases, and increased up to around $30 \%\left(0.6 \mathrm{~mm} \mathrm{~d}^{-1}\right)$ in constant/increasing precipitation forcing cases. For end century $\mathrm{CO}_{2}$ cases (Fig. 5.3-C), all experiments presented depleted Et in relation to control run, from about -5 to $-40 \%$ (more than $0.7 \mathrm{~mm} \mathrm{~d}^{-1}$ ).

The responses in $\Delta$ Es (Figs. 5.3-B, D) had somewhat similar directions than $\Delta$ Et with respect to temperature increase and precipitation changes, ranging from around $-10 \%$ to $+25 \%$ in historical $\mathrm{CO}_{2}$ cases, and from around 10 to $55 \%$ in end century $\mathrm{CO}_{2}$ cases. As the contribution of $\Delta \mathrm{Es}$ to $\Delta \mathrm{ET}$ is smaller, it only prevailed in $\Delta \mathrm{ET}$ when $\Delta \mathrm{Et}$ magnitude was small, e.g., leading to the positive $\Delta \mathrm{ET}$ cases with $\epsilon_{P, T}=5$ and $10 \%{ }^{\circ} \mathrm{C}^{-1}$ in the end century $\mathrm{CO}_{2}$ experiments.

$\mathrm{RH}$ exerts an important role in $\Delta \mathrm{Et}$ and $\Delta \mathrm{Es}$ patterns (Fig. 5.3). We noted that the responses of $\Delta \mathrm{Et}$ and $\Delta \mathrm{Es}$ to $\mathrm{RH}$ were opposite: while $\Delta \mathrm{Et}$ increased with lowering $\mathrm{RH}, \Delta$ Es decreased. Higher $\mathrm{RH}$ cases exhibited more variation with respect to the alike cases than the lower ones, both in $\Delta \mathrm{Et}$ and $\Delta \mathrm{Es}$. It happened possibly because higher $\mathrm{RH}$ cases presented more days with vpd equal to 0 than alike, restricting the Penman-Monteith potential ET to the energy-based term (see Eq. 3.7), thus reducing Et (and consequently increasing Es). In lower RH cases, such mechanism was not addressed.

\subsection{Soil water storage}

Figure 5.4 addresses the differences in available water content (AWC) in the soil profile due to the climatic perturbations.

Regarding the historical $\mathrm{CO}_{2}$ case, we noted that in constant and reduced precipitation forcing cases, AWC reduction along the profile is more accentuated with increasing temperature and depth, although for different reasons. With $\epsilon_{P, T}=-5 \%{ }^{\circ} \mathrm{C}^{-1}$, AWC reduced from 
A

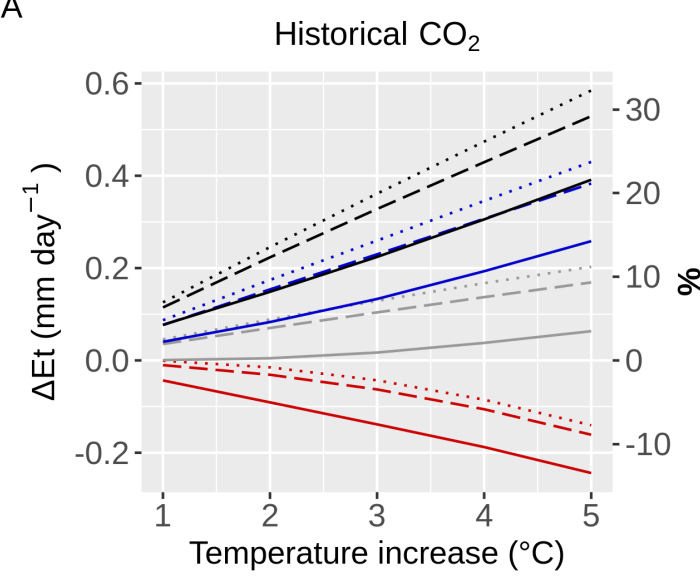

B

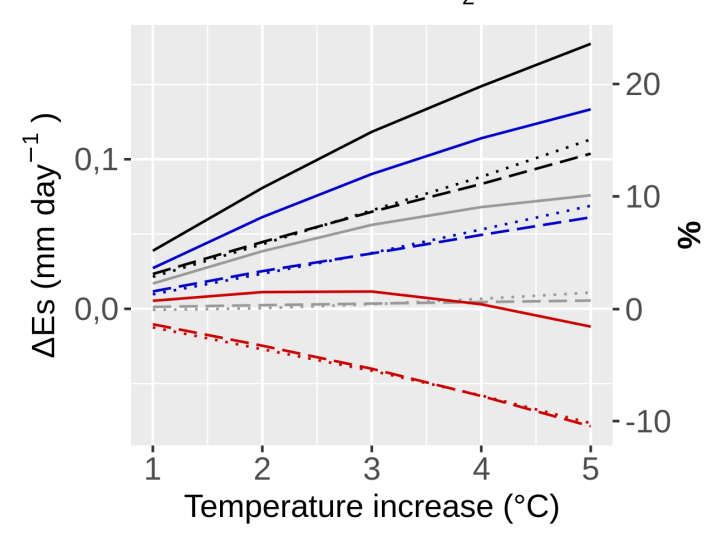

C

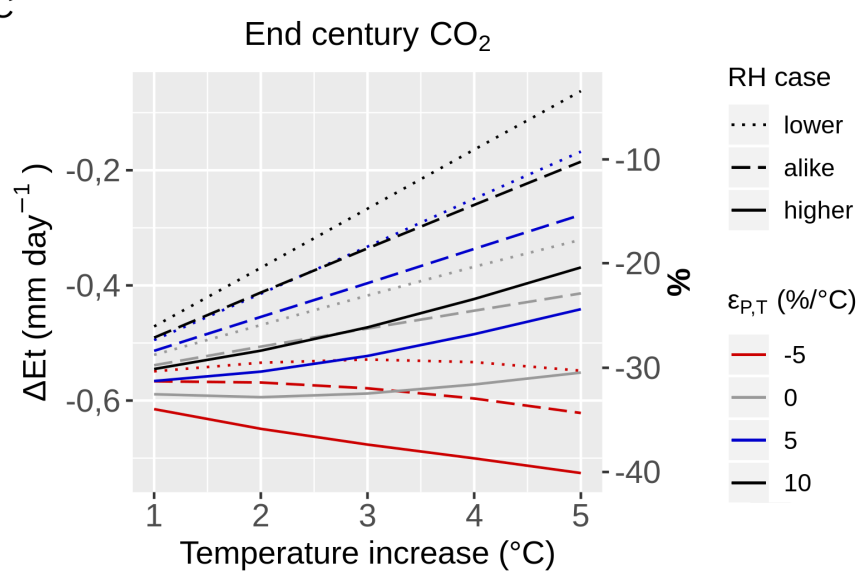

$\mathrm{D}$

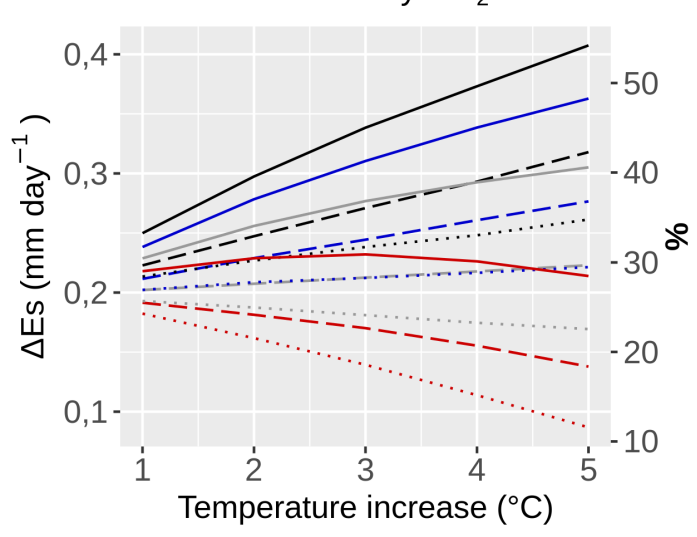

Figure 5.3: Responses in Et ( $\Delta \mathrm{Et}$, panels $\mathrm{A}$ and $\mathrm{C})$ and $\mathrm{Es}(\Delta \mathrm{Es}$, panels $\mathrm{B}$ and $\mathrm{D})$ shown as differences of experiment minus control simulation, in $\mathrm{mm} \mathrm{d}^{-1}$ (left $\mathrm{y}$-axis) and percentage variation (right $\mathrm{y}$-axis), forced by: temperature increase (x-axis, in ${ }^{\circ} \mathrm{C}$ ); elasticity of precipitation to temperature $\epsilon_{P, T}$, in $\%{ }^{\circ} \mathrm{C}^{-1}$ (colors); changes of relative humidity (RH) with the cases lower (dotted line), alike (dashed line) and higher (solid line); and changes of $\mathrm{CO}_{2}$ concentration (historical in panels A-B and end century in panels C-D).

around $-20 \%$ in the top layer to $-60 \%$ in the bottom, using $5^{\circ} \mathrm{C}$ case as example, showing that the negative $\Delta \mathrm{P}$ surpassed the response from negative $\Delta \mathrm{ET}$. On the other hand, with $\epsilon_{P, T}=0 \%{ }^{\circ} \mathrm{C}^{-1}$, the magnitude of depletion is smaller, ranging from $-10 \%$ in the top layer to $-30 \%$, also at $5^{\circ} \mathrm{C}$ case, due to the increase in ET. In increasing precipitation forcing cases, $\Delta \mathrm{P}$ compensated or surpassed $\Delta \mathrm{ET}$ responses, resulting in an $\mathrm{AWC}$ profile close to control or wetter, for $\epsilon_{P, T}=5$ and $10 \%{ }^{\circ} \mathrm{C}^{-1}$, respectively. The increase was up to $20 \%$ in $\epsilon_{P, T}=10 \%{ }^{\circ} \mathrm{C}^{-1}$, and with distinct profile pattern in relation to constant precipitation forcing case.

Differently, in the end century $\mathrm{CO}_{2}$ case, AWC profile is wetter than control essentially for all experiments, due to the reduced transpiration. Experiments comprising reduced or 
constant precipitation forcings presented drier AWC profiles with increasing temperature (arrows direction in Fig. 5.4), whereas the opposite occurred to increasing precipitation cases, as an unfolding of elasticity approach. The differences between precipitation cases is smaller in end century than historical $\mathrm{CO}_{2}$ cases. Using, for example, the $5 \%{ }^{\circ} \mathrm{C}$ case, the difference between $\epsilon_{P, T}=-5$ and $10 \%{ }^{\circ} \mathrm{C}^{-1}$ was at most $40 \%$ in end century against around $80 \%$ in the historical $\mathrm{CO}_{2}$ case.

The response of $\mathrm{RH}$ in AWC profile on both historical and end century cases was coherent to ET patterns: lowering RH increased ET, and thus reduced AWC.

An interesting feature is that some profiles of $\epsilon_{P, T}$ equal to 0 and $-5 \%{ }^{\circ} \mathrm{C}^{-1}$ were pretty similar, although presenting different responses on ET, e.g., $\epsilon_{P, T}=-5$ at $1{ }^{\circ} \mathrm{C}$ increase $(\Delta \mathrm{ET}<0)$ and $\epsilon_{P, T}=0$ at $2{ }^{\circ} \mathrm{C}(\Delta \mathrm{ET}>0)$. Indeed, the attenuation due to water restriction is essentially the same in such cases, but potential transpiration was higher in $\epsilon_{P, T}=0$ because involved higher temperature increases than $\epsilon_{P, T}=-5$ (see Eqs. 3.12 and 3.13).

\subsection{Uncertainties and distribution of events}

In this sub-section it is discussed the impact of climatic perturbations on water fluxes statistical distribution.

Figure 5.5 shows the probability density function (PDF) of precipitation, depicting the separated impacts of elasticity (Fig. 5.5-A) and temperature (Fig. 5.5-B) cases. We noted that control simulation (green lines in Figs. 5.5-A, B) exhibited a trimodal pattern, whose main peak with respect to density addressed values around $1500 \mathrm{~mm} \mathrm{yr}^{-1}$, the second around $1900 \mathrm{~mm} \mathrm{yr}^{-1}$, and the third one around $1000 \mathrm{~mm} \mathrm{yr}^{-1}$, that represented the drought in 2013/2014. Analysing the elasticity cases (Fig. 5.5-A) different than $\epsilon_{P, T}=0$ $\%{ }^{\circ} \mathrm{C}^{-1}$, it can be seen that distributions are displaced to the left (right) with negative (positive) elasticity, and are flattened (i.e., decreasing kurtosis) with respect to control simulation. In $\epsilon_{P, T}=-5 \%{ }^{\circ} \mathrm{C}^{-1}$ case, the mean reduced to about $1300 \mathrm{~mm} \mathrm{yr}^{-1}$, and the extreme low values are around $750 \mathrm{~mm} \mathrm{yr}^{-1}$, i.e, inferior to the drought level. Differently, with $\epsilon_{P, T}=5$ and $10 \%{ }^{\circ} \mathrm{C}^{-1}$ cases, the mean increased to around 1750 and $2000 \mathrm{~mm} \mathrm{yr}^{-1}$, respectively, and maximum reached up to $3000 \mathrm{~mm} \mathrm{yr}^{-1}$ (around twice the control mean).

With respect to temperature (Fig. 5.5-B), the higher the increase the higher the mean and the variance of rainfall distribution. The flattened curves of decreased kurtosis in 


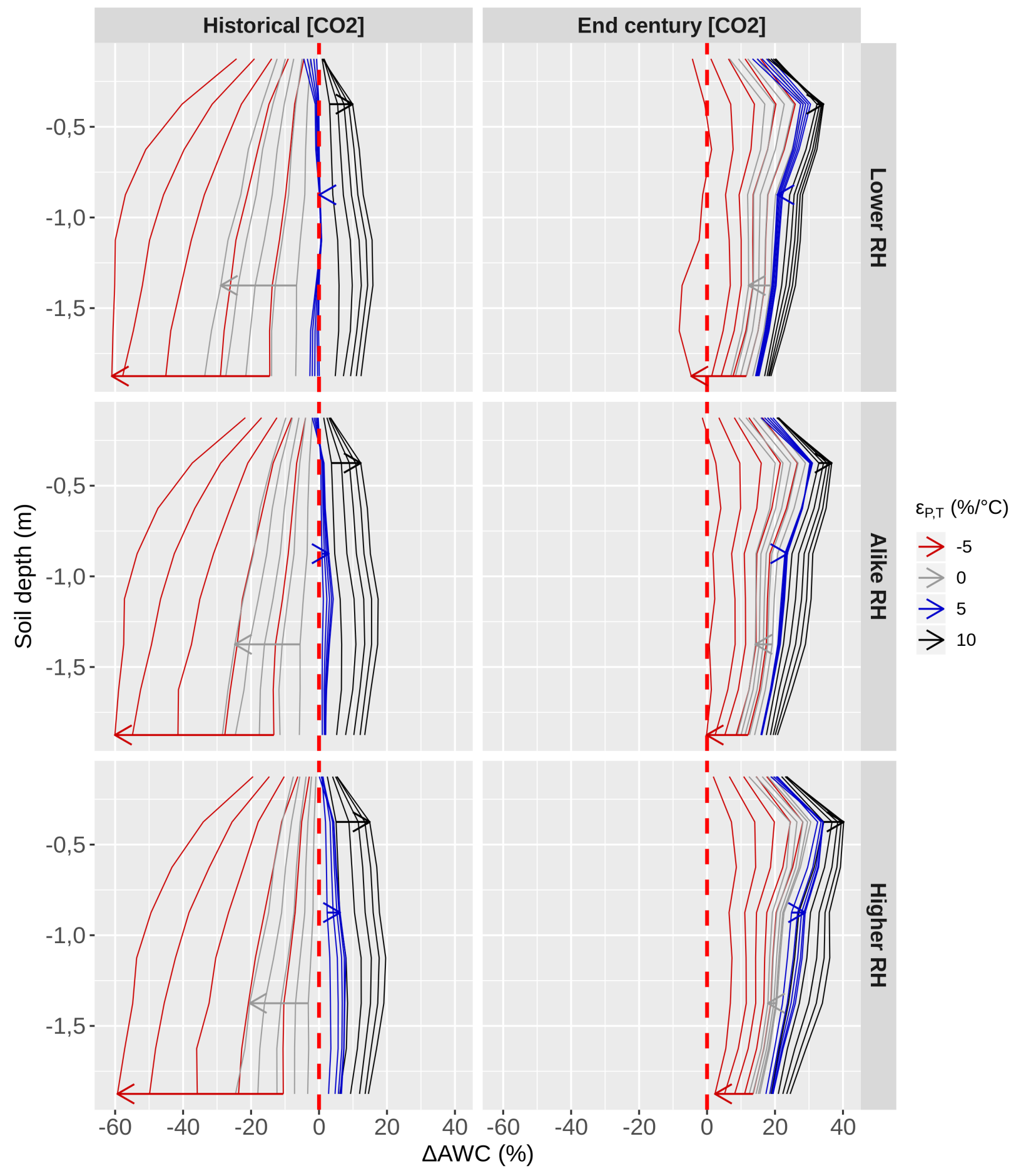

Figure 5.4: Relative change of available water content of experiments with respect to control simulation $(\triangle \mathrm{AWC}$, in $\%, \mathrm{x}$-axis) along $2 \mathrm{~m}$ depth (y-axis), forced by: elasticity of precipitation to temperature $\epsilon_{P, T}$, in $\%{ }^{\circ} \mathrm{C}^{-1}$ (colors); changes of relative humidity (RH) with the cases lower (top panels), alike (mid panels) and higher (bottom panels); and changes of $\mathrm{CO}_{2}$ concentration (historical in the left panels and end century in the right panels). The arrows point to the direction of increasing temperature for each $\epsilon_{P, T}$ case. Vertical dashed lines mark $\Delta \mathrm{AWC}=0$. 
elasticity cases are more evident in the temperature ones, especially for increases above $3{ }^{\circ} \mathrm{C}$. At $5{ }^{\circ} \mathrm{C}$ increase, the distribution presented the wider range of yearly precipitation: around $2200 \mathrm{~mm} \mathrm{yr}^{-1}$, against approximately 1200 from $1^{\circ} \mathrm{C}$ increase case. Focusing on the plateau over $5^{\circ} \mathrm{C}$ case distribution, the higher density is practically equally distributed between 1300 and $2100 \mathrm{~mm} \mathrm{yr}^{-1}$, depicting a condition to enhanced inter-annual variability.

It is important to note that the experiments include larger samples than control simulation, which may explain the single modal distribution of experiments against three modes in control.

The changes in the PDFs from ET and Q are assessed in Figs. 5.6-A, B, similarly to the approach of Fig. 5.5. For simplicity, only the alike RH case is shown once the pattern is essentially the same in lower and higher $\mathrm{RH}$.

Control ET displays a peak in around $940 \mathrm{~mm} \mathrm{yr}^{-1}$, ranging from around 800 to 1020 $\mathrm{mm} \mathrm{yr}^{-1}$. We noted that in the historical $\mathrm{CO}_{2}$ case (top panels in 5.6-A, B), ET presented for all elasticity cases but $0 \%{ }^{\circ} \mathrm{C}^{-1}$ a similar change in distribution pattern to $\mathrm{P}$, despite the smaller impact on the tails. Minimum ET reduced with respect to control in $\epsilon_{P, T}=-5 \%{ }^{\circ} \mathrm{C}^{-1}$ to $640 \mathrm{~mm} \mathrm{yr}^{-1}$, and increased to 830 and $855 \mathrm{~mm} \mathrm{yr}^{-1}$, respectively, for $\epsilon_{P, T}=5$ and $10 \%{ }^{\circ} \mathrm{C}^{-1}$. Regarding the maxima, the less precipitation forcing case did not present significant changes with respect to control, but the remaining cases responded with progressive increases to 1105,1190 and $1252 \mathrm{~mm} \mathrm{yr}^{-1}$ in $\epsilon_{P, T}=0,5$ and $10 \%{ }^{\circ} \mathrm{C}^{-1}$, respectively. Concerning the temperature cases (Fig. 5.6-B), still under historical $\mathrm{CO}_{2}$ concentration, ET distributions are displaced to the right, which means an increase in the mean, mode and variance with increasing temperature. At $5^{\circ} \mathrm{C}$ it can be seen that a secondary peak of reduced ET (around $850 \mathrm{~mm} \mathrm{yr}^{-1}$ ) with respect to control is taking form, which is a response to the cases of less precipitation forcing. Q reproduced the $\mathrm{P}$ changes essentially for all $\epsilon_{P, T}$ and temperature cases, except in $\epsilon_{P, T}=0 \%{ }^{\circ} \mathrm{C}^{-1}$, which presented a reduced Q due to increased ET. We addressed that control P modes are marked in control $\mathrm{Q}$ distribution as well, in around 230,580 and $880 \mathrm{~mm} \mathrm{yr}^{-1}$. The reduction in minimum $\mathrm{Q}$ in $\epsilon_{P, T}=0 \%{ }^{\circ} \mathrm{C}^{-1}$ case is modest $\left(16 \mathrm{~mm} \mathrm{yr}^{-1}\right)$ but in $\epsilon_{P, T}=-5 \%{ }^{\circ} \mathrm{C}^{-1}$ it was $40 \%$ inferior to control simulation $\left(139 \mathrm{~mm} \mathrm{yr}^{-1}\right)$. The maximum Q in control was $900 \mathrm{~mm} \mathrm{yr}^{-1}$, while it reached 1209 and $1629 \mathrm{~mm} \mathrm{yr}^{-1}$ in $\epsilon_{P, T}=5$ and $10 \%{ }^{\circ} \mathrm{C}^{-1}$, respectively. With respect to temperature, Q resembled P distribution as well, stretching the PDF curve with increasing temperature. 


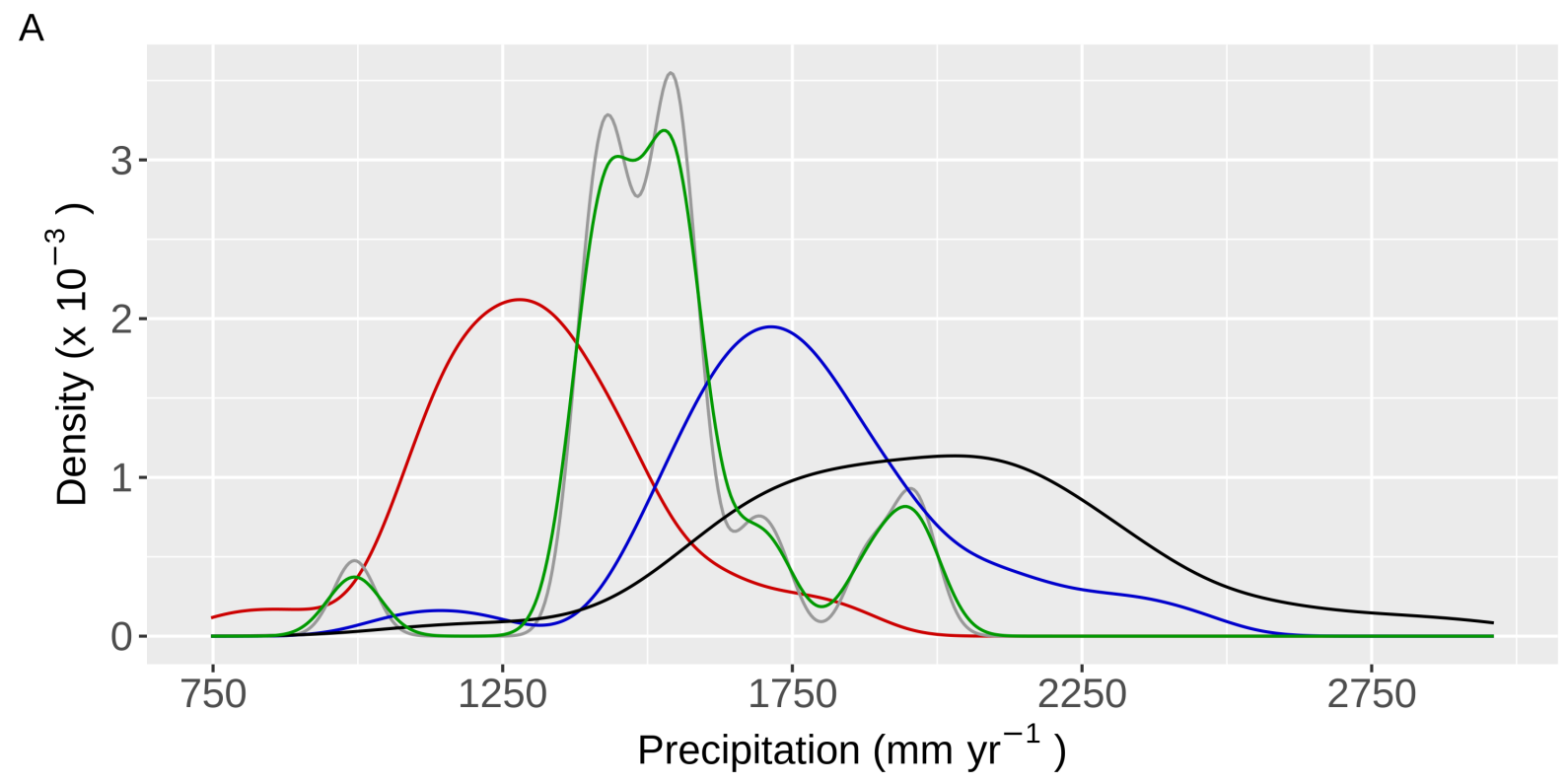

$$
\varepsilon_{\mathrm{P}, \mathrm{T}}\left(\% /{ }^{\circ} \mathrm{C}\right)--5-0-5-10-\text { Control }
$$

\section{B}

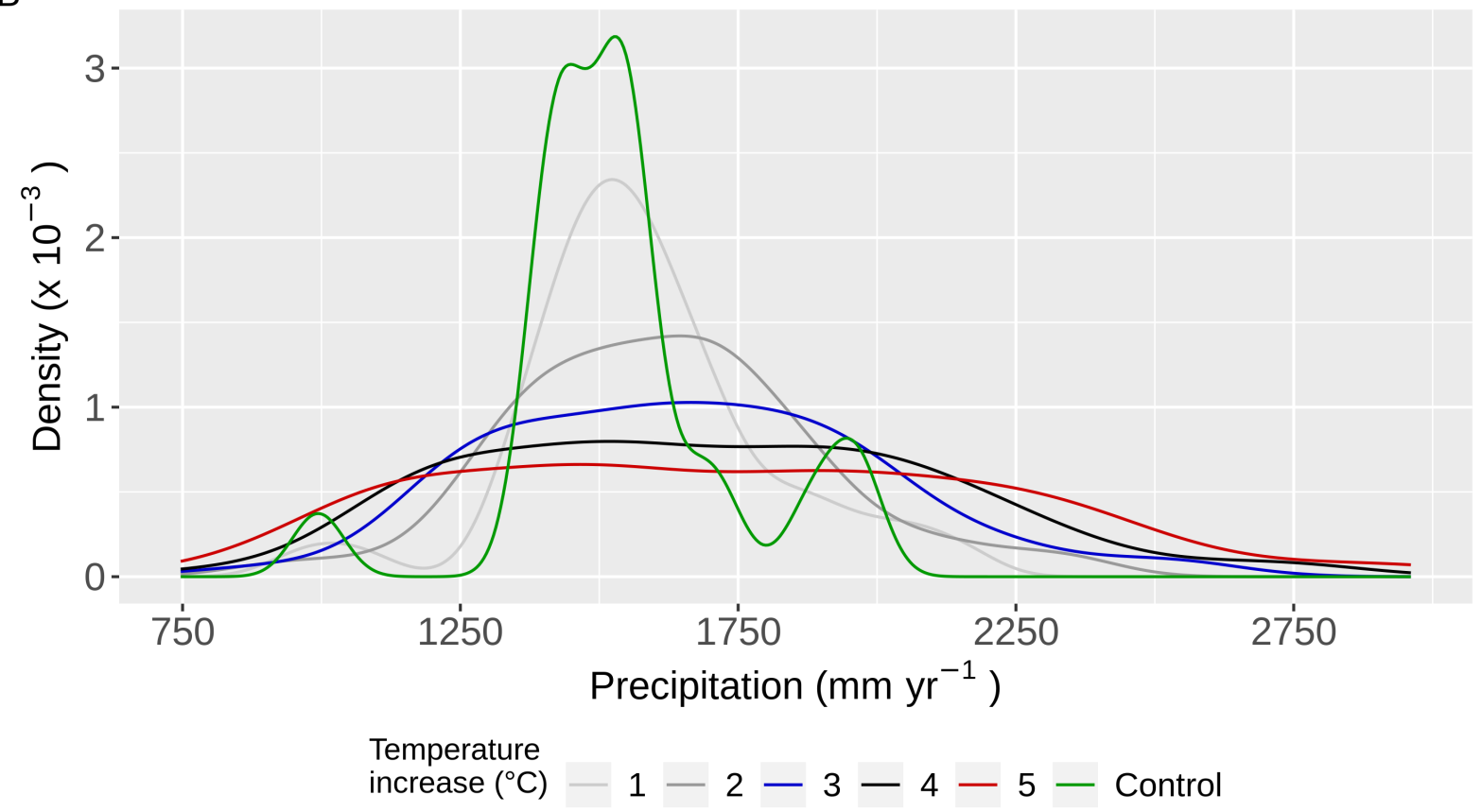

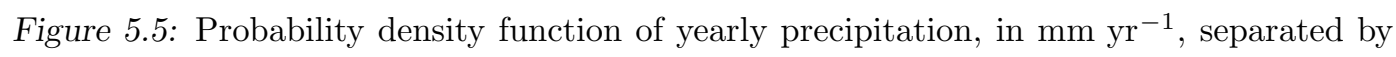
A) elasticity (in $\%{ }^{\circ} \mathrm{C}^{-1}$ ) and $\mathrm{B}$ ) temperature increase (in ${ }^{\circ} \mathrm{C}$ ) cases.

The end century $\mathrm{CO}_{2}$ concentration (bottom panels in Figs. 5.6-A, B) led to a reduction in ET minimum, mean and variance, and, consequently, an increase in Q maximum, mean and variance with respect to the historical case. Under such concentration, ET cases ranged from 590 to $1074 \mathrm{~mm} \mathrm{yr}^{-1}$ (against 640 to $1252 \mathrm{~mm} \mathrm{yr}^{-1}$ in historical case), and 
Q from 164 to $1814 \mathrm{~mm} \mathrm{yr}^{-1}$ (against 139 to $1629 \mathrm{~mm} \mathrm{yr}^{-1}$ in historical case).

A

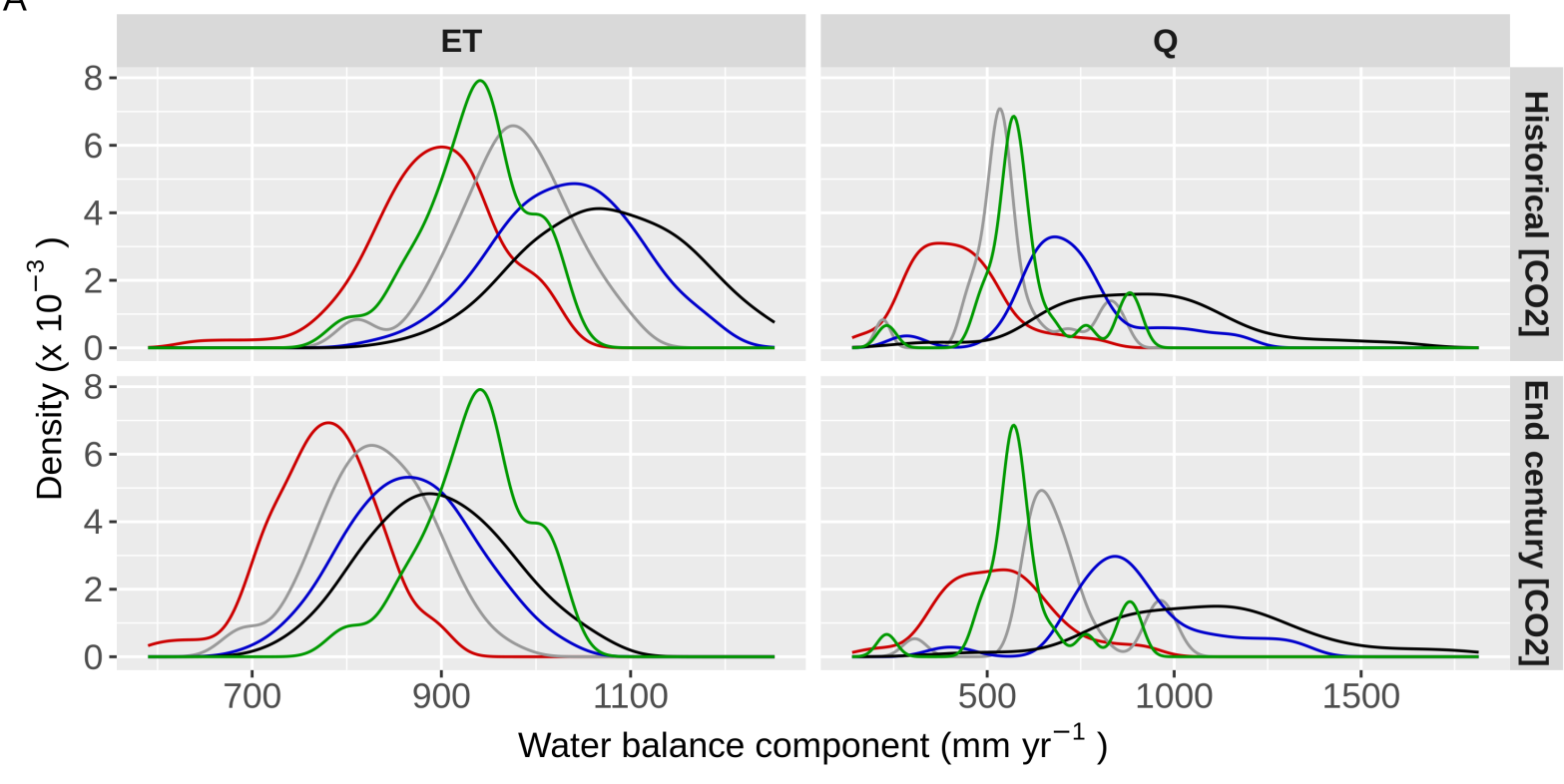$$
\varepsilon_{\mathrm{P}, \mathrm{T}}\left(\% /{ }^{\circ} \mathrm{C}\right)--5-0-5-10-\text { Control }
$$

B

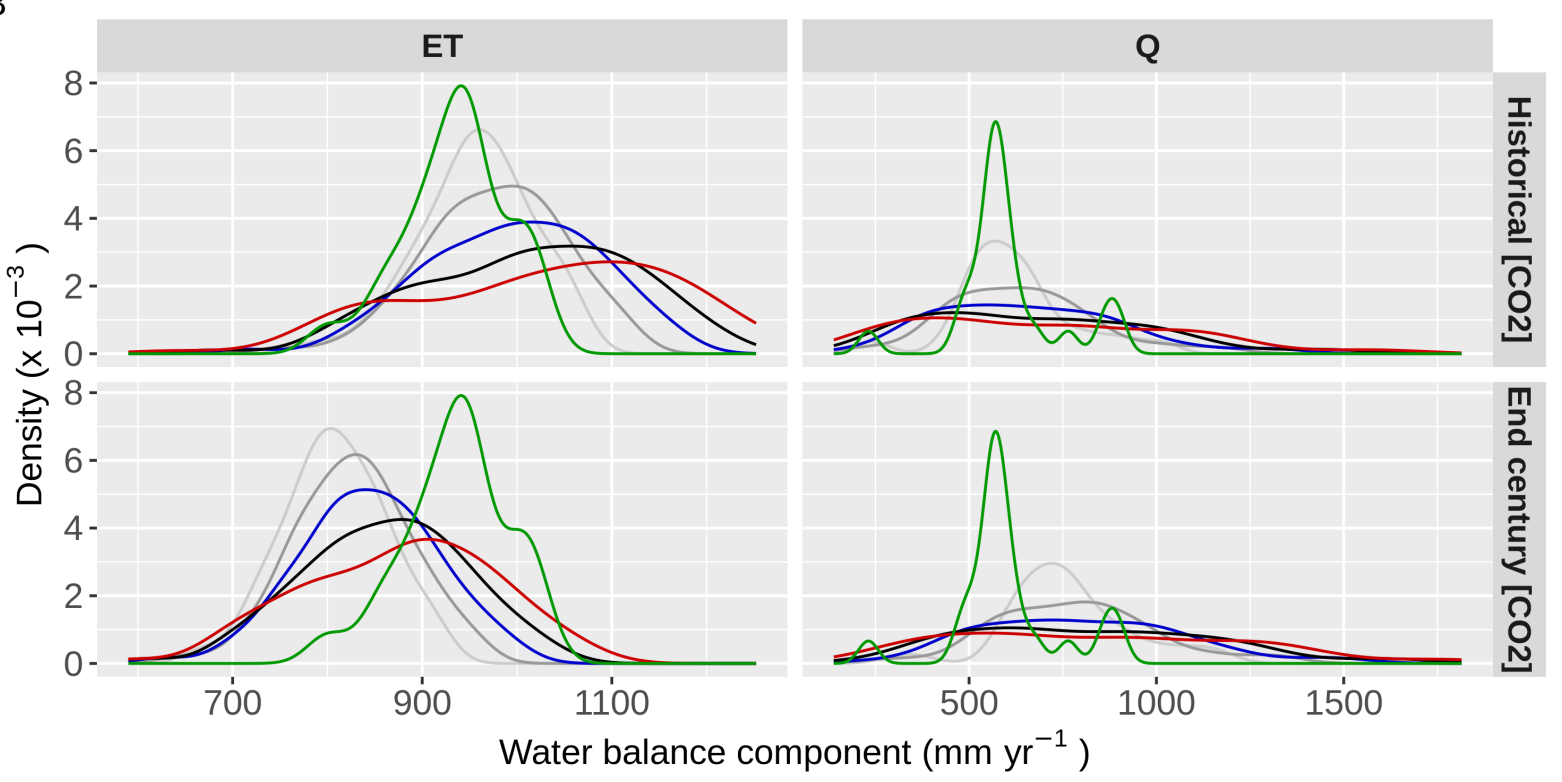

Temperature increase $\left({ }^{\circ} \mathrm{C}\right)-1-2-3-4-5-$ Control

Figure 5.6: Probability density function of yearly ET (left panels) and Q (right panels), in $\mathrm{mm} \mathrm{yr}^{-1}$, separated by A) elasticity (in $\%{ }^{\circ} \mathrm{C}^{-1}$ ) and $\mathrm{B}$ ) temperature increase (in ${ }^{\circ} \mathrm{C}$ ) cases.

Figure 5.7 shows the boxplot of experiment runs, along with the observed data and the outputs of CMIP5 projections assessed by de Abreu et al. (in prep). We present the experiments only for the alike $\mathrm{RH}$ case, and temperature increases of 1,3 and $5^{\circ} \mathrm{C}$, in order 
to simplify the visualization and because the remaining cases not addressed here have the same pattern (RH cases) or intermediate responses (temperature cases). Besides that, the observed boxplots used field yearly P and Q, whereas ET was estimated as P-Q. Finally, the boxplots of CMIP5 outputs did not account for the variance in time as the others, but the variance among climate models. Additionally, the historical and end century $\mathrm{CO}_{2}$ cases comprised different ranges: 1980 to 2004 and 2075 to 2099, respectively, under RCP 8.5 scenario. Q in CMIP5 outputs was estimated as the difference between P and ET.

The observed boxplots present an estimate of the natural variability of water balance components. The whiskers delimit a spanned range of interquantile range (IQR), between $\mathrm{q}_{75 \%}+1.5$ IQR at the top and $\mathrm{q}_{25 \%}-1.5$ IQR at the bottom, where $\mathrm{q}_{75 \%}$ and $\mathrm{q}_{25 \%}$ are the 75th and 25th quantiles, respectively, and IQR $=\mathrm{q}_{75 \%}-\mathrm{q}_{25 \%}$. Outside these limits the events are considered outliers. For instance, the drought in 2014 is marked in P and Q boxplots, as the bottom outlier, while the years of 1995, 1996 and 2009 are the top outliers in $\mathrm{P}$. We noted that in the experiments, the variability increased with increasing temperature and precipitation forcing, as already pointed out previously, and regarding $\mathrm{P}$ and $\mathrm{Q}$, these changes are in most cases comparable or even larger than natural variability of these variables, especially under end century $\mathrm{CO}_{2}$. It is remarked the presence of outliers in the experiments that were not addressed in observation, and their magnitude amplify with heating and more precipitation. On the other hand, ET variability in the individual experiments was always shorter than natural variability. If the set of perturbations are assessed as a whole, we see some reduced ET magnitudes not addressed by natural variability.

Despite not being readily comparable to the observation, due to the different period in the historical case, the boxplots from CMIP5 (pink plots in Fig. 5.7) underestimated $\mathrm{P}$ and $\mathrm{Q}$, and overestimated ET, with respect to their observed medians. We observed that the spread of long term mean values among models of CMIP5 is higher than the natural variability of $\mathrm{P}$ and $\mathrm{Q}$. For instance, the outliers in $\mathrm{P}$ ranged from around 800 to $2200 \mathrm{~mm} \mathrm{yr}^{-1}$. The changes in the median from historical to end century cases in CMIP5 ensemble were considerably small in $\mathrm{P}(3 \%)$, and this pattern was reproduced in both ET and Q (+0.4 and $-3 \%$, respectively). These results lead, again, to the understanding that the small changes from historical to end century cases are due to the spread of different responses regionally among CMIP5 models under RCP 8.5, as already shown in Fig. 3.6, rather than a systematic small response of models individually. Notwithstanding, the P- 
ET estimation of CMIP5 models did not compare as well to observation as control SWAT simulated Q.

ET in the end century case was slightly higher than historical case in CMIP5, on median, $\mathrm{q}_{75 \%}$ and $\mathrm{q}_{25 \%}$, possibly addressing the prevailing effect of temperature increase rather than $\mathrm{CO}_{2}$ on stomatal conductance. The CMIP-ET distribution presented an outlier of around $1400 \mathrm{~mm} \mathrm{yr}^{-1}$, $\approx 40 \%$ larger than median. Differently, SWAT end century experiments did not surpass $1100 \mathrm{~mm} \mathrm{yr}^{-1}$ due to the shorter variance and the $\mathrm{CO}_{2}$ effect. Regarding $\mathrm{Q}$ distribution in CMIP5, we noted that $\mathrm{q}_{75 \%}$ increased from historical to end century, and outliers marked around $1400 \mathrm{~mm} \mathrm{yr}^{-1}$, possibly due to the contribution of $8 \%$ of models with elasticity of more than $20 \%{ }^{\circ} \mathrm{C}^{-1}$ for P-ET (Fig. 3.6).

So far, we showed the responses of climatic perturbations in long term or yearly-based means, not addressing the impacts in daily time series of such perturbations. Figure 5.8 presents the histogram of daily precipitation depicted in the elasticity cases. It can be seen that less precipitation forcing increases (decreases) the distribution below (above) 10 $\mathrm{mm} \mathrm{d}{ }^{-1}$ with respect to $\epsilon_{P, T}=0 \%{ }^{\circ} \mathrm{C}^{-1}$, and events above $100 \mathrm{~mm} \mathrm{~d}^{-1}$ are not accounted. In general, the cases with $\epsilon_{P, T}=5$ and $10 \%{ }^{\circ} \mathrm{C}^{-1}$ presented the opposite pattern: less events with $\mathrm{P}<10 \mathrm{~mm} \mathrm{~d}^{-1}$ and more with $\mathrm{P}>10 \mathrm{~mm} \mathrm{~d}^{-1}$ than the control case. In these cases, for example, the $50 \mathrm{~mm} \mathrm{~d}^{-1}$ event is around 2 and 3 times the control count for $\epsilon_{P, T}=5$ and $10 \%{ }^{\circ} \mathrm{C}^{-1}$, respectively, and the latter reaches up to $150 \mathrm{~mm} \mathrm{~d}^{-1}$ events, i.e., extreme events are more numerous when $\epsilon_{P, T}>0$.

The flow duration curves of climatic perturbation experiments are shown in Fig. 5.9, in order to discuss the extremes in the daily base. As in Fig. 5.7, only alike RH case and temperature increases of 1,3 and $5^{\circ} \mathrm{C}$ are presented for simplicity.

We noted that the patterns of experiment responses, in general, were homogeneous along the probability classes for discharge maxima (Fig. 5.9-A), with approximately parallel curves with respect to control simulation (green curves in Fig. 5.9), and similar to the change in mean $\mathrm{Q}$ as discussed before, for both historical and end century $\mathrm{CO}_{2}$ cases. However, an exception was given in $\epsilon_{P, T}=10 \%{ }^{\circ} \mathrm{C}^{-1}$ case, in which the increase in discharge below the exceedance probability of $0.1 \%$ was enhanced, for both $\mathrm{CO}_{2}$ cases as well. In such condition, discharge can be as high as around 2.5 times the control case, changing from $137 \mathrm{~m}^{3} \mathrm{~s}^{-1}$ to $325 \mathrm{~m}^{3} \mathrm{~s}^{-1}$ in the historical case and to $367 \mathrm{~m}^{3} \mathrm{~s}^{-1}$ in the end century at a $5^{\circ} \mathrm{C}$ increase. For instance, an outflow threshold of $100 \mathrm{~m}^{3} \mathrm{~s}^{-1}$ is set 


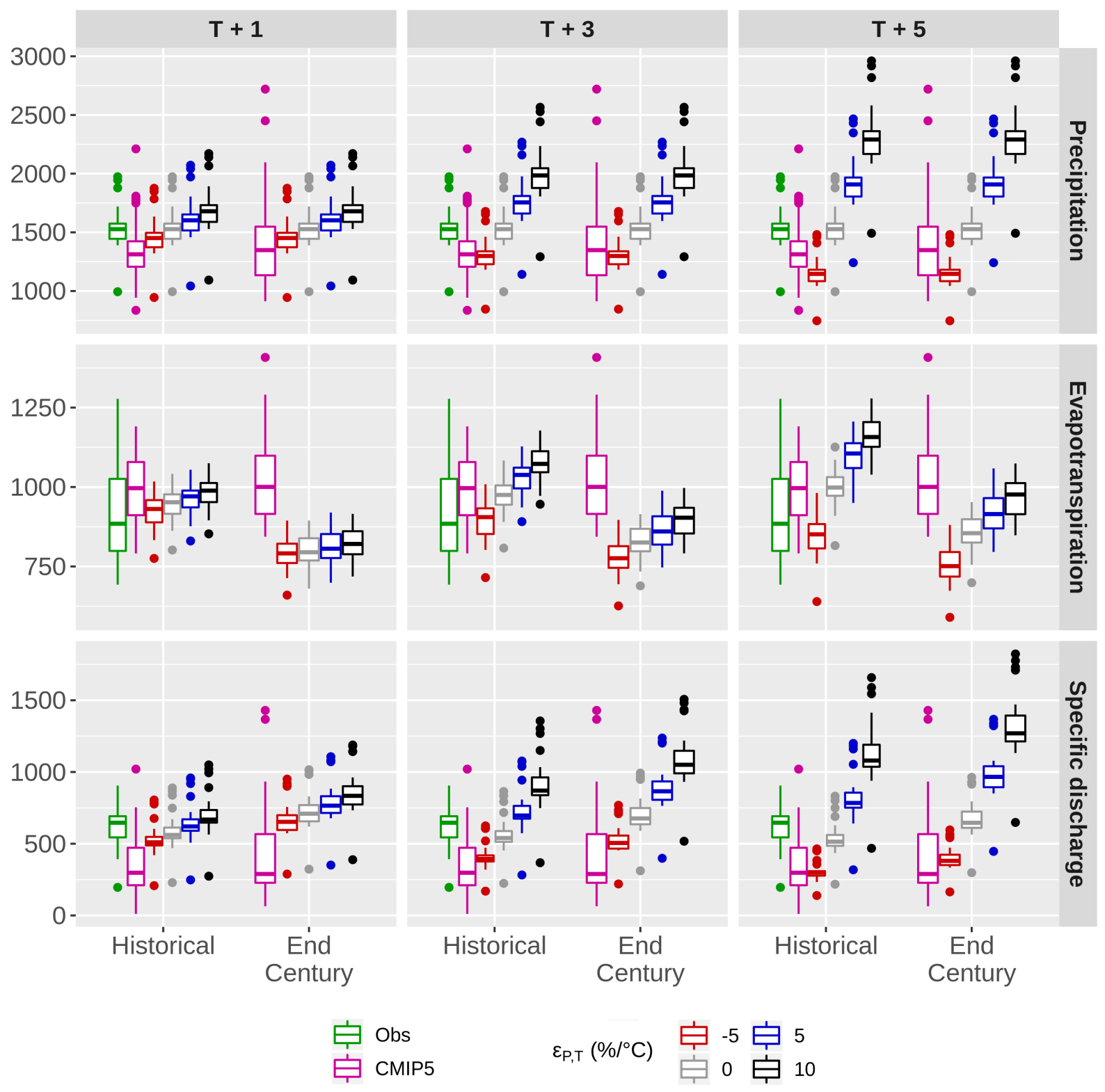

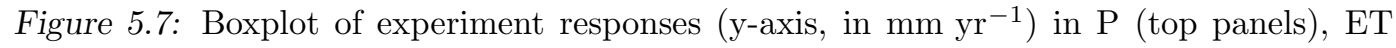
(middle panels) and $\mathrm{Q}$ (bottom panels), forced by: temperature increases (in ${ }^{\circ} \mathrm{C}$, columns), elasticity cases (in $\%{ }^{\circ} \mathrm{C}^{-1}$, colors), and $\mathrm{CO}_{2}$ concentration cases (historical and end century, $\mathrm{x}$-axis). Observed boxplots are shown in historical cases (green plots) and CMIP5 model outputs ensemble (pink plots) are displayed.

for the downstream area of the Jaguari/Jacareí reservoir, in order to avoid "floods and undesirable impacts" (ANA and DAEE, 2010).

To analyse the minima, Fig. 5.9-B presents a transformed x-axis to 100-exceedance probability, in \%. The same pattern of homogeneity around the probabilities was observed. Discharge had smaller changes below $1 \%$ probability for each experiment. The larger 


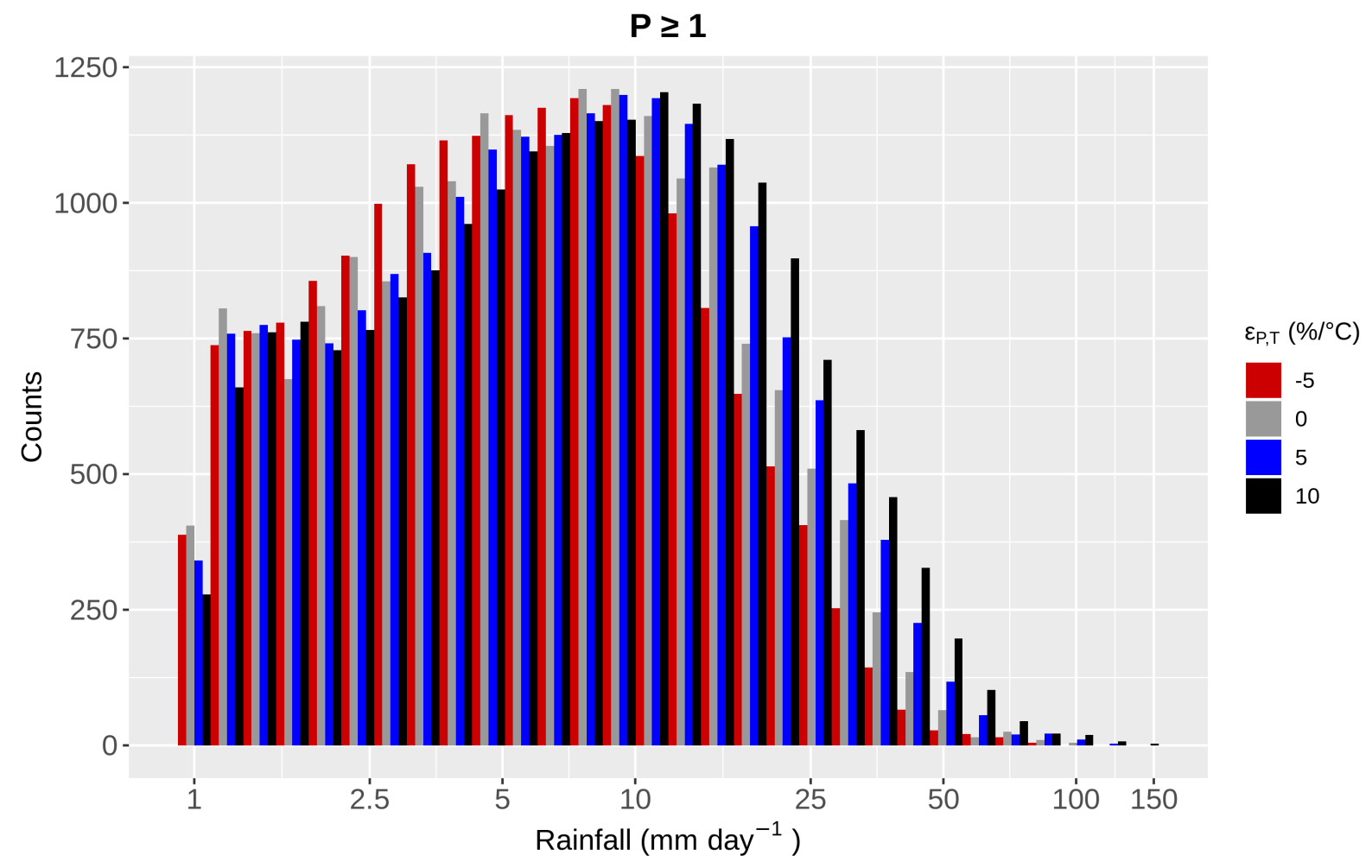

Figure 5.8: Histogram of daily precipitation, in $\mathrm{mm} \mathrm{d}^{-1}$, depicted by elasticity cases $\left(\%{ }^{\circ} \mathrm{C}^{-1}\right.$, colors $)$.

reduction was $29 \%$ with respect to control in the historical case, and $16 \%$ in the end century at a $5^{\circ} \mathrm{C}$ increase and $\epsilon_{P, T}=-5 \%{ }^{\circ} \mathrm{C}^{-1}$. The minima corresponded to 2014 simulated discharge in each experiment, and interestingly, even in the end century cases (Fig. 5.9$\mathrm{B}$, right panel), with an expected reduced ET due to stomatal conductance depletion, the magnitudes are of same order than observed that year. In other words, 2014 drought can be replicated in the future at similar magnitudes, especially with $\epsilon_{P, T}=-5$ and $0 \%{ }^{\circ} \mathrm{C}^{-1}$. On the other hand, the larger increases were in $\epsilon_{P, T}=10 \%{ }^{\circ} \mathrm{C}^{-1}$, up to $24 \%$. In comparison, considering $\epsilon_{P, T}=10 \%{ }^{\circ} \mathrm{C}^{-1}$ case, the increases in maximum discharge are much higher than in the minimum, and even than mean Q. It is possibly due to two factors: (1) the surface flow contribution to maximum discharge, which does not update soil moisture; (2) lateral flow domination over percolation. In summary, the response patterns in $\mathrm{Q}$ to the climatic perturbations were somewhat homogeneous along the probability classes, but the percentage changes in maxima are more expressive than in mean and minimum values, alerting to more numerous events of flood. 
A

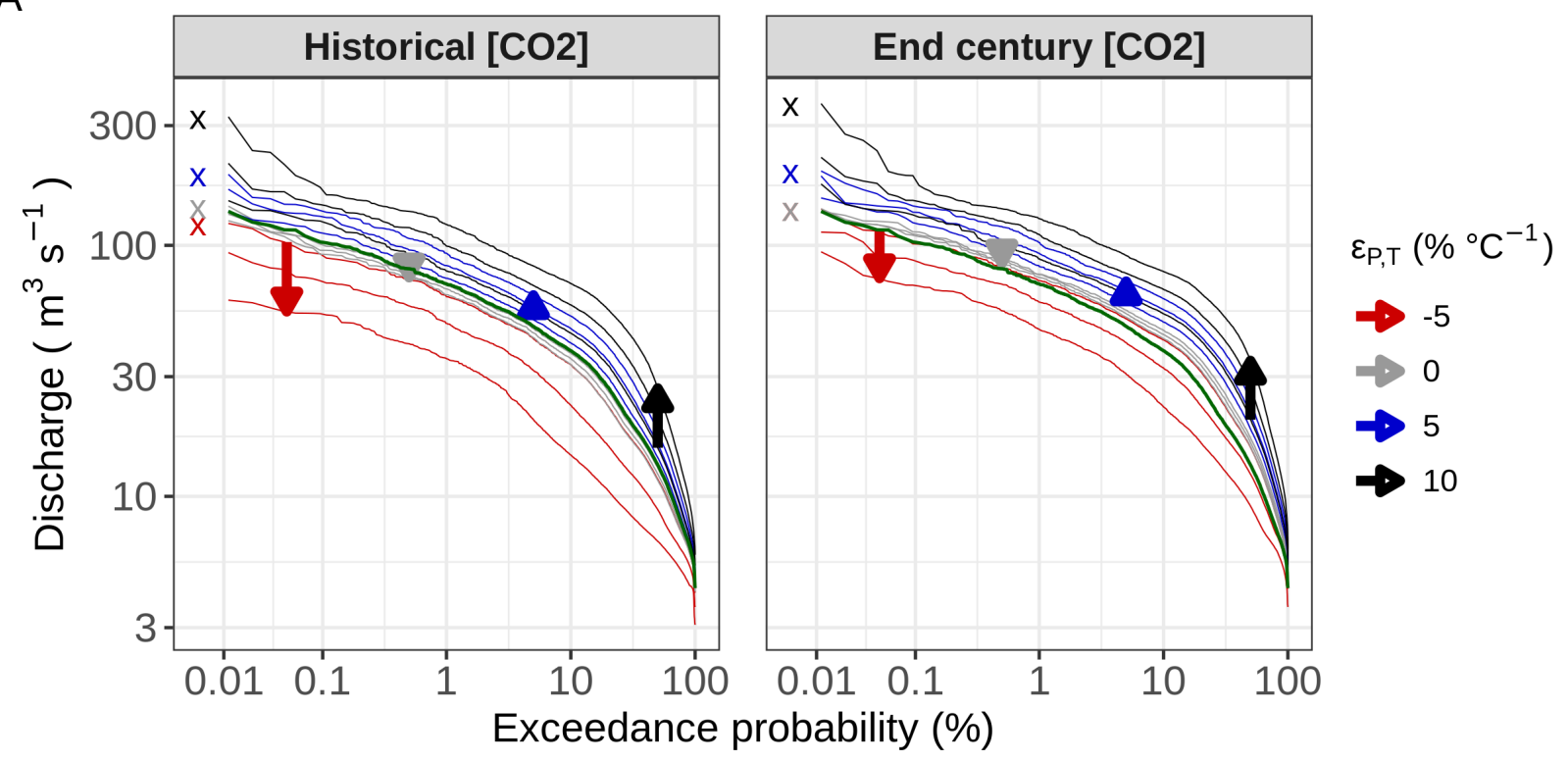

B

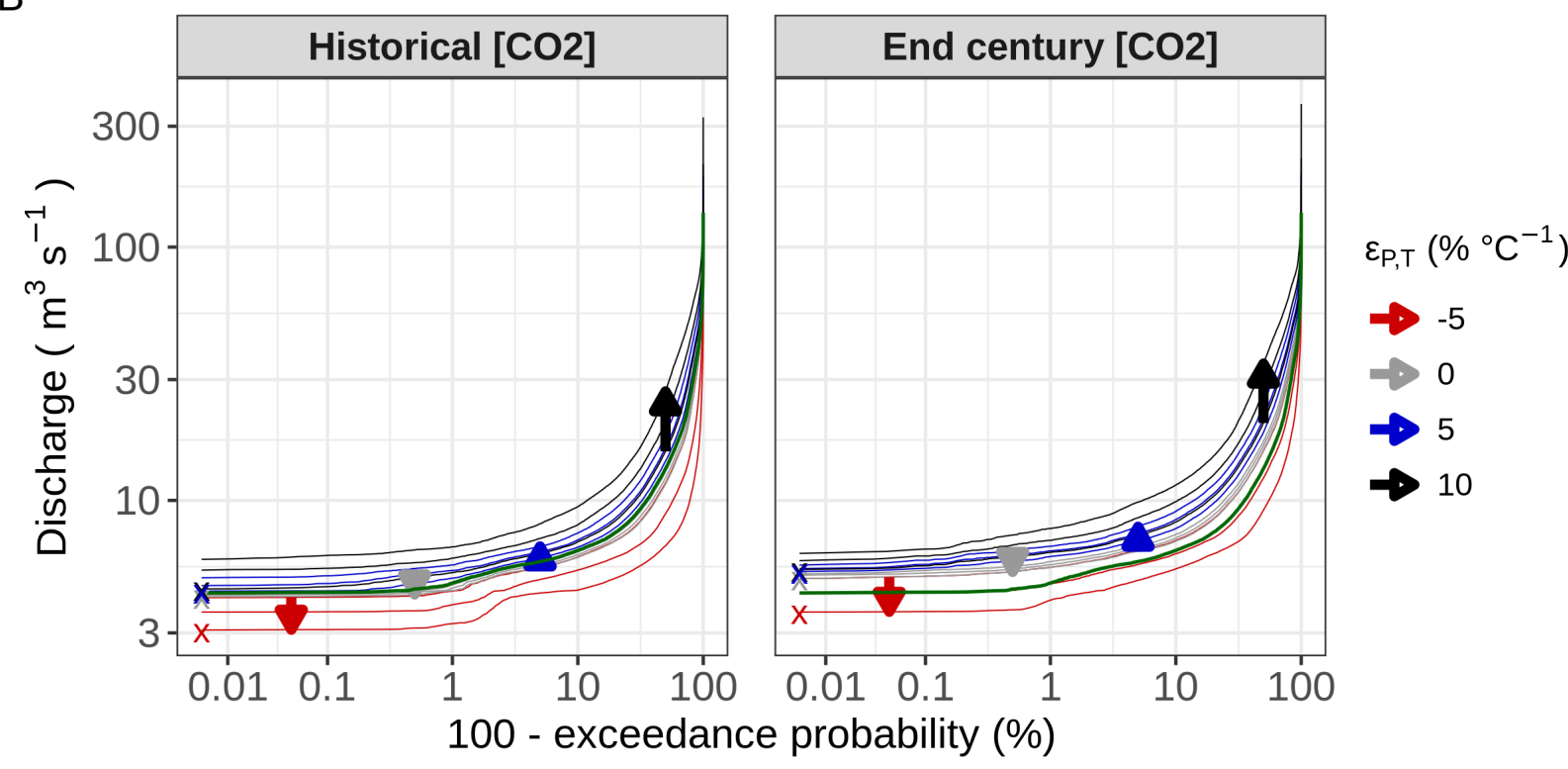

Figure 5.9: A. Flow duration curve of experiment discharges, in $\mathrm{m}^{3} \mathrm{~s}^{-1}$, forced by elasticity of precipitation to temperature $\epsilon_{P, T}$, in $\%{ }^{\circ} \mathrm{C}^{-1}$ (colors) and changes of $\mathrm{CO}_{2}$ concentration (historical in the left panels and end century in the right panels). The arrows point to the direction of increasing temperature $\left(1,3\right.$ and $\left.5^{\circ} \mathrm{C}\right)$ for each $\epsilon_{P, T}$ case. Thick green line depicts the control simulation. B. Idem to A, but with $\mathrm{x}$-axis transformed to 100 -exceedance probability, in \%. Log transformation is applied to values above 0.01 and linear extrapolation from 0.01 to 0 . Maximum and minimum values of distribution are marked as "X"above 0 . 
Chapter 6

\section{Conclusions}

We were concerned about a recent historical drought and spread water shortage that affected much of São Paulo city during 2014 to 2015, and envisaged to assess the impacts of climate change on the water budget of the main basin at the Cantareira reservoirs system, in an attempt to foresee the variability of future hydrological regime compared to the natural variability. We stress the concern to climate change in Southeast Brazil as there is significant expectation of temperature increase but very little consensus for changes in rainfall, that ultimately adds more uncertainty to the management of water resources.

Our methods essentially used climate forcings based on the whole and significant variability range of key climatic variables (temperature, rainfall, air humidity and $\mathrm{CO}_{2}$ concentration) predicted by all CMIP5 models for our domain of investigation, and searched for responses with simulations for the historical and future time using a thoroughly calibrated physically-based (SWAT) model. We chose a strategy that, firstly, tried to circumvent issues of common strategies that use hydrological modelling with only one or few climate projections, and that create uncertainties due to the coarse scale downscaling to different $\mathrm{CO}_{2}$ scenarios. Secondly, we attempted to investigate the particular control of each climatic variable on the variability of the water budget, to help responding our main question, where there is usually very little information.

The mean variability of P-ET provided by the set of CMIP5 models did not compare the observations as well as the calculated discharge with the SWAT model. Our strategy of calibration to approach and improve both evapotranspiration and discharge possibly helped the hydrological simulations at regional scale to succeed and improve over the estimates from global models.

In general, we found two main and opposite responses of possibilities in the future, if 
rainfall increases or decreases. With the temperature increase spanning from 1 to $5^{\circ} \mathrm{C}$, the chances with more rainfall showed that the evapotranspiration was about to increase up to $25 \%$ and discharge by $90 \%$. With less precipitation, evapotranspiration decreased up to about $10 \%$ and discharge to $50 \%$. Meanwhile, the $\mathrm{CO}_{2}$ concentration brought a strong effect on stomatal conductance that substantially helped to reduce the evapotranspiration in the future, and in turn to increase the discharge in near proportion. On the other hand, the particular roles of temperature and relative humidity alone on the biophysical processes were significant to augment evapotranspiration, of less than about 7 and $2 \%$ respectively, thus not so determining when compared to the rainfall and $\mathrm{CO}_{2}$ concentration.

The responses of extreme events were very pronounced. The maximum discharge more than doubled in the future with increasing rainfall. The minimum flow was reduced up to about $30 \%$ in case of less precipitation. However, the estimate of changes in maximum discharge is possibly a weakness of the experimental design. The high peaks of discharge in our subtropical region are caused, in general, by episodic intense rainfall on hourly basis and/or successive accumulation of a few rainy days, both of which being phenomena that were not exactly met on how precipitation was perturbed. The elasticity of precipitation to temperature was based on the mean states of the historical and future time slices, that did not account how more or less intense the daily precipitation episodes changed or not. We also see weakness in the assessment of changes in the minimum flow, though possibly minor. Whether in the future the frequency of droughts increases, or whether typical drought length increases, our strategy does not cope with either the two phenomena. Despite that, it is not uncommon in the tropics that above the average rainfall years are usually correlated with occurrence of high daily discharge events, and so the opposite for below the average years correlated with longer dry spells. Those were, in general, some limitations noted in our strategy, but they are believed not to be sufficient to penalize the overall arguments of the mean changes.

Regarding the minimum flow, the worst case scenario was addressed with the less precipitation forcing using the time series of 2014, due to the drought event, which presented a depletion of $29 \%$ with respect to control. Considering the impacts of such drought, and a scenario of increased population in the future, the addressed depletion in our experiments may lead to an enhanced vulnerability of water supply in an already critical area. We stress that, even under end century $\mathrm{CO}_{2}$ concentration, discharge levels close to 2014 are 
replicated.

The probability of increasing mean rainfall in the future was only slightly higher than to decrease. As a transdisciplinary advice to policy making for water resources management, these two directions seem well likely so far, and cautions to overcome the bad effects of either are to be investigated and planned in more detail.

\subsection{Suggestions for upcoming works}

We suggest the following tasks for upcoming works:

- Address the changes in the frequency of events and spatial heterogeneity, such as proposed by Kilsby et al. (2007) work using a weather generator model applied to climate projections;

- Use of rainfall interception module to improve ET partition terms;

- Implement a dynamical vegetation approach to account the effects of $\mathrm{CO}_{2}$ enrichment on LAI curve, which can counterpoint the impacts of reduced stomatal conductance on transpiration. Works such as Strauch and Volk (2013) already addressed an adapted model to Brazilian tropical Cerrado in SWAT, and could be used as starting point;

- Improve the spatial resolution of climate variables besides rainfall, especially temperature and humidity, using statistical models such as proposed by Martin et al. (2020) to evaluate topography effects on ET and Q;

- Assess the model uncertainty in calibration/validation (non-uniqueness parameters) along with the set of climate perturbations to improve the variability assessment;

- Address the land use change in the calibration and in the scenarios;

- Couple the hydrological model to a climate model in order to fully assess the interaction between surface and atmosphere under climate change. For instance, a scenario of reduced precipitation which generates higher rates of ET during a given time helps to increase the precipitable water in atmosphere, which in turn, can increase precipitation. 


\section{Bibliography}

Abbaspour, K. C., 2015: SWAT-CUP: SWAT Calibration and Uncertainty Programs A User Manual. Eawag, Dübendorf, Switzerland, URL http://swat.tamu.edu/media/ 114860/usermanual_swatcup.pdf, [Online; Accessed at 01/Jun/2017].

Agência Nacional de Águas - ANA, 2018: Hidroweb: Séries históricas de estações. URL https://www.snirh.gov.br/hidroweb/serieshistoricas, [Online; Accessed at $31 /$ Out $/ 2018]$.

Agência Nacional de Águas - ANA, Departamento de Águas e Energia Elétrica - DAEE, 2010: Dispõe sobre as condições de operação dos reservatórios do sistema cantareira no período de controle de cheias. Tech. rep. Resolução Conjunta ANA/DAEE n.614, de 09 de novembro de 2010 .

Agência Nacional de Águas - ANA, Departamento de Águas e Energia Elétrica - DAEE, 2015: Dados de referência acerca da outorga do Sistema Cantareira. V 1.1. Tech. rep. URL http://www.ana.gov.br/sala-de-situacao/sistema-cantareira/ documentos-2015/dados-de-referencia-12-06-2015.

Agência Nacional de Águas - ANA, Departamento de Águas e Energia Elétrica - DAEE, 2017: Dispõe sobre as condições de operação para o Sistema Cantareira - SC, delimitado, para os fins desta Resolução, como o conjunto dos reservatórios Jaguari-Jacareí, Cachoeira, Atibainha e paiva Castro. Tech. rep. URL https://arquivos.ana.gov.br/resolucoes/ 2017/925-2017.pdf, Resolução Conjunta ANA/DAEE n.925, de 29 de maio de 2017.

Ainsworth, E. A., and A. Rogers, 2007: The response of photosynthesis and stomatal conductance to rising $\left[\mathrm{CO}_{2}\right]$ : mechanisms and environmental interactions. 
Plant, Cell \& Environment, 30 (3), 258-270, doi:10.1111/j.1365-3040.2007.01641.x, URL https://onlinelibrary.wiley.com/doi/abs/10.1111/j.1365-3040.2007.01641.x, https: //onlinelibrary.wiley.com/doi/pdf/10.1111/j.1365-3040.2007.01641.x.

Alaska Satellite Facility Distributed Active Archive Center - ASF DAAC, 2015: ALOS PALSAR Radiometric Terrain Corrected low res. URL 10.5067/JBYK3J6HFSVF, [Online; Accessed at 30/Apr/2018].

Andréassian, V., L. Coron, J. Lerat, and N. Le Moine, 2016: Climate elasticity of streamflow revisited - an elasticity index based on long-term hydrometeorological records. $H y$ drology and Earth System Sciences, 20 (11), 4503-4524, doi:10.5194/hess-20-4503-2016, URL https://www.hydrol-earth-syst-sci.net/20/4503/2016/.

Arnell, N. W., 2011: Uncertainty in the relationship between climate forcing and hydrological response in uk catchments. Hydrology and Earth System Sciences, 15 (3), 897-912, doi:10.5194/hess-15-897-2011, URL https://www.hydrol-earth-syst-sci.net/ $15 / 897 / 2011 /$.

Betts, R. A., and Coauthors, 2007: Projected increase in continental runoff due to plant responses to increasing carbon dioxide. Nature, 448, 1037-1041, doi:10.1038/nature06045, https://doi.org/10.1038/nature06045.

Beven, K., and J. Freer, 2001: Equifinality, data assimilation, and uncertainty estimation in mechanistic modelling of complex environmental systems using the glue methodology. Journal of Hydrology, 249 (1), 11 - 29, doi:https://doi.org/10.1016/S0022-1694(01) 00421-8, URL http://www.sciencedirect.com/science/article/pii/S0022169401004218.

Byrne, M. P., and P. A. O'Gorman, 2016: Understanding decreases in land relative humidity with global warming: Conceptual model and GCM simulations. Journal of Climate, 29 (24), 9045-9061, doi:10.1175/JCLI-D-16-0351.1, URL https://doi.org/10. 1175/JCLI-D-16-0351.1, https://doi.org/10.1175/JCLI-D-16-0351.1.

Centro Nacional de Monitoramento e Alertas de Desastres Naturais - CEMADEN, 2018: Mapa interativo: Estações pluviométricas. URL http://www.cemaden.gov.br/ mapainterativo/, [Online; Accessed at 31/Out/2018]. 
Coelho, C. A. S., and Coauthors, 2016: The 2014 southeast Brazil austral summer drought: regional scale mechanisms and teleconnections. Climate Dynamics, 46 (11-12), 3737-3752, doi:10.1007/s00382-015-2800-1, URL http://dx.doi.org/10. 1007/s00382-015-2800-1.

Collins, M., and Coauthors, 2013: Long-term climate change: Projections, commitments and irreversibility. Climate Change 2013: The Physical Science Basis. Contribution of Working Group I to the Fifth Assessment Report of the Intergovernmental Panel on Climate Change, T. F. Stocker, D. Qin, G.-K. Plattner, M. Tignor, S. K. Allen, J. Doschung, A. Nauels, Y. Xia, V. Bex, and P. M. Midgley, Eds., Cambridge University Press, Cambridge, UK, 1029-1136, doi:10.1017/CBO9781107415324.024.

Companhia de Saneamento Básico do Estado de São Paulo - SABESP, 2018: Série histórica de dados pluviométricos e fluviométricos. URL http://mananciais.sabesp.com. br/HistoricoSistemas?SistemaId=0, [Online; Accessed at Jun, 01, 2018].

Companhia de Saneamento Básico do Estado de São Paulo - SABESP, 2020: Dados dos sistemas produtores. URL http://mananciais.sabesp.com.br/HistoricoSistemas/, [Online; Accessed at Jun, 08, 2020].

Companhia de Saneamento Básico do Estado de São Paulo - SABESP, 2021: Situação dos mananciais. URL http://mananciais.sabesp.com.br/Situacao, [Online; Accessed at Jan, 02, 2021].

da Rocha, H. R., and L. M. Domingues, 2017: Efeitos da seca de 2013/2014 no sistema cantareira: Uma breve revisão. Governança da Água no Contexto da Escassez Hídrica., P. R. Jacobi, A. P. Fracalanza, and V. Empinotti, Eds., IEE-USP, UFABC, GovAmb, São Paulo, 19-29.

da Rocha, H. R., and Coauthors, 2009: Patterns of water and heat flux across a biome gradient from tropical forest to savanna in Brazil. Journal of Geophysical Research, 114, G00B12, doi:10.1029/2007JG000640, URL http://doi.wiley.com/10.1029/ 2007JG000640.

de Abreu, R.C., da Rocha, H.R., et al., in prep: Change in mean climate and precipitation extremes in Southeast Brazil under climate change conditions. 
Dee, D. P., and Coauthors, 2011: The ERA-Interim reanalysis: Configuration and performance of the data assimilation system. Quarterly Journal of the Royal Meteorological Society, 137 (656), 553-597, doi:10.1002/qj.828.

Deusdará-Leal, K., and Coauthors, 2020: Implications of the new operational rules for cantareira water system: Re-reading the 2014-2016 water crisis. Journal of Water Resource and Protection, 12, 261 - 274, doi:10.4236/jwarp.2020.124016, URL http: //www.sciencedirect.com/science/article/pii/S0921800917300587.

Di Baldassarre, G., and Coauthors, 2011: Future hydrology and climate in the River Nile basin: a review. Hydrological Sciences Journal, 56 (2), 199-211, doi:10.1080/02626667. 2011.557378, URL https://doi.org/10.1080/02626667.2011.557378, https://doi.org/10. 1080/02626667.2011.557378.

Dirmeyer, P. A., X. Gao, M. Zhao, Z. Guo, T. Oki, and N. Hanasaki, 2006: GSWP-2: Multimodel Analysis and Implications for Our Perception of the Land Surface. Bulletin of the American Meteorological Society, 87 (10), 1381-1397, doi:10.1175/BAMS-87-10-1381, URL http://journals.ametsoc.org/doi/abs/10.1175/BAMS-87-10-1381.

Döll, P., T. Trautmann, D. Gerten, H. M. Schmied, S. Ostberg, F. Saaed, and C.-F. Schleussner, 2018: Risks for the global freshwater system at $1.5^{\circ} \mathrm{C}$ and $2{ }^{\circ} \mathrm{C}$ global warming. Environmental Research Letters, 13 (4), 044 038, doi:10.1088/1748-9326/aab792, URL https://doi.org/10.1088\%2F1748-9326\%2Faab792.

Domingues, L. M., 2014: O balanço de água superficial no Brasil calculado com o modelo SiB2-Regional: padrões médios e sensibilidade a eventos de aquecimento e seca. M.S. thesis, Instituto de Astronomia, Geofísica e Ciências Atmosféricas, Universidade de São Paulo, 106 pp., Brazil.

Easterling, W. E., N. J. Rosenberg, M. S. McKenney, C. A. Jones, P. T. Dyke, and J. Williams, 1992: Preparing the erosion productivity impact calculator (EPIC) model to simulate crop response to climate change and the direct effects of $\mathrm{CO}_{2}$. Agricultural and Forest Meteorology, 59 (1), 17 - 34, doi:https://doi.org/10.1016/0168-1923(92)90084-H, URL http://www.sciencedirect.com/science/article/pii/016819239290084H, a methododlogy for assessing regional agricultural consequences of climate change: Application Missouri-Iowa-Nebraska-Kansas (Mink) region. 
Escobar, H., 2015: Drought triggers alarms in Brazil's biggest metropolis. Science, 347, 812, doi:10.1126/science.347.6224.812.

Fowler, H. J., S. Blenkinsop, and C. Tebaldi, 2007: Linking climate change modelling to impacts studies: recent advances in downscaling techniques for hydrological modelling. International Journal of Climatology, 27 (12), 1547-1578, doi:10.1002/ joc.1556, URL https://rmets.onlinelibrary.wiley.com/doi/abs/10.1002/joc.1556, https: //rmets.onlinelibrary.wiley.com/doi/pdf/10.1002/joc.1556.

Franks, P. J., and Coauthors, 2013: Sensitivity of plants to changing atmospheric $\mathrm{CO}_{2}$ concentration: from the geological past to the next century. New Phytologist, 197 (4), 1077-1094, doi:10.1111/nph.12104, URL https://nph.onlinelibrary.wiley.com/doi/abs/ 10.1111/nph.12104, https://nph.onlinelibrary.wiley.com/doi/pdf/10.1111/nph.12104.

Gassman, P. W., M. R. Reyes, C. H. Green, and J. G. Arnold, 2007: The Soil and Water Assessment Tool : historical development, applications, and future research directions. Transactions of the ASAE, 50 (4), 1211-1250, doi:10.1.1.88.6554, URL http://publications.iowa.gov/archive/00005419/01/paper\{_\}12744.pdf.

Gesualdo, G. C., P. T. Oliveira, D. B. B. Rodrigues, and H. V. Gupta, 2019: Assessing water security in the São Paulo metropolitan region under projected climate change. $H y$ drology and Earth System Sciences, 23 (12), 4955-4968, doi:10.5194/hess-23-4955-2019, URL https://hess.copernicus.org/articles/23/4955/2019/.

Guo, D., S. Westra, and H. R. Maier, 2017: Sensitivity of potential evapotranspiration to changes in climate variables for different Australian climatic zones. Hydrology and Earth System Sciences, 21 (4), 2107-2126, doi:10.5194/hess-21-2107-2017, URL https: //www.hydrol-earth-syst-sci.net/21/2107/2017/.

Habermann, E., J. A. B. S. Martin, D. R. Contin, V. P. Bossan, A. Barboza, M. R. B. Braga, M. Groppo, and C. A. Martinez, 2019: Increasing atmospheric $\mathrm{CO}_{2}$ and canopy temperature induces anatomical and physiological changes in leaves of the $\mathrm{C} 4$ forage species Panicum maximum. PLoS ONE, 14.

Held, I. M., and B. J. Soden, 2006: Robust Responses of the Hydrological Cycle to Global Warming. Journal of Climate, 19 (21), 5686-5699, doi:10.1175/JCLI3990.1, URL 
https://doi.org/10.1175/JCLI3990.1， https://journals.ametsoc.org/jcli/article-pdf/19/ 21/5686/3800493/jcli3990_1.pdf.

Henriques, E. F., 2019: Padrões hidroclimatológicos de bacias de mesoescala em São Paulo. M.S. thesis, Instituto de Astronomia, Geofísica e Ciências Atmosféricas, Universidade de São Paulo, 159 pp., URL https://www.teses.usp.br/teses/disponiveis/14/ 14133/tde-18042020-094417/publico/relatorio.pdf.

Her, Y., S.-H. Yoo, J. Cho, S. Hwang, J. Jeong, and C. Seong, 2019: Uncertainty in hydrological analysis of climate change: multi-parameter vs. multi-GCM ensemble predictions. Scientific Reports, 9 (4974), doi:https://doi.org/10.1038/s41598-019-41334-7.

Instituto Brasileiro de Geografia e Estatística - IBGE, 2015: Arquivo vetorial de cobertura e uso da terra do Brasil para o ano de 2012. URL ftp://geoftp.ibge.gov.br/ mapas_tematicos/mapas_murais/shapes/cobertura_e_uso_da_terra.

Jensen, M., R. D. Burman, and R. G. Allen, 1990: Evapotranspiration and irrigation water requirements. ASCE Manuals and Reports on Engineering Practice No. 70, ASCE, New York, USA.

Kelman, J., 2015: Water supply to the two largest brazilian metropolitan regions. Aquatic Procedia, 5, 13 - 21, doi:https://doi.org/10.1016/j.aqpro.2015.10.004, URL http://www. sciencedirect.com/science/article/pii/S2214241X15002825, at the Confluence Selection from the 2014 World Water Week in Stockholm.

Kilsby, C., and Coauthors, 2007: A daily weather generator for use in climate change studies. Environmental Modelling \& Software, 22 (12), 1705 - 1719, doi:https://doi. org/10.1016/j.envsoft.2007.02.005, URL http://www.sciencedirect.com/science/article/ pii/S136481520700031X.

Krause, P., D. P. Boyle, and F. Bäse, 2005: Comparison of different efficiency criteria for hydrological model assessment. Advances in Geosciences, 5, 89-97, doi: 10.5194/adgeo-5-89-2005, URL https://www.adv-geosci.net/5/89/2005/.

Leavesley, G., 1994: Modeling the effects of climate change on water resources - a review. Climatic Change, 28, 159-177, doi:10.1007/BF01094105. 
Liu, J., Q. Zhang, Y. Zhang, X. Chen, J. Li, and S. K. Aryal, 2017: Deducing climatic elasticity to assess projected climate change impacts on streamflow change across China. Journal of Geophysical Research: Atmospheres, 122 (19), 10,22810,245, doi:10.1002/2017JD026701, URL https://agupubs.onlinelibrary.wiley.com/doi/ abs/10.1002/2017JD026701, https://agupubs.onlinelibrary.wiley.com/doi/pdf/10.1002/ 2017JD026701.

Liu, W., L. Wang, J. Zhou, Y. Li, F. Sun, G. Fu, X. Li, and Y.-F. Sang, 2016: A worldwide evaluation of basin-scale evapotranspiration estimates against the water balance method. Journal of Hydrology, 538, 82 - 95, doi:https://doi.org/10.1016/j.jhydrol.2016.04.006, URL http://www.sciencedirect.com/science/article/pii/S0022169416301871.

Loan, P. G., and I. D. Moore, 1984: Modeling Subsurface Stormflow on Steeply Sloping Forested Watersheds. Water Resources Research, 20 (12), 1815-1822.

Lockwood, J., 1999: Is Potential Evapotranspiration and Its Relationship with Actual Evapotranspiration Sensitive to Elevated Atmospheric $\mathrm{CO}_{2}$ Levels? Climatic Change, 41, 193-212, doi:https://doi.org/10.1023/A:1005469416067.

Magliano, P. N., R. Giménez, J. Houspanossian, R. A. Páez, M. D. Nosetto, R. J. Fernández, and E. G. Jobbágy, 2017: Litter is more effective than forest canopy reducing soil evaporation in Dry Chaco rangelands. Ecohydrology, 10 (7), e1879, doi:10.1002/eco.1879, URL https://onlinelibrary.wiley.com/doi/abs/10.1002/eco.1879, e1879 ECO-17-0049.R1, https://onlinelibrary.wiley.com/doi/pdf/10.1002/eco.1879.

Magrin, G. O., J. A. Marengo, J.-P. Boulanger, M. S. Buckeridge, E. Castellanos, G. Poveda, and V. Scarano, 2014: Central and south america. Climate Change 2014: Impacts, Adaptation, and Vulnerability. Part B: Regional Aspects. Contribution of Working Group II to the Fifth Assessment Report of the Intergovernmental Panel on Climate Change, V. Barros, C. Field, D. Dokken, M. Mastrandrea, K. Mach, T. Bilir, M. Chatterjee, K. Ebi, Y. Estrada, R. Genova, B. Girma, E. Kissel, A. Levy, S. MacCracken, P. Mastrandrea, and L. White, Eds., Cambridge University Press, Cambridge, United Kingdom and New York, NY, USA, 1499-1566.

Marthews, T., D. Burslem, S. Paton, F. Yangüez, and C. Mullins, 2008: Soil drying in a tropical forest: Three distinct environments controlled by gap size. Ecological Modelling, 
216 (3), 369 - 384, doi:https://doi.org/10.1016/j.ecolmodel.2008.05.011, URL http:// www.sciencedirect.com/science/article/pii/S0304380008002317.

Martin, T. C., H. R. Rocha, and G. M. P. Perez, 2020: Fine scale surface climate in complex terrain using machine learning. International Journal of Climatology, 1-18, doi:10.1002/joc.6617, URL https://rmets.onlinelibrary.wiley.com/doi/abs/10.1002/joc. 6617, https://rmets.onlinelibrary.wiley.com/doi/pdf/10.1002/joc.6617.

Milano, M., E. Reynard, G. Muniz-Miranda, and J. Guerrin, 2018: Water supply basins of São Paulo Metropolitan Region: Hydro-climatic characteristics of the 2013-2015 water crisis. Water, 10 (11), 1-19.

Millington, N., 2018: Producing water scarcity in São Paulo, Brazil: The 2014-2015 water crisis and the binding politics of infrastructure. Political Geography, 65, 26 - 34, doi:https://doi.org/10.1016/j.polgeo.2018.04.007, URL http://www.sciencedirect.com/ science/article/pii/S0962629817301452.

Milly, P., and K. Dunne, 2016: Potential evapotranspiration and continental drying. Nature Climate Change, 6, 946-949, doi:https://doi.org/10.1038/nclimate3046.

Miralles, D. G., T. R. H. Holmes, R. A. M. De Jeu, J. H. Gash, A. G. C. A. Meesters, and A. J. Dolman, 2011: Global land-surface evaporation estimated from satellite-based observations. Hydrology and Earth System Sciences, 15 (2), 453-469, doi: 10.5194/hess-15-453-2011, URL http://www.hydrol-earth-syst-sci.net/15/453/2011/.

Mohor, G. S., and E. M. Mendiondo, 2017: Economic indicators of hydrologic drought insurance under water demand and climate change scenarios in a Brazilian context. Ecological Economics, 140, 66 - 78, doi:https://doi.org/10.1016/j.ecolecon.2017.04.014, URL http://www.sciencedirect.com/science/article/pii/S0921800917300587.

Moriasi, D. N., M. W. Gitau, N. Pai, and P. Daggupati, 2015: Hydrologic and Water Quality Models: Performance Measures and Evaluation Criteria. Transactions of the ASABE, 58 (6), 1763-1785, doi:10.13031/trans.58.10715.

Mota da Silva, J., 2013: O serviço ambiental hidrológico das áreas de proteção permanente: um estudo de caso com modelagem numérica em pequena e mesoescala na bacia do Rio 
Piracicaba. Ph.D. thesis, Universidade de São Paulo, 100 pp., URL http://www.teses. usp.br/teses/disponiveis/14/14133/tde-11052014-114604/en.php.

Mu, Q., M. Zhao, and S. W. Running, 2011: Improvements to a modis global terrestrial evapotranspiration algorithm. Remote Sensing of Environment, 115 (8), 1781 - 1800, doi: https://doi.org/10.1016/j.rse.2011.02.019, URL http://www.sciencedirect.com/science/ article/pii/S0034425711000691.

Nakicenovic, N., J. Alcamo, A. Grubler, K. Riahi, R. Roehrl, H.-H. Rogner, and N. Victor, 2000: Special Report on Emissions Scenarios (SRES), A Special Report of Working Group III of the Intergovernmental Panel on Climate Change. Cambridge University Press, Cambridge.

Nash, J., and J. Sutcliffe, 1970: River flow forecasting through conceptual models part I a discussion of principles. Journal of Hydrology, 10 (3), 282 - 290, doi:https://doi.org/ 10.1016/0022-1694(70)90255-6, URL http://www.sciencedirect.com/science/article/pii/ 0022169470902556.

Neitsch, S., J. Arnold, J. Kiniry, and J. Williams, 2011: Soil \& Water Assessment Tool Theoretical Documentation Version 2009. Texas Water Resources Institute, 1-647, doi: 10.1016/j.scitotenv.2015.11.063.

Nobre, C. A., J. A. Marengo, M. E. Seluchi, L. A. Cuartas, and L. M. Alves, 2016: Some characteristics and impacts of the drought and water crisis in southeastern brazil during 2014 and 2015. Journal of Water Resource and Protection, 08, 252-262.

Otto, F. E. L., and Coauthors, 2016: Factors Other Than Climate Change, Main Drivers of 2014/15 Water Shortage in Southeast Brazil. Bulletin of the American Meteorological Society, 96 (12), S35-S40, doi:10.1175/BAMS-D-15-00120.1, URL https://doi.org/10. 1175/BAMS-D-15-00120.1, https://journals.ametsoc.org/bams/article-pdf/96/12/S35/ 3748899/bams-d-15-00120_1.pdf.

Pebesma, E. J., 2004: Multivariable geostatistics in s: the gstat package. Computers $\mathcal{E}$ Geosciences, 30 (7), 683 - 691, doi:https://doi.org/10.1016/j.cageo.2004.03.012, URL http://www.sciencedirect.com/science/article/pii/S0098300404000676. 
Pontes, L. M., M. R. Viola, M. L. N. Silva, D. F. A. Bispo, and N. Curi, 2016: Hydrological modeling of tributaries of Cantareira System, Southeast Brazil, with the SWAT model. Eng. Agríc., 4430 (6), 1037-1049, doi:10.1590/1809-4430-Eng.Agric.v36n6p1037-1049/ 2016, URL http://dx.doi.org/10.1590/1809-4430-Eng.Agric.v36n6p1037-1049/2016.

Prudhomme, C., and Coauthors, 2014: Hydrological droughts in the 21st century, hotspots and uncertainties from a global multimodel ensemble experiment. Proceedings of the National Academy of Sciences, 111 (9), 3262-3267, doi:10.1073/pnas.1222473110, URL https://www.pnas.org/content/111/9/3262, https://www.pnas.org/content/111/ 9/3262.full.pdf.

Purcell, C., S. P. Batke, C. Yiotis, R. Caballero, W. K. Soh, M. Murray, and J. C. Mcelwain, 2018: Increasing stomatal conductance in response to rising atmospheric $\mathrm{CO}_{2}$. Annals of Botany, 121, 1137-1149, doi:10.1093/aob/mcx208.

R Core Team, 2013: R: A Language and Environment for Statistical Computing. Vienna, Austria, R Foundation for Statistical Computing, URL http://www.R-project.org/.

Rafee, S. A. A., C. B. Uvo, J. A. Martins, L. M. Domingues, A. P. Rudke, T. Fujita, and E. D. Freitas, 2019: Large-Scale Hydrological Modelling of the Upper Paraná River Basin. Water, 11 (5).

Raftery, A., A. Zimmer, D. Frierson, R. Startz, and P. Liu, 2017: Less than $2^{\circ} \mathrm{C}$ warming by 2100 unlikely. Nature Clim Change, 7, 637-641, doi:https://doi.org/10.1038/ nclimate3352.

Randall, D. A., and Coauthors, 2007: Climate models and their evaluation. Climate Change 200\%: The Physical Science Basis. Contribution of Working Group I to the Fourth Assessment Report of the Intergovernmental Panel on Climate Change, S. Solomon, D. Qin, M. Manning, Z. Chen, M. Marquis, K. Averyt, T. Tignor, and H. Miller, Eds., Cambridge University Press, Cambridge, United Kingdom and New York, NY, USA.

Riahi, K., and Coauthors, 2017: The shared socioeconomic pathways and their energy, land use, and greenhouse gas emissions implications: An overview. Global Environmental Change, 42, 153 - 168, doi:https://doi.org/10.1016/j.gloenvcha.2016.05.009, URL http: //www.sciencedirect.com/science/article/pii/S0959378016300681. 
Save, H., S. Bettadpur, and B. D. Tapley, 2016: High-resolution CSR GRACE RL05 Mascons. Journal of Geophysical Research: Solid Earth, 121 (10), $7547-$ 7569, doi:10.1002/2016JB013007, URL https://agupubs.onlinelibrary.wiley.com/doi/ abs/10.1002/2016JB013007, https://agupubs.onlinelibrary.wiley.com/doi/pdf/10.1002/ 2016JB013007.

Schürz, C., 2019: SWATplusR: Running SWAT2012 and SWAT+ Projects in R. doi:10. 5281/zenodo.3373859, URL https://github.com/chrisschuerz/SWATplusR, R package version 0.2.7.

SCS, 1972: Section 4 Hydrology. National Engineering Handbook, USDA Soil Conservation Service, Washington, USA.

Stocker, T., and Coauthors, 2013: Technical summary. Climate Change 2013: The Physical Science Basis. Contribution of Working Group I to the Fifth Assessment Report of the Intergovernmental Panel on Climate Change, T. Stocker, D. Qin, G.K. Plattner, M. Tignor, S. Allen, J. Boschung, A. Nauels, Y. Xia, V. Bex, and P. Midgley, Eds., Cambridge University Press, Cambridge, United Kingdom and New York, NY, USA, book section TS, 33-115, doi:10.1017/CBO9781107415324.005, URL www.climatechange2013.org.

Stockle, C. O., J. R. Williams, N. J. Rosenberg, and C. Jones, 1992: A method for estimating the direct and climatic effects of rising atmospheric carbon dioxide on growth and yield of crops: Part I-Modification of the EPIC model for climate change analysis. Agricultural Systems, 38 (3), 225 - 238, doi:https://doi.org/10.1016/0308-521X(92)90067-X, URL http://www.sciencedirect.com/science/article/pii/0308521X9290067X.

Strauch, M., and M. Volk, 2013: SWAT plant growth modification for improved modeling of perennial vegetation in the tropics. Ecological Modelling, 269, 98-112, doi:10.1016/j. ecolmodel.2013.08.013, URL http://dx.doi.org/10.1016/j.ecolmodel.2013.08.013.

Taffarello, D., G. S. Mohor, M. do Carmo Calijuri, and E. M. Mendiondo, 2016: Field investigations of the 2013-14 drought through quali-quantitative freshwater monitoring at the headwaters of the Cantareira System, Brazil. Water International, 41 (5), 776800, doi:10.1080/02508060.2016.1188352, URL https://doi.org/10.1080/02508060.2016. 1188352, https://doi.org/10.1080/02508060.2016.1188352. 
Taffarello, D., R. Srinivasan, G. S. Mohor, J. L. B. Guimarães, M. do Carmo Calijuri, and E. M. Mendiondo, 2018: Modeling freshwater quality scenarios with ecosystembased adaptation in the headwaters of the Cantareira system, Brazil. Hydrology and Earth System Sciences, 22 (9), 4699-4723, doi:10.5194/hess-22-4699-2018, URL https: //hess.copernicus.org/articles/22/4699/2018/.

Taylor, K. E., R. J. Stouffer, and G. A. Meehl, 2012: An Overview of CMIP5 and the Experiment Design. Bulletin of the American Meteorological Society, 93 (4), 485-498, doi:10. 1175/BAMS-D-11-00094.1, URL https://doi.org/10.1175/BAMS-D-11-00094.1, https: //journals.ametsoc.org/bams/article-pdf/93/4/485/3739006/bams-d-11-00094_1.pdf.

Teng, J., F. H. S. Chiew, J. Vaze, S. Marvanek, and D. G. C. Kirono, 2012: Estimation of Climate Change Impact on Mean Annual Runoff across Continental Australia Using Budyko and Fu Equations and Hydrological Models. Journal of Hydrometeorology, 13 (3), 1094-1106, doi:10.1175/JHM-D-11-097.1, URL https:// doi.org/10.1175/JHM-D-11-097.1, https://journals.ametsoc.org/jhm/article-pdf/13/3/ 1094/4112015/jhm-d-11-097_1.pdf.

Thoning, K., A. Crotwell, and J. Mund, 2020: Atmospheric Carbon Dioxide Dry Air Mole Fractions from continuous measurements at Mauna Loa, Hawaii, Barrow, Alaska, American Samoa and South Pole. 1973-2019. National Oceanic and Atmospheric Administration (NOAA), Global Monitoring Laboratory (GML), Boulder, Colorado, USA, doi:https://doi.org/10.15138/yaf1-bk21.

Tundisi, J. G., and T. M. Tundisi, 2015: As múltiplas dimensões da crise hídrica. Revista USP, São Paulo, URL https://www.revistas.usp.br/revusp/article/view/109780/ 108286

Universidade Federal de Viçosa - UFV, Fundação Centro Tecnológico de Minas Gerais - CETEC, Universidade Federal de Lavras - UFLA, Fundação Estadual do Meio Ambiente - FEAM, 2010: Mapa de solos do estado de Minas Gerais. URL http://www. feam.br/noticias/1/949-mapas-de-solo-do-estado-de-minas-gerais, online; Accessed at $15 / \mathrm{Apr} / 2018$.

van Vuuren, D. P., and Coauthors, 2011: The representative concentration pathways : an overview. Climatic Change, 109, 5-31, doi:10.1007/s10584-011-0148-z. 
Vecchi, G. A., and B. J. Soden, 2007: Global Warming and the Weakening of the Tropical Circulation. Journal of Climate, 20 (17), 4316-4340, doi:10.1175/JCLI4258.1, URL https://doi.org/10.1175/JCLI4258.1, https://journals.ametsoc.org/jcli/article-pdf/20/ 17/4316/3936675/jcli4258_1.pdf.

Whately, M., and P. Cunha, 2007: Cantareira 2006 - Um olhar sobre o maior manancial de água da Região Metropolitana de São Paulo. Resultados do Diagnóstico Socioambiental Participativo do Sistema Cantareira. Instituto Socioambiental, São Paulo.

Wilby, R. L., and I. Harris, 2006: A framework for assessing uncertainties in climate change impacts: Low-flow scenarios for the River Thames, UK. Water Resources Research, 42 (2), doi:10.1029/2005WR004065, URL https://agupubs.onlinelibrary.wiley.com/ doi/abs/10.1029/2005WR004065, https://agupubs.onlinelibrary.wiley.com/doi/pdf/10. 1029/2005WR004065.

Xu, C., 1999: Climate change and hydrologic models: A review of existing gaps and recent research developments. Water Resources Management, 13, 369-392, doi:https: //doi.org/10.1023/A:1008190900459.

Xu, C., E. Widén, and S. Halldin, 2005: Modelling hydrological consequences of climate change - progress and challenges. Adv. Atmos. Sci, 22, 789-797, doi:https://doi.org/10. 1007/BF02918679.

Xu, H., R. G. Taylor, and Y. Xu, 2011: Quantifying uncertainty in the impacts of climate change on river discharge in sub-catchments of the yangtze and yellow river basins, china. Hydrology and Earth System Sciences, 15 (1), 333-344, doi:10.5194/hess-15-333-2011, URL https://www.hydrol-earth-syst-sci.net/15/333/2011/.

Zhang, K., J. S. Kimball, R. R. Nemani, and S. W. Running, 2010: A continuous satellite-derived global record of land surface evapotranspiration from 1983 to 2006. Water Resources Research, 46 (9), doi:10.1029/2009WR008800, URL https: //agupubs.onlinelibrary.wiley.com/doi/abs/10.1029/2009WR008800, https://agupubs. onlinelibrary.wiley.com/doi/pdf/10.1029/2009WR008800.

Zhang, L., N. Potter, K. Hickel, Y. Zhang, and Q. Shao, 2008: Water balance modeling over variable time scales based on the Budyko framework - Model development and testing. 
Journal of Hydrology, 360 (1), 117 - 131, doi:https://doi.org/10.1016/j.jhydrol.2008. 07.021, URL http://www.sciencedirect.com/science/article/pii/S0022169408003582.

Zhang, R., and Coauthors, 2018: Season-based rainfall-runoff modelling using the probability-distributed model (PDM) for large basins in southeastern Brazil. Hydrological Processes, 32 (14), 2217-2230, doi:https://doi.org/10.1002/hyp.13154, URL https: //onlinelibrary.wiley.com/doi/abs/10.1002/hyp.13154, https://onlinelibrary.wiley.com/ doi/pdf/10.1002/hyp.13154.

Zheng, F., H. R. Maier, W. Wu, G. C. Dandy, H. V. Gupta, and T. Zhang, 2018: On lack of robustness in hydrological model development due to absence of guidelines for selecting calibration and evaluation data: Demonstration for data-driven models. Water Resources Research, 54 (2), 1013-1030, doi:10.1002/2017WR021470, URL https://agupubs.onlinelibrary.wiley.com/doi/abs/10.1002/2017WR021470, https: //agupubs.onlinelibrary.wiley.com/doi/pdf/10.1002/2017WR021470. 